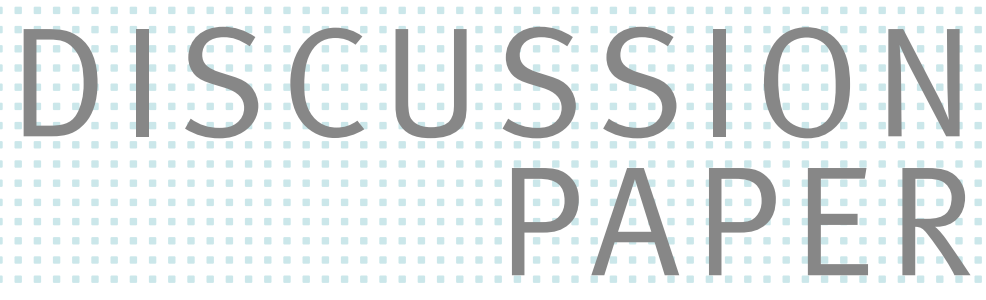

/ / MARTIN LANGE AND OLE MONSCHEUER

Spreading the Disease:

Protest in Times of Pandemics 


\title{
Spreading the Disease: \\ Protest in Times of Pandemics
}

\author{
Martin Lange ${ }^{1}$ and Ole Monscheuer ${ }^{2}$ \\ ${ }^{1} Z E W$ Mannheim \\ ${ }^{2}$ Humboldt University of Berlin
}

February 8, 2021

\begin{abstract}
This study analyzes the impact of COVID-19 deniers on the spread of COVID-19 in Germany. In a first step, we establish a link between regional proxies of COVID-19 deniers and infection rates. We then estimate the causal impact of large anti-lockdown protests on the spread of COVID-19 using an event study framework. Employing novel data on bus stops of travel companies specialized in driving protesters to these gatherings, and exploiting the timing of two large-scale demonstrations in November 2020, we find sizable increases in infection rates in protesters' origin regions after these demonstrations. Individual-level evidence supports the main results by documenting that COVID-19 deniers engage less in health protection behavior. Our results contribute to the debate about the public health costs of individual behavior that has detrimental externalities for the society.
\end{abstract}

JEL classification: I18, I12, D62, P16

Keywords: COVID-19 deniers, protests, public health

${ }^{*}$ Martin Lange, ZEW Mannheim, L7 1, 68161 Mannheim, Email: martin.lange@zew.de; Ole Monscheuer, Department of Economics, Spandauer Strasse 1, 10178 Berlin, Email: ole.monscheuer@hu-berlin.de. We thank Sebastian Blesse, Peter Haan, Melina Ludolph, Guido Neidhöfer, Friedhelm Pfeiffer, Katrin Sommerfeld, Alexandra Spitz-Oener, and seminar participants at ZEW Mannheim for valuable comments. Ole Monscheuer gratefully acknowledges financial support from the German Research Foundation (DFG project number 280092119) through CRC TRR 190. 


\section{Introduction}

Societal cohesion is key in confining the outbreak of diseases that threaten collective survival. If some part of the society does not comply with public health precautions aimed at stopping the spread of a deadly disease, the effectiveness of public policy and preventative efforts undertaken by others are substantially constrained. The ongoing COVID-19 pandemic is a case in point. Even with over 100 million people infected by the disease worldwide and more than 2 million associated deaths, a notable segment of the population denies the threat posed by-or even the existence of - the novel coronavirus SARS-CoV-2. According to survey data from YouGov Cambridge (2020), 13 percent of people in the U.S. believe the coronavirus probably or definitely does not exist. Similar figures are reported for Germany and France (10 percent).

How does this group contribute to the spread of COVID-19? Do COVID-19 deniers behave differently than the majority of the population? And do large protests of this group affect the transmission of the disease? In this study, we show that the spread of COVID-19 can be substantially increased by individuals who downplay the disease's public health threat and reject both recommended and mandatory behaviors aimed at curtailing its transmission.

In a first step, we establish a link between different proxies for the regional presence of COVID19 deniers and infection rates in Germany. Motivated by the observation that COVID-19 deniers disproportionally support populist parties (e.g., Roose, 2020) and largely oppose vaccinations (e.g., Nachtwey et al., 2020), we use regional information on vote shares of the largest populist party in Germany and the share of children vaccinated against measles as proxies for a potentially high share of COVID-19 deniers. We find a significant and sizable correlation between these proxies and COVID-19 infection rates, which suggests that a higher share of COVID-19 deniers in a region may facilitate the spread of the coronavirus.

Building upon this observation, we show in a second step that COVID-19 deniers indeed contribute significantly to regional disparities in COVID-19 infection rates. Specifically, we estimate the causal impact of large anti-lockdown protests organized by COVID-19 deniers on the spread of COVID-19. For identification, we exploit the particularity that an alliance of bus companies has specialized in transporting anti-lockdown protesters to rallies across Germany. Using web-scraped data on all possible points of departure offered by this alliance allows to identify the home regions of protesters. This information is used in an event study framework where we compare the development of infection rates in regions with and without such bus stops in the aftermath of two large-scale demonstrations in November 2020. Our results show a significant increase in new COVID-19 cases in home areas of protesters after the demonstrations. The effects are most pronounced in regions where bus stops exist even in small towns with fewer than 20,000 residents. This finding is in line with the interpretation that regions with the highest demand for transportation to the demonstrations see the highest increases in COVID-19 infections after the protests. We estimate that those areas faced a 35.9 percent higher infection rate by the end of 2020 .

Our results are robust to a number of sensitivity checks. Allowing county-level characteristics associated with the spread of COVID-19 to have differential effects on our outcome variables over time does not change our results. For example, we include interactions between time dummies and the infection rate just before the protests, nursing home capacities, population density, GDP 
per capita, and bus stops from the largest commercial bus travel operator. Our results also do not depend on states that see a particularly high increase in infection rates or share a border with highly affected neighboring countries. Moreover, using different measures of COVID-19 infections does not change our main findings qualitatively.

Finally, we complement our regional evidence with individual-level survey data from the beginning of the pandemic. Regression results from this survey suggest that individuals who downplay the risk of COVID-19 infections also engage less in COVID-19 mitigation strategies, exhibit lower trust in the government and in public health institutions, and are less likely to acquire information about COVID-19 from established media sources.

To the best of our knowledge, this is the first study to quantify the impact of COVID-19 deniers on the local spread of this disease. There are, however, a number of studies analyzing related questions. One strand of the economics' COVID-19 literature focuses on the influence of large-scale events or gatherings on the spread of COVID-19. For instance, Dave et al. (2020) investigate the spread of COVID-19 as a consequence of a large U.S. gathering of motorcycle enthusiasts that took place without any infection mitigation strategies. They estimate that counties with the highest share of event attendees experienced 6.4 to 12.5 percent higher COVID19 cases than counties without attendees. In a similar vein, Harris (2020) investigates the outbreak of COVID-19 at the University of Wisconsin and concludes that a cluster of bars facilitated the spread of the coronavirus. Large gatherings do not automatically contribute to an increase of COVID-19 cases, as shown by Dave et al. (2020). Their study looks at the impact that Black Lives Matter gatherings have on the spread of COVID-19 and find that these demonstrations - at which participants largely complied with coronavirus mitigation strategieshave no or only a marginal effect on COVID-19 infections.

By analyzing the effect of large-scale political protests where participants deliberately disobeye health care regulations, our study directly relates to the trade-off when civil liberties and public health policies seem at odds. Citizens' right to protest is a corner stone of modern democracies. In times of public crisis, such as a pandemic, local authorities may, however, deem such protests as too dangerous for society. As Alsan et al. (2020) show, individuals are heterogeneous in their willingness to trade these civil liberties for uncertain public health improvements. Our results quantify the public health costs associated with this trade-off.

Our study also relates to the finding that partisanship is a major driver of health outcomes and behavior in the U.S. during the current pandemic (see Allcott et al., 2020; Clinton et al., 2020; Gadarian et al., 2020; Grossman et al., 2020; Makridis and Rothwell, 2020, among others). Democrats are usually more willing to reduce mobility and voluntarily engage in social distancing; Republicans are less likely to do so. Less is known, however, about COVID-19 containment behavior along political lines in less politically polarized countries. Barbieri and Bonini (2020) and Mellacher (2021) show evidence that individual mobility and COVID-19 related deaths are higher in areas where populist parties enjoy larger vote shares. Our study documents this relationship for Germany, the largest economy and democracy in Europe and a country where the biggest populist party systematically downplays the threat of COVID-19.

Our findings also contribute to studies that document the spatial influence of social capital on the spread of COVID-19. Individuals living in areas of the U.S. or Europe with higher social capital reduce their mobility much more than individuals living in regions with lower social 
capital (Bargain and Aminjonov, 2020; Brodeur et al., 2020; Barrios et al., 2021; Durante et al., 2021). Similarly, Bartscher et al. (2020) show that COVID-19 spreads more slowly in European regions with higher social capital. Social capital is mainly measured by trust in politicians or institutions, blood or organ donations, and electoral turnout. By validating that skepticism about COVID-19 is associated with less trust in institutions, we add a novel measure of trust in public health care - that is, regions with a high share COVID-19 deniers - to the existing spatial measures of institutional trust.

Moreover, this study is related to research that is concerned about how media coverage of COVID-19 influences public health. We document that individuals who believe COVID-19 poses no great threat to their personal health nor to public health are less likely to turn to established media for information about COVID-19. Given German TV, radio, and newspapers' rather homogenous coverage of risks associated with the coronavirus, COVID-19 deniers must use other (social media) channels to access and disseminate their views about the pandemic. This evidence is in line with findings of Bursztyn et al. (2020) and Simonov et al. (2020) who show that the downplaying of the coronavirus threat by Fox News cable programs increases infection and death rates associated with COVID-19.

This study continues as follows. We present background information about the spread of COVID-19 in Germany and discuss its relationship to COVID-19 deniers and their protest movement. The section thereafter introduces the data employed for the empirical analysis. In Section 4, we present our main descriptive and causal event study estimates including several sensitivity analyses. In the subsequent section, our empirical analysis is complemented by individual evidence that offers potential explanations for our main results. Finally, in Section 6, we discuss the broader relevance of our findings.

\section{Background}

\subsection{COVID-19 in Germany}

In Germany, the Robert Koch Insitut (RKI) advises disease and epidemic control and collects official statistics about COVID-19 cases and related deaths. In 2020, the RKI officially reported 1,752,015 cases and 35,373 deaths, as well as approximately 1,423,591 recoveries from COVID-19. Figure 1 shows the development of COVID-19 infections and associated deaths in Germany in 2020. Two distinct COVID-19 waves are clearly visible - a common pattern in most Western countries.

The first COVID-19 infection in Germany was confirmed on January 27, 2020 near Munich, Bavaria. It was followed by clusters in Baden-Württemberg and North Rhine-Westphalia, with the first death reported on March 9, 2020. As a result of these clusters as well as the arrivals of people from countries with high infection rates, COVID-19 started to disperse more broadly throughout Germany. Policy-makers first attempted to control outbreaks by minimizing the expansion of clusters. As infections kept spreading, German states started on March 13 to mandate school and kindergarten closures, postpone academic semesters, and prohibit visits to nursing homes in order to protect older and vulnerable populations. Two days later, Germany's borders with Austria, Denmark, France, Luxembourg, and Switzerland were closed. By March 22, curfews were imposed in six German states while other states banned physical contact with 
more than one person from outside one's own household (Robert Koch Institut, 2020c).

Figure 1: COVID-19 in Germany

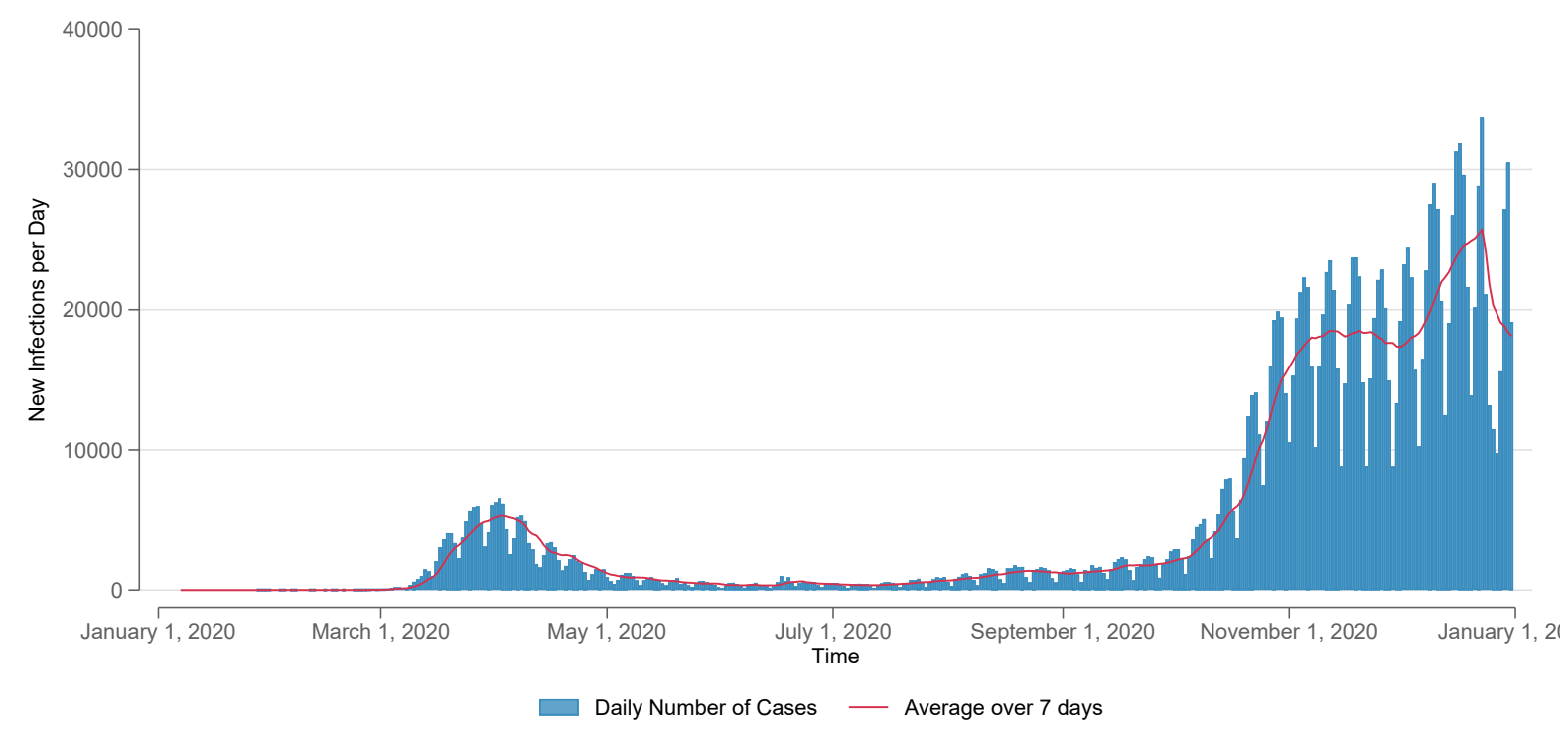

(a) Number of New Cases of COVID-19

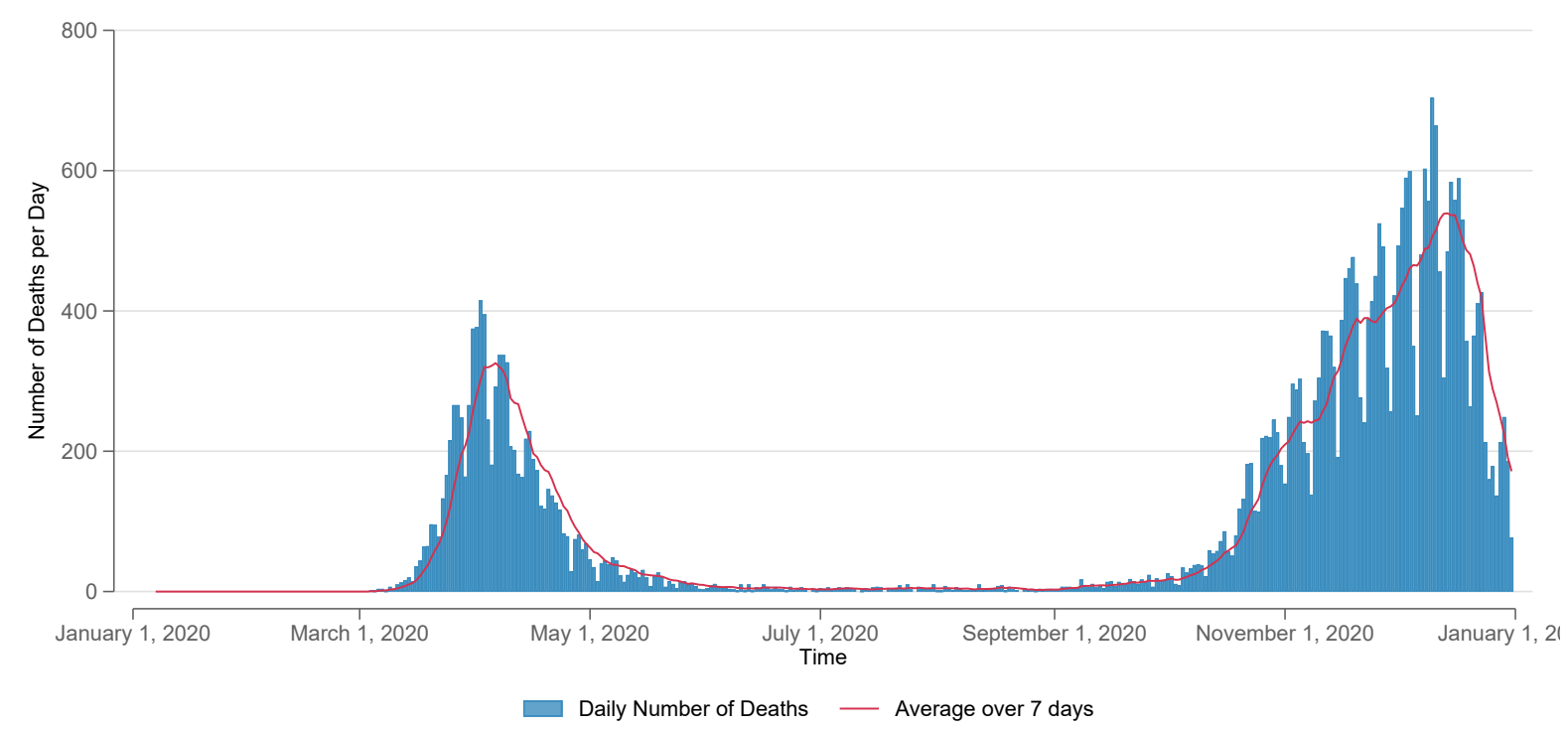

(b) Number of Deaths Associated with COVID-19

Notes: The figure shows the development of the number of COVID-19 cases and deaths related to COVID-19 in Germany during 2020.

By mid-April, the number of cases had fallen substantially, and many restrictions were eased (Robert Koch Institut, 2020c). During the summer, the number of cases was rather low, with some local outbreaks in meat processing plants, manufacturing facilities, and agricultural companies (e.g., Robert Koch Institut, 2020d,b). By late August, infection numbers started to rise again, and the second COVID-19 wave was underway in mid-October with exponential growth of cases. In response, a partial lock-down was imposed on November 2. Restaurants and bars were closed, as were cultural and leisure facilities. There was also an urgent appeal to the population to keep all personal contact to a minimum (Bundesregierung, 2020). The infection numbers 
stabilized at a high level (Oltermann, 2020). On November 25 and December 15 the chancellor and the state premiers agreed to extend the partial lockdown, deciding on slightly more stringent corona protection measures but relaxing the rules about gathering over the Christmas holidays (Hille, 2020).

While COVID-19 outbreaks during the first wave were mostly driven by distinct clusters, the second wave saw infections more evenly distributed across Germany. Increasingly, infections were caused by diffuse transmission, with numerous clusters connected to private gatherings, celebrations, or public events and to outbreaks linked to educational facilities, nursing and long-term care homes, occupational settings, or religious events (Robert Koch Institut, 2020a). However, there still existed great regional heterogeneity, especially during the partial lockdown in November. Figure 2 illustrates this heterogeneity by reporting the seven-days-incidence rate for counties at different points in time. ${ }^{1}$ The seven-days-incidence rate is the number of COVID-19 cases in the last seven days per 100,000 residents. Figure 2 illustrates that North German regions had substantially lower infection rates than South German regions during both COVID-19 waves. The maps also show that most East German states have had very low COVID-19 rates during the first wave. This tendency shifted dramatically during the second wave when especially southern East German states such as Saxony reported the highest infection rates in Germany.

Figure 2: COVID-19 Incidence across Germany over Time

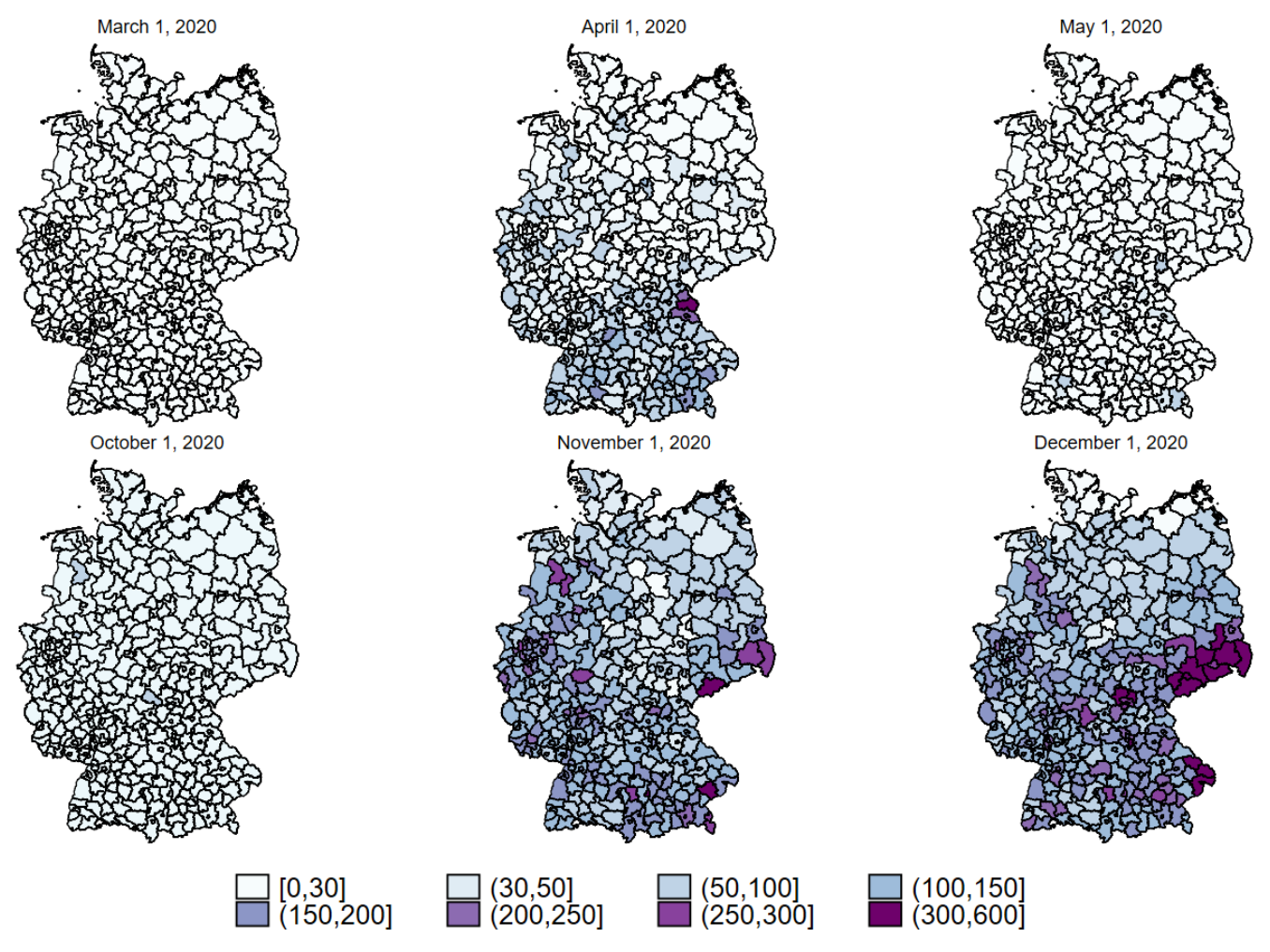

Notes: The figure shows the seven-days-incidence rate for counties at different points in time. The seven-days-incidence rate indicates the number of COVID-19 cases in the last seven days per 100,000 residents.

\footnotetext{
${ }^{1}$ German counties correspond to the NUTS 3 level in the EU geocode standard and are comparable in size to US counties.
} 


\subsection{COVID-19 Deniers and Protests across Germany}

The COVID-19 pandemic has been accompanied by the emergence and spread of conspiracy theories. Surprisingly large swaths of the populations in many countries deny the threat posed by the novel coronavirus or its existence. A survey by YouGov Cambridge (2020) found that 13 percent of U.S. residents said the coronavirus probably or definitely does not exist. In France and Germany, this figure is about 10 percent. In comparison, more than 75 percent of the German population supports the government's measures to fight COVID-19 (Deutschlandfunk, 2020).

Since April 2020, several demonstrations have been held in Germany to protest the government's COVID-19 measures (Nachtwey et al., 2020). The first protests, organized in Berlin, became known as the "hygiene demo." Since summer, the main force behind these protests has been a group called Querdenken ("lateral thinking"), which was initially based in Stuttgart, but soon also organized rallies in Berlin and other cities. Esoteric, monarchist, and far-right groups and parties joined the protests, united around a common grievance: that the pandemic is an invention aimed at suppressing their freedom. There are also various conspiracy theories around the COVID-19 vaccination, Bill Gates, and QAnon (Soldt, 2020; Morris and Beck, 2020; Deutschlandfunk, 2020; The Economist, 2020).

Well organized, the Querdenken group is able to mobilize its supporters all around Germany to take part in demonstrations, including through its logistical relationship with Honk for Hope. Honk for Hope was originally a group of small bus operators who opposed lockdown measures, but it now operates as a regular COVID-19 travel agency (Machowecz, 2020; Soldt, 2020). The Querdenken group registers demonstrations, and Honk for Hope organizes bus transportation for the protest participants. At the Honk for Hope website, visitors find a booking window with hundreds of departure points for anti-COVID-19 demonstrations throughout Germany. Querdenken also mobilizes protesters via social networks (Soldt, 2020). This attention to logistics has enabled the Querdenken movement (and related organizations) to assemble large numbers of supporters at demonstrations in many cities since August 2020.

The first large-scale rally unfolded on August 1, when about 20,000 people showed up to protest in Berlin, violating infection-control face mask and social distancing requirements. A similar mobilization occurred on August 29, 2020, when several hundred people stormed the blocked stairs of the Reichstag Building, sparking widespread political debate (DW News, 2020; The Economist, 2020).

On November 7, massive numbers of protesters congregated at a Querdenken-demonstration in Leipzig's city center. The police spoke of 20,000 participants; a research group at the University of Leipzig estimated a crowd size as large as 45,000 (Forschungsgruppe Durchgezählt, 2020). In tandem, numerous counter-demonstrations took place in the same area on the same day. Rioting, violent attacks on the press and police, and ongoing violations of public health regulations continued through the day. In the aftermath, the city of Leipzig, the police, and the Ministry of the Interior were criticized nationwide (Mitteldeutscher Rundfunk, 2020; Morris and Beck, 2020).

On November 18, Querdenken and related groups announced a blockade of the parliament to prevent a vote on an amendment to the Infection Protection Act. Tensions ran high as protesters attempted to reach the Reichstag Building, where the Bundestag was in session to discuss the law. The protesters - estimated to number more than 10,000-were dispersed, but 
close to 80 police officers were injured. On the same day, verbally aggressive individuals entered the Bundestag. It was alleged that they had entered the building on the invitation of a politician from the populist, far-right Alternative for Germany (AfD) (Zeit Online, 2020; Pechtold et al., 2020). Later demonstrations in Frankfurt an der Oder (November 28) and Düsseldorf (December 6) attracted only about 1,000 to 1,500 protesters (Berliner Zeitung, 2020; Süddeutsche Zeitung, 2020a).

Querdenken-demonstrations (and anti-lockdown protests organized by related groups) have established themselves as rallies at which like-minded people deliberately ignore public health measures. If any participants are infected with COVID-19, these demonstrations are primed to become superspreader events. Given the travel support provided by the bus lines, it is easy for protesters to travel within Germany to attend the demonstrations and likely that they are spreading the novel coronavirus during or after the rally. This is particularly true for demonstrations in November 2020 when COVID-19 incidence rates were high.

\section{Data}

This section provides an overview on the data used in the empirical analysis. Summary statistics can be found in Panel A of Table A1 in the appendix.

\subsection{COVID-19 Cases and Related Deaths}

Data on COVID-19 infections and associated deaths are retrieved from the RKI. We use the daily number of infections and deaths at the county level reported from 01.01.2020 to 23.12.2020. The RKI receives the number of COVID-19 cases and the number of deaths from the public health offices of the German states which, in turn, obtain this information from their local branches. Each case has a reporting date, which is the date on which the local public health office became aware of the case and recorded it electronically. Because the median incubation time the time it takes before an individual develops symptoms of COVID-19) is five to six days, with a maximum of 14 days, and the time it takes to get tested and receive a test result, it may be seven to 20 days before a COVID-19 infection is reported to a public health office. COVID-19 statistics, thus, inhere a substantial time lag, and this has to be kept in mind when interpreting these figures.

In most of our empirical analysis, we use the so-called seven-days-incidence rate. It reports COVID-19 cases in the last seven days per 100,000 residents in a county. Using the weekly COVID-19 rates solves two problems at once. First, it alleviates the dependency on the day of the week, as some local public health offices report COVID-19 numbers on the weekend while others do not. Second, normalizing by local population makes these rates comparable across counties within Germany. In additional analyses, we use the the cumulative number of COVID19 cases per 100,000 residents as well as the seven-days-fatality rate that reports the number of COVID-19 related deaths in the last seven days per 100,000 residents.

\subsection{Identifying COVID-19 Deniers}

It is challenging to identify COVID-19 deniers and their local distribution. Only a few individuallevel surveys on COVID-19 and health care behavior are publicly available. In addition, the 
available data sources are small in sample size and do not allow to analyze the relationship between local heterogeneity in COVID-19 attitudes and COVID-19 infections.

Instead of relying on survey data, we utilize regional proxies of COVID-19 deniers in our main analysis. More specifically, we use spatial information on support for political parties that downplay the threat of COVID-19, the share of children vaccinated against measles, and the presence of anti-COVID-19-policy protesters. Through these three different proxies, we aim to capture different aspects of the population of COVID-19 skeptics.

\subsubsection{Support for the "Alternative für Deutschland"}

One way to approximate the regional distribution of COVID-19 deniers is to look at electoral support for parties that propagate assumptions and speculations about COVID-19 similar to those held by COVID-19 deniers. We focus on the AfD as the largest political party, in terms of votes cast at previous elections, that acknowledges the concerns of COVID-19 deniers. AfD politicians have increasingly acted as the mouthpieces of the novel coronavirus skeptics, regularly downplaying the risks of COVID-19. According to Roose (2020), two thirds of AfD supporters agree or think that it is very likely that the coronavirus is a pretext in order to suppress the people. AfD politicians have also participated in or supported anti-lockdown demonstrations (Süddeutsche Zeitung, 2020b).

Indeed, previous electoral support for the AfD may correlate with contemporary political preferences of COVID-19 deniers. According to a survey among COVID-19 protesters, the AfD would receive the highest vote share at the next election among this group (Nachtwey et al., 2020). In order to quantify the regional heterogeneity of COVID-19 deniers, we use AfD vote shares from the election of the European Parliament in 2019. ${ }^{2}$ These vote shares should capture the political dimension of COVID-19 denial and, thereby, the regional population potential of this group.

\subsubsection{Regional Measles Vaccination Rates}

As a second proxy for skepticism about the existence of COVID-19 and related policy measures, we look at measles vaccination rates at the county level. Alongside AfD vote shares, the measles vaccination rates for children should capture the general public health concerns of COVID-19 deniers. Indeed, participants at anti-lockdown protests are very skeptic about vaccinations. According to Nachtwey et al. (2020), about 84 percent would refuse to be vaccinated against COVID-19.

The data about measles vaccination rates comes from the $K V$-Impfsurveillance provided by vacmap (see Rieck et al., 2018, for further information). It is based on physicians' billing to the Association of Statutory Health Insurance Physicians and includes all vaccinations administered under the public health insurance scheme. We utilize information on the share of children who received their first measles vaccination at age 15 months. All federal states recommend that children receive their first vaccination against measles by this age. The data refer to the cohort born in 2014 .

\footnotetext{
${ }^{2}$ The results do not change when using AfD vote shares from the last federal election in 2017.
} 


\subsubsection{Honk for Hope Bus Stops}

Our most innovative proxy for COVID-19 deniers makes use of the regional distribution of antiCOVID-19-policy protesters. More specifically, we web-scraped data on Honk for Hope bus stops, from which protesters could book a trip to the major anti-COVID-19 demonstrations in Leipzig and Berlin.

Honk for Hope was founded in April 2020 to lobby for government protection for coach companies facing negative economic consequences from COVID-19. However, Honk for Hope quickly evolved into a service provider to transport thousands of people to large-scale Querdenken demonstrations (Machowecz, 2020; Soldt, 2020). Since July, bus operator Thomas Kaden from Plauen in Saxony has been one of the most visible figures of Honk for Hope. Newspapers report that he coordinates the bookings of thousands of COVID-19 demonstration travelers through hundreds of bus entrepreneurs. The website of Kaden-Reisen / Honk for Hope includes a booking tool that allows travelers to select among more than 200 departure points in Germany. Exactly how many buses and passengers travel through Germany on a demonstration weekend is not known, but hundreds of buses were seen at the demonstration in Leipzig on November 7 (Machowecz, 2020; Soldt, 2020).

We retrieved the data on possible cities of departure from the website of Honk for Hope / Kaden-Reisen. We downloaded the bookable points of departure to two demonstrations in Leipzig and Berlin offered by Honk for Hope in December 2020 and January 2021. ${ }^{3}$ The list of possible departures is very persistent over time, but Honk for Hope offers fewer stops very close to the respective destination. Hence, the combination of the two lists of departures should represent the nation-wide network of Honk for Hope bus stops. ${ }^{4}$

Honk for Hope offers bus stops in most large cities, indicating that it takes advantage, at least in part, of a general network of bus companies. However, when comparing the regional distribution of the Honk for Hope bus stops with those of FlixBus, a major bus company in Europe with significant coverage in Germany, it becomes clear that Honk for Hope is concentrated in particular regions in Germany. This is even more evident when looking at its bus stops in small and medium-sized cities.

Figure 3 shows the distribution of Honk for Hope bus stops and FlixBus stops in cities in general (top row), and in cities with fewer than 50,000 residents (middle row) and those with 20,000 or fewer residents (bottom row). Overall, about 54 percent of all German counties have a Honk for Hope bus stop (dark grey). 26 percent of the counties have a bus stop in a city with fewer than 50,000 inhabitants. About 10 percent of German counties have a bus stop in a town with fewer than 20,000 inhabitants. It is likely that the Honk for Hope stops in smaller cities exist largely to meet the high demand for transportation to COVID-19 demonstrations. Consequently, we argue that counties with Honk for Hope bus stops in small cities are counties with a particularly high concentration of COVID-19 deniers.

Using Honk for Hope bus stops as a proxy for COVID-19 deniers offers the advantage that this measure is directly connected to attitudes regarding COVID-19, as compared to AfD vote

\footnotetext{
${ }^{3}$ First, we downloaded the list of bus stops for a demonstration in Leipzig that was planned to take place on December 19 (date of access on December 11, 2020) Second, we downloaded the list of departures offered to a demonstration in Berlin on March 20, 2021 (date of access on January 28, 2020).

${ }^{4}$ We combine the possible points of departure in our main analysis, but as a robustness check we show that results are very similar when using the list of departures to Leipzig or Berlin separately.
} 
share and vaccination rates, which only correlate with those attitudes.

Figure 3: Distribution of Honk for Hope and FlixBus stops

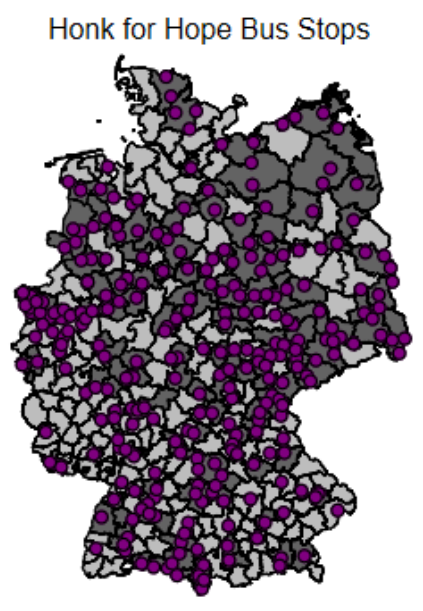

\section{$[0,0](186)$}

$(0,1](215)$

Honk for Hope Bus Stops $(<50,000)$

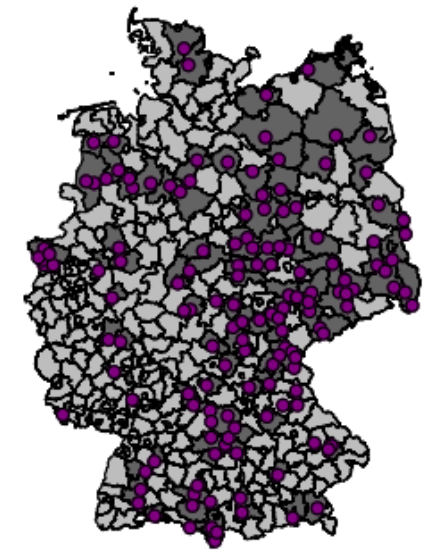

$[0,0](296)$

Honk for Hope Bus Stops $(<20,000)$

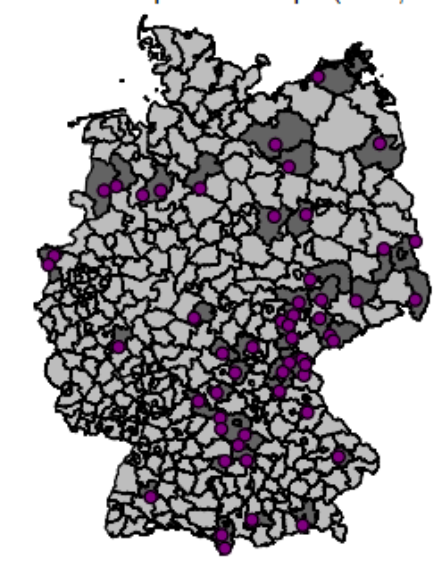

$[0,0](359)$

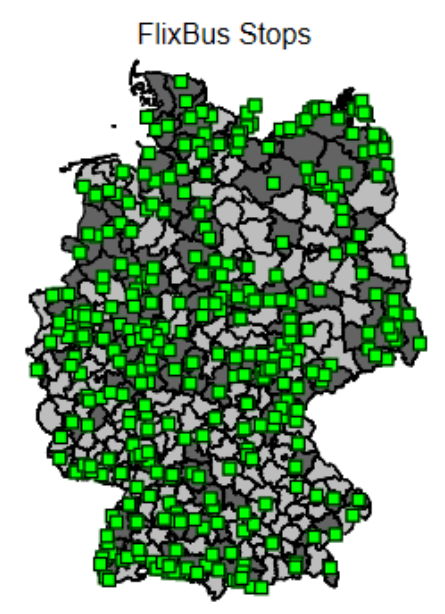

$[0,0](175)$

$(0,1](226)$

FlixBus Stops $(<50,000)$

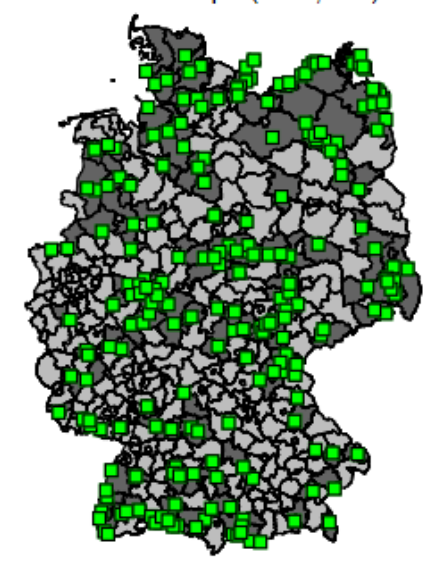

$[0,0](277)$

$(0,1](124)$

\begin{abstract}
Flixbus Stops $(<20,000)$
\end{abstract}

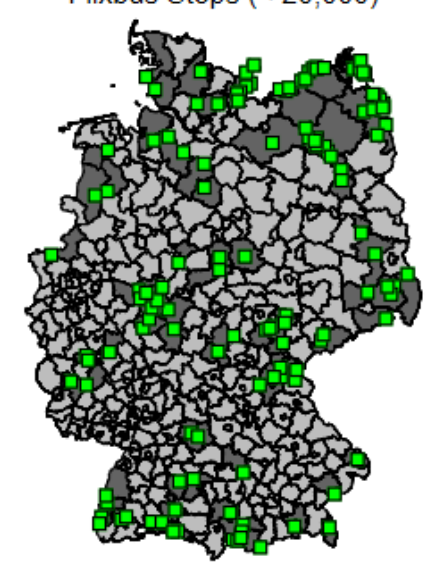

$[0,0](334)$

$(0,1](67)$

Notes: The figure shows the regional distribution of Honk for Hope and FlixBus bus stops across Germany. The dark shaded areas correspond to the treated counties according to the three treatment definitions employed: having a bus stop in general, having a bus stop in cities with fewer than 50,000 inhabitants, having a bus stop in a city with fewer than 20,000 inhabitants. 


\subsection{Control Variables}

In our empirical analysis of COVID-19 deniers' impact on the spread of the novel coronavirus, we use several control variables at the county level.

First, we control for regional factors associated with a faster outbreak of COVID-19. In particular, we obtained county-level data on population density from the Federal Statistical Office. It is measured as of the population per square kilometer on December 31, 2019. In addition, we use information on capacities of nursing homes per 10,000 residents and the number of asylum applicants per 1,000 residents since COVID-19 proved to spread in large-size co-living arrangements. This data is retrieved from the INKAR data base and refers to 2017. Second, we use data on the local unemployment rate and GDP per capita to control for economic differences among counties. These figures also come from INKAR and refer to the same base year. Third, we control for the voter turnout at the European election in May 2019 when we analyze AfD vote shares. Finally, as noted previously, we have acquired information on the number of FlixBus bus stops at the county level via web-scraping. FlixBus is the largest commercial long-distance bus company operating in Germany. We use the presence of its bus stops to flexibly control for the demand for bus travel.

\section{COVID-19 Deniers and Public Health Consequences}

To analyze the effects of COVID-19 deniers on the spread of COVID-19, we proceed in two steps. First, we descriptively investigate the relationship between our first two proxies of COVID-19 deniers (the AfD vote share and children's measles vaccination rate) and the seven-days-incidence rate over time. This first step reveals a sizable correlation between the proxies and the spread of COVID-19 during Germany's second wave of infection. In a second step, we estimate the causal effect of Querdenken demonstrations on the spread of COVID-19 in counties with Honk for Hope bus stops, using an event study approach. This second step shows that COVID-19 deniers did, indeed, contribute significantly to regional disparities in COVID-19 infection rates.

\subsection{Descriptive Spatial Evidence}

First, we descriptively study the spatial relationship between the spread of COVID-19 and regional, prior to the outbreak of COVID-19-determined proxies for the presence of COVID-19 deniers. Moreover, we investigate its development over time. To do so, we repeatedly estimate, regression models of the following type for weekly data between January and December 2020:

$$
Y_{c}=\beta_{0}+\beta_{1} \text { COVID-19 } \text { Denier }_{c}+\beta_{2} X_{c}+\gamma_{s}+\varepsilon_{c} .
$$

The outcome $Y_{c}$ is the seven-days-incidence rate. COVID-19 Denier ${ }_{c}$ is either the AfD vote share from the election of the European Parliament in May 2019 or the share of children that obtained a measles vaccination by the age of 15 months. $\gamma_{s}$ are state fixed effects. $X_{c}$ includes the full set of control variables at the county-level as defined in the previous section. ${ }^{5}$

\footnotetext{
${ }^{5}$ These include nursing home capacities, the share of asylum applicants, population density, unemployment rate, GDP per capita, and, in case of AfD vote shares as the dependent variable, voter turnout.
} 
Figure 4: AfD Vote Shares / Measles Vaccine Rates and COVID-19 Incidence over Time

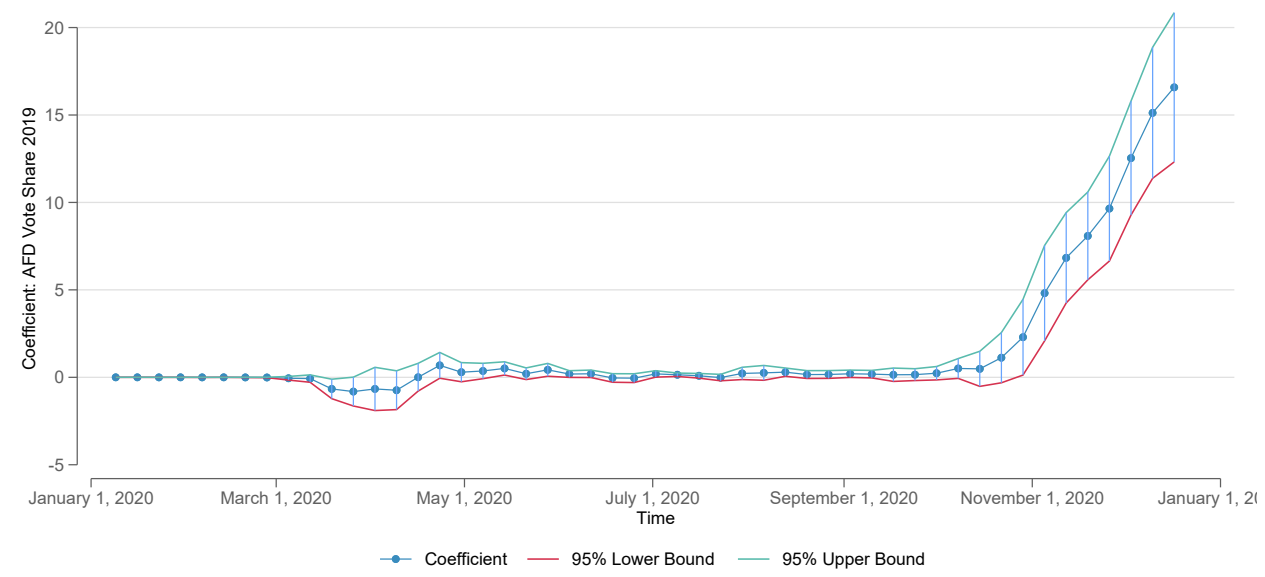

(a) AfD Vote Shares at the European Parliamentary Election 2019

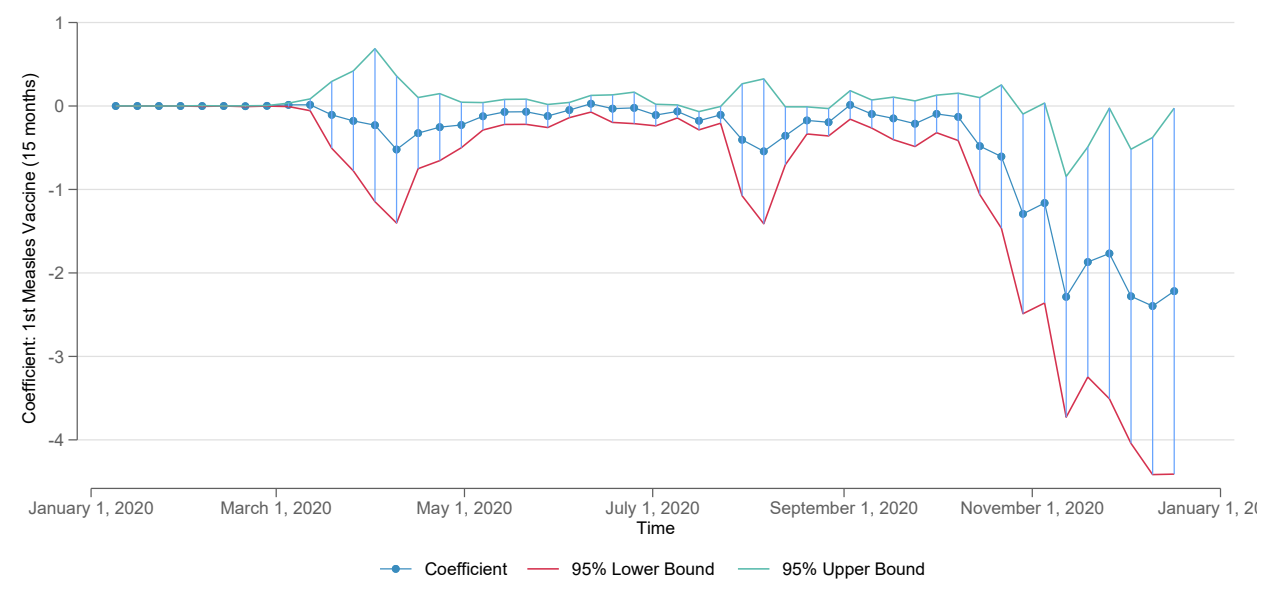

(b) Share of 15 Months-Old with 1st Measles Vaccine

Notes: The figure plots multiple estimates of $\beta_{1}$ and its confidence interval for (a) AfD vote shares and (b) Measles Vaccine Rates, based on equation (1). Control variables include state fixed effects, nursing home capacities per 10,000 residents, the share of asylum applicants, population density, unemployment rate, and GDP per capita. Panel (a) also includes voter turnout at election of the European Parliament in 2019.

Figure 4 plots the $\beta_{1}$-coefficients of equation (1) for the two different proxies of COVID-19 deniers over time. The estimates are identified only from within-state variation, conditional on the set of county-level control variables. Each coefficient can be interpreted as the conditional correlation between our measures of interest and COVID-19 cases in a given week of 2020 .

Panel (a) documents a strong positive correlation between the regional support for the AfD and COVID-19 infection rates during the second infection wave in Germany. A one percentage point increase in the AfD vote share corresponds to an increase of the seven-day-incidence rate of approximately 15 at the end of 2020. Similarly, panel (b) describes a negative correlation between the demand for measles vaccines and the spread of COVID-19. That is, areas with a one percentage point higher coverage of 15 -month old children vaccinated against measles see, on average, about two fewer infections per 100,000 residents over seven days from November onward. Although these $\beta_{1}$-coefficients are smaller in size than the AfD estimates, the descriptive evidence from vaccination rates fits neatly to the pattern observed in panel (a) of Figure 4. 
We do not find this relationship between our proxies of COVID-19 deniers and the seven-daysincidence rate for the beginning of the pandemic, but the $\beta_{1}$ coefficients increase substantially during the second wave and, in particular, during the lockdown in November. This result may be intuitive. Given the more even distribution of the virus across Germany by the end of 2020, the differential behavior of COVID-19 deniers is likely to matter more for the transmission of infections in the second wave than in the first. This is especially true given that government restrictions had been relaxed and individual behavior became more important in November than in March and April 2020.

While support for the AfD and lower measles vaccination rates are likely to correlate with a disregard for public health protocols and policies designed to slow down the spread of COVID-19, they may also correlate with other factors that affect COVID-19 incidence rates. Examples could be the share of foreign populations, commuter flows, or physical distance from countries with high incidence rates. However, the fact that these correlations are very strong even when we include state fixed effects and several control variables indicates that the relationships between our proxies for COVID-19 deniers and the infection rates are very robust.

In a next step, we analyze the influence of COVID-19 deniers on the spread of the disease in a more systematic framework that allows under certain assumptions to conclude causality.

\subsection{Event-Study: Anti-COVID-19-Policy Protests}

We now use the locations of Honk for Hope bus stops to estimate the causal effect of the Querdenken demonstrations in November 2020 on the COVID-19 infections in the origin counties of the protesters. More specifically, we employ an event study approach and analyze how the demonstrations in Leipzig and Berlin impacted COVID-19 infection rates in counties that have bus stops for travel to these demonstrations.

\subsubsection{Empirical Approach}

In usual applications of event studies there exists one clearly defined event. We have two-on November 7 and 18-that may have spread COVID-19. We expect the Querdenken demonstration in Leipzig on November 7 to have the most striking impact on infections. It was by far the largest demonstration in November, and the risk of infections carried by its participants to their origin counties was particularly high. Moreover, media reported cases among participants after the demonstration (e.g., Tagesspiegel, 2020). The rally in Berlin on November 18 attracted about 10,000 protesters and also may have spread infections in the protesters' home regions.

Since infections take on average about ten days to appear in the data of the RKI, November 18 is the first day when infections from the Leipzig demonstration may be detected. That is the date where we center the event study. Generally, we would expect infection rates to grow slowly after November 17. We restrict our sample to observations up to December 23, since COVID-19 data after that point becomes less reliable due to the Christmas holidays. Accordingly, we can observe the outcomes 35 days after the event. We drop observations prior to October 14, which is 35 days before the event. ${ }^{6}$

We run separate analyses for three different treatment definitions. More specifically, treated counties have 1) Honk for Hope bus stops in general, 2) bus stops in cities with fewer than

\footnotetext{
${ }^{6}$ The results do not depend on the choice of the event date or the time period before or after the event.
} 
50,000 inhabitants, or 3) bus stops in cities with fewer than 20,000 inhabitants. As discussed previously, we expect the causal effect of the November demonstrations to be largest for the last two treatment definitions as bus stops in small towns are likely to reflect a particularly high demand for travel to Querdenken demonstrations. Given the treatment definitions, we restrict our sample to rural counties, since counties with only one large city cannot be treated according to the second and third definition. ${ }^{7}$

We run variants of the following model:

$$
\begin{aligned}
Y_{c t}=\gamma_{c}+\gamma_{t}+\sum_{j=-35}^{-2} & \pi_{j} D\left\{B u s_{c}\right\} * D\{t=j\}+\sum_{j=0}^{35} \phi_{j} D\left\{B u s_{c}\right\} * D\{t=j\} \\
& +\sum_{j=-35}^{-2} \alpha_{j} X_{c} * D\{t=j\}+\sum_{j=0}^{35} \beta_{j} X_{c} * D\{t=j\}+\varepsilon_{c t}
\end{aligned}
$$

Our main outcome $Y_{c t}$ is the daily seven-days-incidence rate. As an additional results, we investigate effects on the total number of cases per 100,000 residents. $\gamma_{c}$ and $\gamma_{t}$ are county and time fixed effects. Our variables of interest are $D\left\{B u s_{c}\right\} * D\{t=j\} . D\left\{B u s_{c}\right\}$ is a treatment indicator that is equal to one if a county has Honk for Hope bus stops and zero otherwise (according to one of the three treatment definitions). The treatment variable is interacted with the event-study dummy variables that are equal to one if an observation is $j$ days from November 18. $\pi_{j}$ capture pre-treatment trends in $Y_{c t}$, and $\phi_{j}$ are post-treatment coefficients. They identify the differential growth in daily incidence rates in the aftermath of the demonstrations in counties with Honk for Hope bus stops.

$X_{c}$ includes control variables at the county level, which are also interacted with relative time dummy variables. In our baseline specification, $X_{c}$ includes the value of the seven-days-incidence rate on November 7, allowing for different development in COVID-19 cases depending on the initial level of infections. In several robustness checks, we extend $X_{c}$ by different control variables that may affect the infections in counties. Standard errors are clustered at the county level.

The main assumption to identify a causal effect is that the seven-days-incidence rates in counties with Honk for Hope bus stops would have developed parallel to those in other counties, had COVID-19 deniers not been present at the demonstrations in Leipzig and Berlin. The event study approach allows us to investigate this parallel trends assumption directly through the visualization of pre-treatment trends $\pi_{j}$. We investigate potential other threats to identification in the robustness section.

\subsubsection{Event Study Results}

Figure 5 presents event study results showing the effect of the Querdenken demonstrations in Leipzig and Berlin on the spread of COVID-19 in German counties. The three graphs plot the coefficients $\pi_{j}$ and $\phi_{j}$ from regression model (2) and their 95 percent confidence intervals for the three definitions of our treatment. The corresponding regression results can be seen in Table A2 in the appendix.

For all three definitions of treated counties, the figures show a very parallel trend in COVID-19

\footnotetext{
${ }^{7} \mathrm{~A}$ balance table of covariates and outcomes can be found in Panel B of Table A1 in the appendix.
} 
infection rates over the entire pre-treatment period. Conditional on the control variables, counties with Honk for Hope bus stops did not have significantly different growth rates in COVID-19 cases during the second wave before the demonstrations in Leipzig and Berlin. This parallel trend is observable up to about November 23. Afterwards, there is a clear break, and the coefficients in all three models increase until the end of our observation window (December 23). About two weeks after the demonstration in Leipzig and one week after the demonstration in Berlin, counties that include cities that have a Honk for Hope bus stop experience higher COVID-19 incidence rates. These higher rates become statistically significant at a 5 percent level by the end of November. On December 23, counties with Honk for Hope bus stops in small towns $(<20,000$ inhabitants) have seven-days-incidence rates about 75 cases higher per 100,000 residents than counties without bus stops. Given an average seven-days-incidence rate of 284 in treated counties, this effect corresponds to a 35.9 percent increase in the seven-days-incidence rate on December $23((100 /(284-75)) * 75)$.

The general picture is similar across the three definitions of our treatment groups. However, there are notable differences in the significance and effect size that support our causal interpretation. In particular, the incidence rates increases are much higher and more significant among counties with Honk for Hope bus stops in small towns, compared to the effect when we employ the alternative treatment definition. In fact, the effect size monotonically increases as the treatment definition becomes stricter. This aligns with the idea that Honk for Hope bus stops in small towns reflect demand for travel to anti-lockdown demonstrations and, therefore, indicate the presence of a large number of COVID-19 deniers.

In a next step, we show that the results on the seven-days-incidence are also reflected when analyzing the effect of the November demonstrations on the cumulative number of cases per 100,000 inhabitants. Figure 6 again shows very parallel trends between treated and non-treated counties when it comes to the development of total cases per 100,000. This trend diverges for all three treatment definitions after November 23, as does the trend in the seven-days-incidence rates. The coefficients increase until the end of our observation window, and become significantly different from zero at the 5 percent level in Figure 6 (b) and (c). On December 23, counties with Honk for Hope bus stops in small towns ( $<20,000$ inhabitants) have 243 more COVID-19 cases per 100,000 inhabitants than those without bus stops. The mean value of cases is 2001 in treated counties on December 23, implying that the demonstrations increased the total number of cases in treated counties by about 13.8 percent $((100 /(2001-243)) * 243)$. 
Figure 5: Event Study Results - Querdenken Demonstrations and Seven-Days-Incidence Rates

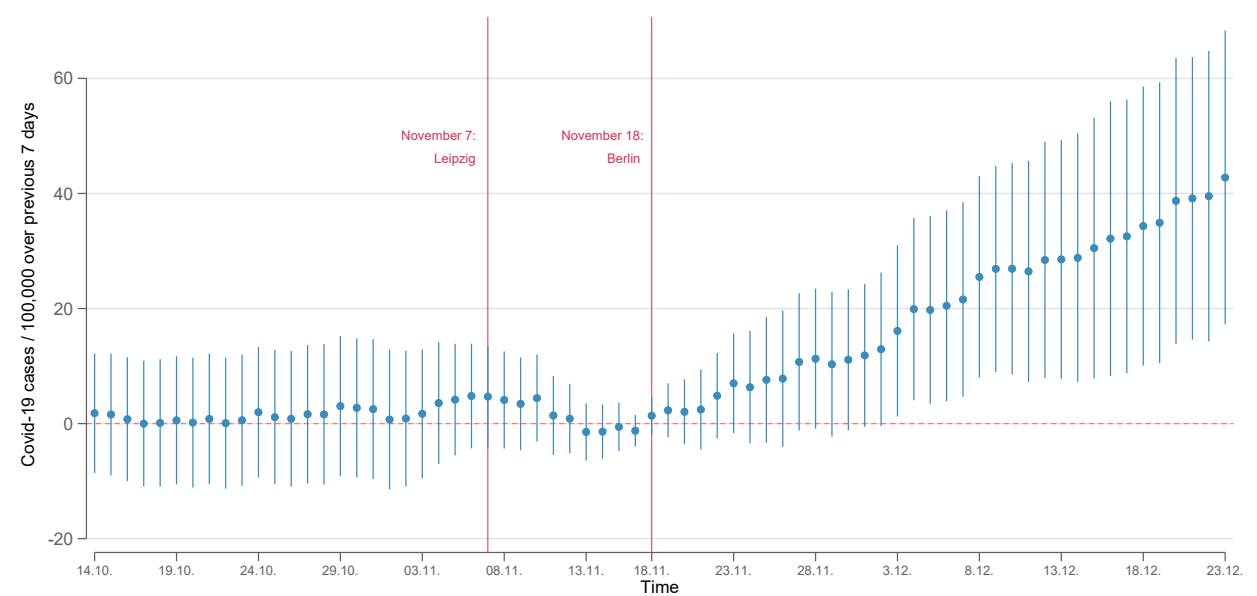

(a) Treated: Honk for Hope Stops

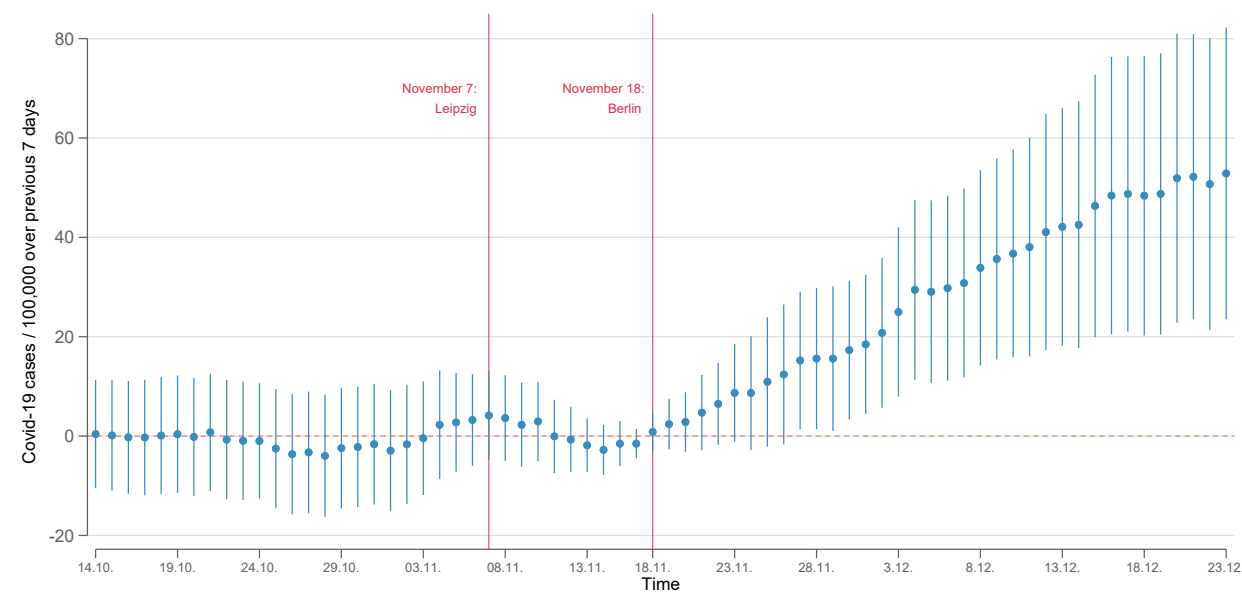

(b) Treated: Honk for Hope Stops (Cities Smaller than 50,000)

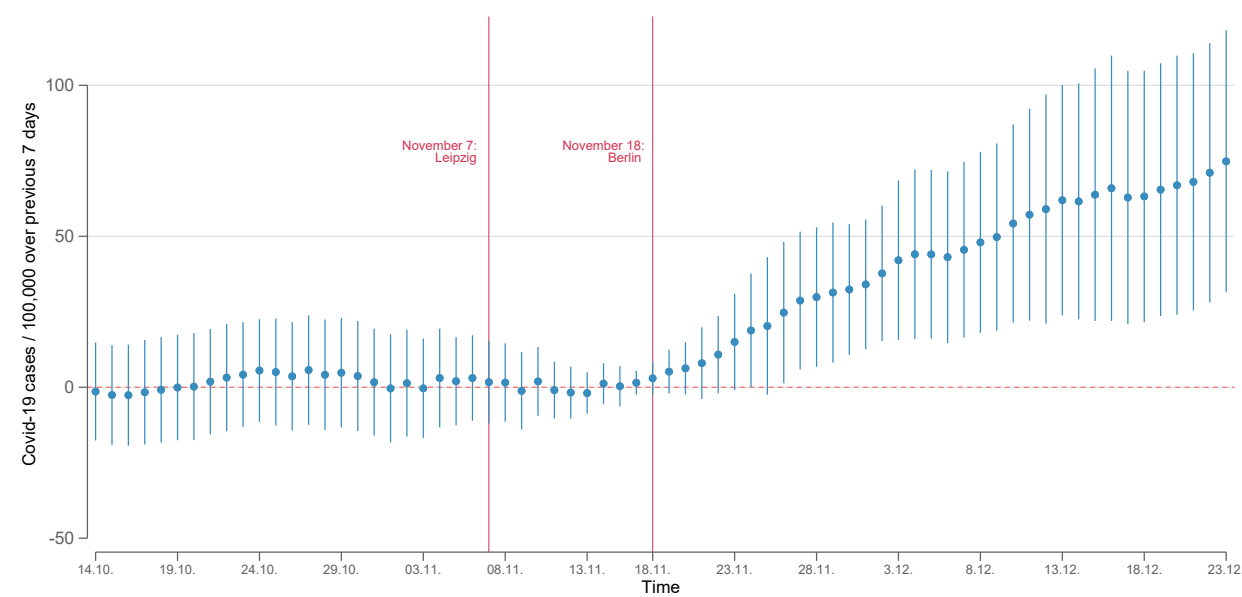

(c) Treated: Honk for Hope Stops (Cities Smaller than 20,000)

Notes: The figures plot the event study coefficients and their 95 percent confidence intervals on the effect of the Querdenken demonstrations in Leipzig and Berlin on the seven-days-incidence rates in German counties. The treated group are counties with Honk for Hope bus stops in general, in cities with fewer than 50,000 inhabitants, or in cities with fewer than 20,000 inhabitants. The sample is restricted to rural counties and a 35-days window around November 18 . All models control for county and day fixed effects, as well as interactions between days and the incidence rate on November 7 . 
Figure 6: Event Study Results - Querdenken Demonstrations and Cumulative Number of Cases / 100,000

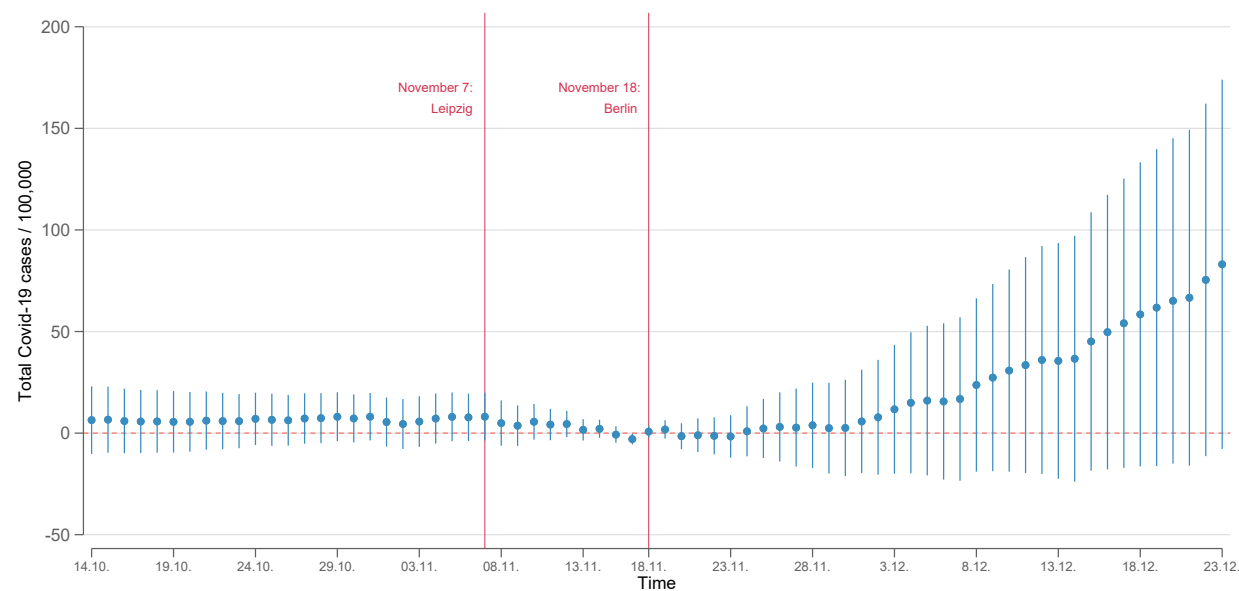

(a) Treated: Honk for Hope Stops

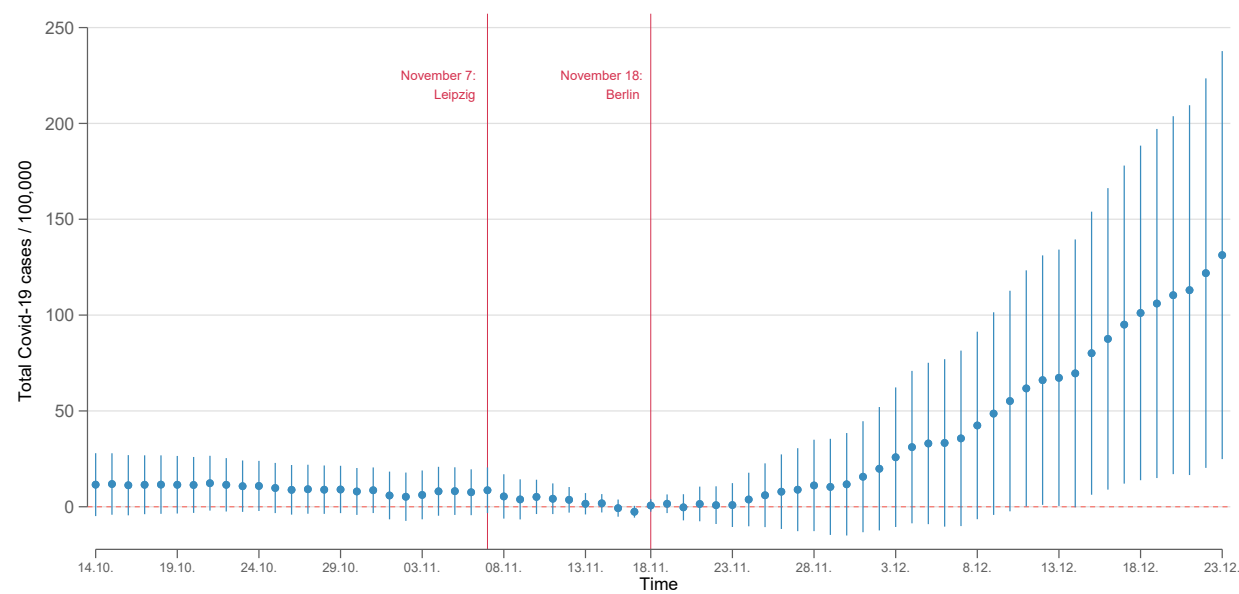

(b) Treated: Honk for Hope Stops (Cities Smaller than 50,000)

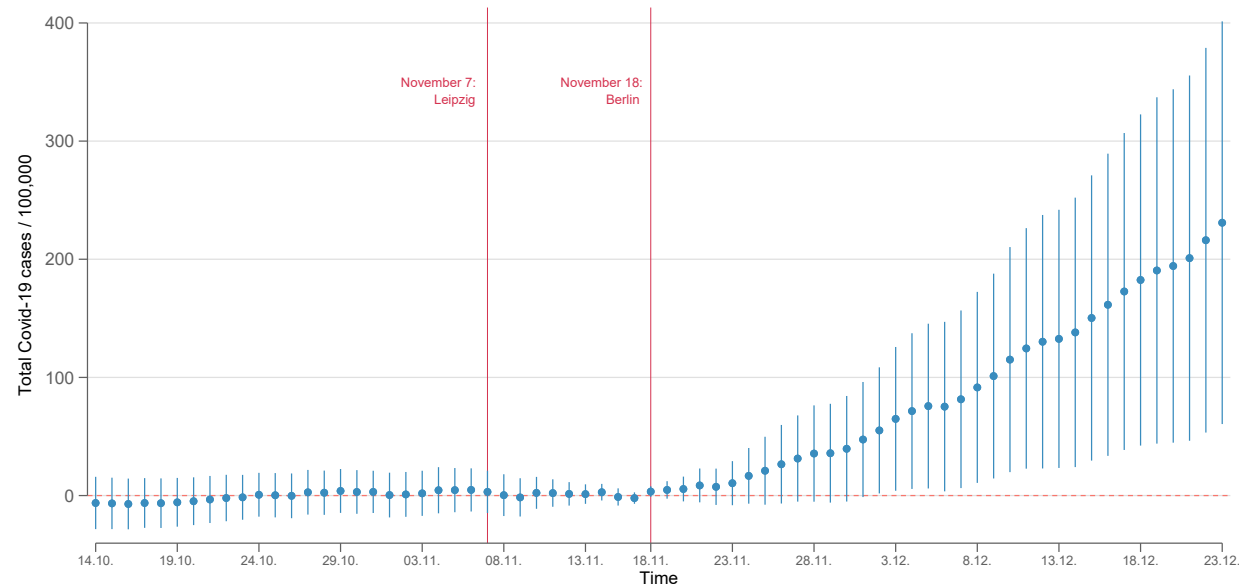

(c) Treated: Honk for Hope Stops (Cities Smaller than 20,000)

Notes: The figures plot the event study coefficients and their 95 percent confidence intervals on the effect of the Querdenken demonstrations in Leipzig and Berlin on the total number of COVID-19 case per 100,000 inhabitants. The treated group are counties with Honk for Hope bus stops in general, in cities with fewer than 50,000 inhabitants, or in cities with fewer than 20,000 inhabitants. The sample is restricted to rural counties and a 35-days window around November 18. All models control for county and day fixed effects, as well as interactions between days and the incidence rate on November 7 . 


\subsubsection{Robustness}

In this subsection, we investigate the robustness of our results along different margins, addressing multiple concerns for the validity of our causality claims. Since we observe the largest effects for counties with Honk for Hope bus stops in small towns with fewer than 20,000 inhabitants, we focus our robustness section on this treatment definition and its effect on the seven-days-incidence rate. $^{8}$

First, we extend our baseline model (2) by several control variables that are interacted with time dummies (extend $X_{c}$ in $\sum_{j=-35}^{-2} \alpha_{j} X_{c} * D\{t=j\}$ and $\sum_{j=0}^{35} \beta_{j} X_{c} * D\{t=j\}$ ). This allows the seven-days-incidence rates to develop differently in counties that differ in variables that may be associated with regional heterogeneity in the spread of COVID-19.

In a first step, we extend $X_{c}$ by a dummy variable indicating whether a county has a FlixBus stop in a small town with fewer than 20,000 inhabitants. ${ }^{9}$ The motivation for this robustness check is that our treatment definition may reflect the connectedness of counties more generally, independent of the distribution of COVID-19 deniers. More specifically, Honk for Hope bus stops may simply resemble the regional distribution of bus connections. If bus stops correlate with the increase in COVID-19 infections, this omitted variable will bias our findings. The results in column (1) of Table A3 show that the our main results remain almost unchanged when allowing counties with FlixBus stops to have different infection rates over time. In particular, we see that the pre-treatment coefficients $\pi_{j}$ are close to zero and insignificant, while $\phi_{j}$ again increase after November $22(j=4)$ through to the end of our observation window. The effect size decreases only slightly (e.g., 72.9 instead of 74.8 for December $23 / j=35$ ). Figure A1 (a) plots the event study coefficients $\alpha_{j}$ and $\beta_{j}$ for the FlixBus dummy variables from this specification. FlixBus stops appear very differently related to the development in the seven-days-incidence rates than do Honk for Hope bus stops. This finding supports the argument that our treatment definition identifies regions with a high share of COVID-19 deniers, and not more or less connected regions.

In a second step, we extend $X_{c}$ by different control variables that aim to approximate regional factors associated with faster outbreaks of COVID-19. In particular, we add the counties' population density, nursing home capacities, and share of asylum applicants. If counties with Honk for Hope bus stops are, by coincidence, counties that favor the spread of COVID-19 for other reasons, this may drive our results, although the parallel trends in our main specification prior to the demonstrations make it unlikely. Indeed, the estimates in column (2) of Table A3 show our main results as very robust to the inclusion of the 207 additional controls variables. Again, there are parallel trends prior to the demonstrations, and significant increases in $\phi_{j}$ after November $23(j=5)$ through to the end of our observation window. The effect size decreases only slightly compared to the previous specification (e.g., 69.9 instead of 72.9 for December 23 / $j=35)$.

Third, we investigate whether counties' varying economic circumstances affect our results. For this, we add the local unemployment rate and GDP per capita to $X_{c}$. One concern may be that counties with Honk for Hope bus stops differ along economic lines, which may affect the infection rates through differences in housing arrangements or mobility. In column (3) of

\footnotetext{
${ }^{8}$ Robustness checks for the other treatment definitions are available upon request.

${ }^{9}$ The same results are reached when defining the FlixBus dummy variable as counties that have FlixBus stops in general or in cities with fewer than 50,000 inhabitants.
} 
Table A3, we only add the economic factors and drop the controls from the previous paragraph. In column (4) we add the full set of control variables interacted with time dummy variables. The results are highly robust when allowing for counties with dissimilar economic power to see differing growth in incidence rates. The results are very similar to the previous models, both with respect to the effect size and the statistical significance. Again, the effect size decreases slightly when including the full set of controls in column (4) compared to the previous model in column (2) of Table A3 (e.g., 60.0 instead of 69.9 for December $23 / j=35$ ). Figure A1 (b) plots the event study coefficients of the treated counties from the full specification in column (4) of Table A3. The graph looks fairly similar to the main results in Figure 5.

Another concern with regard to the causal interpretation of our results is that our results could be driven omitted factors particular to specific regions. If, for example, our results are entirely driven by counties in Saxony, our treatment effects may reflect variation in the proximity to Czech Republic, which had higher infection rates in October. One argument against this concern is that we cover some of this heterogeneity in our main specification by controlling for county fixed effects and by allowing different growth in the incidence rates depending on the initial level of the seven-days-incidence rate. Moreover, previous extensions of our baseline model may address this concern to some extent. To test for this more explicitly, we re-run our baseline model 16 times and successively exclude each federal state from the sample. The results are plotted in Figures A2 and A3. They show that our main results are not explained by a particular federal state, e.g. Saxony (Figure A2 (f)) or Bavaria (Figure A2 (a)), as the results look similar across the 16 graphs. This is evidence that proximity to Czech Republic with its high infection rates did not cause our results.

Next, we test the sensitivity of our main results with regard to the definition of our outcome variables, the seven-days-incidence rate. A first concern may be that absolute differences between counties may become proportionally less important over time with growth in COVID-19 infection among all counties. We address this issue in Table A4 by re-running our main models using transformed outcome variables. Specifically, our outcome in column (1) is normalized by taking the daily mean and variance into account: $\frac{\left(Y_{c t}-\overline{Y_{t}}\right)}{\sqrt{\operatorname{Var}\left(Y_{t}\right)}}$. In column $(2)$, we use the logarithm of the seven-days-incidence rate. Results in Table A4 are qualitatively very similar to the main results. Most importantly, the parallel trend assumption holds for the transformed outcomes. Also, the deviations from the parallel trend are the same as for the non-normalized variables, both in terms of the size and significance of the coefficients. This result can also be seen in Figure A1 (c), which illustrates the estimated coefficients for the normalized seven-days-incidence rate for counties with fewer than 20,000 inhabitants (coefficients from Table A4, column (1)).

A second concern in this respect may be that the incidence rate depends on testing. If testing capacities change selectively over time, this may bias our results. To overcome this concern, we re-run our main specification for the seven-days-fatality rate, which gives the number of COVID19 related deaths per 100,000 inhabitants over the previous seven days. An argument to use the fatality rate is that it is more precisely measurable. Results in column (3) of Table A4 show that the COVID-19 fatality trends prior to the demonstrations are parallel as the pre-treatment coefficients $\pi_{j}$ are close to zero and insignificant. After the demonstrations, the coefficients are rather noisily estimated but starting around December 8 , the seven-days-fatality rate veers 
upward. The delay in this increase is to be expected given the average time it takes for higher COVID-19 infection rates to be reflected in COVID-19 related deaths. Given the rather low number of cases in our outcome variable, the effect size is small, but coefficients are significant at a 10 percent significance level by the end of our observation window. Counties with Honk for Hope bus stops see 1.3 more deaths per 100,000 over seven days leading up to December 23 than do counties without bus stops in small towns. In fact, this reflects an increase in the seven-days-fatality rate of about 33 percent in treated counties, given a mean value of the treated group on December 23 of $6.3((100 /(6.3-1.3)) * 1.3)$.

Finally, we investigate whether our results depend on the list of Honk for Hope stops that we use to construct the treatment status of counties. As described earlier, we combine in our main analysis the points of departure to go to two demonstrations in Berlin and Leipzig. In Figure A4 we present the results of our main specification for all Honk for Hope bus stops (a), those available when booking a trip to Leipzig (b), and those available when booking a trip to Berlin (c). Results are very similar among the three lists of bus stops, indicating that our results do not depend on a particularity of either of the two events.

\section{Potential Mechanisms - Individual-Level Evidence}

Why do some individuals willingly ignore or deny the threat of COVID-19? Our spatial evidence shows that denying COVID-19 poses a substantial threat to oneself and to others. How do individuals obtain information that foster their beliefs about the disease? In this section, we use one of the few survey data sets on COVID-19 suitable for these questions. In particular, we use individual survey data from a special COVID-19 questionnaire of the GESIS Panel Study (GESIS Panel Team, 2020), and identify individuals who do not believe in the threats posed by COVID-19. We analyze their self-reported mitigation strategies, trust in institutions, and media consumption.

The special COVID-19 survey is conducted on a random set of the larger GESIS Panel Study and covers 3,765 respondents surveyed March 17-29, 2020. To identify COVID-19 deniers we use a set of questions relating to the likelihood of contracting COVID-19 and the consequences of the disease. ${ }^{10}$ Answers to these questions could be given on a seven-point Likert scale ranging from "Not at all likely" to "Absolutely likely." We classify respondents as COVID-19 deniers if they answer every question with "Not at all likely." This is a rather restrictive definition, since assigning the lowest possible value to the likelihood of COVID-19 infections for yourself and others signals a strong disbelief about the threat of the disease. Close to 1 percent of the sample is classified as COVID-19 denier according to this definition.

We then study whether our classification of COVID-19 deniers correlates with fewer precautions to mitigate the spread of the coronavirus. To do this, we regress whether an individual engages in COVID-19 infection mitigation behavior on our COVID-19 denier categorization. Table A5 shows that COVID-19 deniers are significantly less likely to avoid public places, keep their distance in public areas, wash their hands regularly, reduce contacts, wear masks, and comply

\footnotetext{
${ }^{10}$ We use the answers to the following four questions: "How likely is it in your opinion that in the next two months... (1) ...you get infected with the coronavirus? (2) ...someone from your close social surroundings (family, friends, colleagues) gets infected with the coronavirus? (3) ...you need to be hospitalized in case you get infected with the coronavirus? (4) ...you get infected with the coronavirus and spread it to other people?".
} 
with curfews. This evidence is robust to controlling for basic socioeconomic variables including gender, age, education, household size, and labor force status.

We then explore why COVID-19 deniers hold their divergent beliefs. One reason may be the lack in trust in institutions. Table A6 indeed documents severe mistrust among COVID-19 deniers. Running regressions of how much individuals trust public institutions on our COVID-19 denier variable reveals that COVID-19 deniers are significantly less likely to trust public health institutions, may these be local, such as respondent's local health office, or global, such as the World Health Organization (WHO). In addition, COVID-19 deniers do not trust as much as others in the federal government, the chancellor of Germany, Angela Merkel, and scientists in general. Controlling for basic socioeconomic indicators does not result in insignificant coefficient estimates of the COVID-19 Denier variable.

Finally, Table A7 demonstrates how COVID-19 deniers' media consumption deviates from that of other respondents. The dependent variables are equal to one if individuals obtain their information about COVID-19 from the listed media channel. COVID-19 deniers are significantly less likely to turn to conventional media sources, including public TV and radio or newspapers when they seek information about the novel coronavirus. Other respondents' high reliance on these media (92.3 percent use public TV and radio, 67 percent newspapers) reveals these to be the most trusted sources of information. Yet COVID-19 deniers seem to have turned away from "mainstream media." We find no evidence that COVID-19 deniers obtain their information predominantly from social media platforms, but their disaffection with established media suggests that they either do not inform themselves at all or they consume media sources that feed their opinions on COVID-19. Individual evidence from COVID-19 deniers confirms that this group is less engaged in COVID-19 mitigation strategies, has less trust in public institutions, and does not rely on established media sources that report (most of the time) evidence-based COVID19 news. These findings corroborate the results of the spatial analysis and match anecdotal evidence presented in news articles. Our results suggest that COVID-19 deniers may pose a threat to society, both by neglecting public health rules at large-scale protests and through their everyday behavior.

\section{Conclusion}

This study looks at how COVID-19 deniers contribute to novel coronavirus infection rates. Our findings inform the ongoing debate about the public health threat posed by people who deny the dangers of COVID-19 and documents their unwillingness to engage in COVID-19 mitigation strategies. In Germany's second infection wave, when individual behavior became a more important factor in containing the disease, locations with a high concentration of COVID-19 deniers saw a steeper rise in COVID-19 cases.

In addition, our event study reveals large negative public health consequences when antiCOVID-19 protesters congregate at mass rallies. Our causal estimates suggest that between 16,000 to 21,000 COVID-19 infections could have been prevented if local authorities had canceled two large-scale anti-COVID-19 policy protests. This finding underscores the health costs of allowing COVID-19 deniers to protest without any (enforceable) coronavirus containment strategies. Moreover, these results highlight the clash between civil liberties and public health that 
most governments around the world currently face. Since the public health costs associated with this trade-off are hard to judge for policymakers, our estimates give some indication of their size.

In sum, our study documents that a radical minority can pose a significant risk to the entire population. Given the severe negative public health consequences reported in this study, policymakers would do well to direct more attention to what causes beliefs and behavior that are harmful to society. Stepped-up efforts to foster greater trust in institutions, policymakers, and scientific evidence could be pathways toward overcoming such divisions that threaten public health and societal cohesion. 


\section{Bibliography}

Allcott, H., L. Boxell, J. Conway, M. Gentzkow, M. Thaler, and D. Yang (2020). Polarization and public health: Partisan differences in social distancing during the coronavirus pandemic. Journal of Public Economics 191, 104254.

Alsan, M., L. Braghieri, S. Eichmeyer, M. J. Kim, S. Stantcheva, and D. Yang (2020). Civil liberties in times of crisis. NBER Working Paper Series (27972).

Barbieri, P. and B. Bonini (2020). Populism and political (mis-)belief effect on individual adherence to lockdown during the COVID-19 pandemic in italy. SSRN Electronic Journal (3640324).

Bargain, O. and U. Aminjonov (2020). Trust and compliance to public health policies in times of COVID-19. Journal of Public Economics 192, 104316.

Barrios, J. M., E. Benmelech, Y. V. Hochberg, P. Sapienza, and L. Zingales (2021). Civic capital and social distancing during the covid-19 pandemic. Journal of Public Economics 193, 104310.

Bartscher, A., S. Seitz, M. Slotwinski, N. Wehrhöfer, and S. Siegloch (2020). Social Capital and the Spread of Covid-19: Insights from European Countries. ZEW Discussion Paper (20-023).

Berliner Zeitung (2020). Gegen Corona-Maßnahmen: Deutsch-polnische Demo an der Grenze. (https://www.berliner-zeitung.de/news/corona-massnahmen-deutsch-polnischedemo-an-der-grenze-li.122196, accessed on January 18, 2021).

Brodeur, A., I. Grigoryeva, and L. Kattan (2020). Stay-At-Home Orders, Social Distancing and Trust. IZA Discussion Paper Series (13234).

Bundesregierung (2020). Corona-Eindämmung - Diese Regeln gelten jetzt. (https://www. bundesregierung.de/breg-de/themen/coronavirus/regelungen-ab-2-november-1806818, accessed on January 18, 2021).

Bursztyn, L., A. Rao, C. Roth, and D. Yanagizawa-Drott (2020). Misinformation during a pandemic. NBER Working Paper Series (27417).

Clinton, J., J. Cohen, J. Lapinski, and M. Trussler (2020). Partisan pandemic: How partisanship and public health concerns affect individuals' social mobility during COVID-19. Science Advances 7(2), eabd7204.

Dave, D., A. Friedson, K. Matsuzawa, J. Sabia, and S. Safford (2020). Black lives matter protests, social distancing, and COVID-19. NBER Working Paper Series (27408).

Dave, D., D. McNichols, and J. Sabia (2020). The contagion externality of a superspreading event: The sturgis motorcycle rally and COVID -19. Southern Economic Journal.

Deutschlandfunk (2020). Corona-Demonstrationen - Wer marschiert da zusammen? (https://www.deutschlandfunk.de/corona-demonstrationen-wer-marschiert-dazusammen.2897.de.html?dram:article_id=483465, accessed on January 18, 2021).

Durante, R., L. Guiso, and G. Gulino (2021). Asocial capital: Civic culture and social distancing during COVID-19. Journal of Public Economics 194, 104342. 
DW News (2020). Protests in Germany: 45 officers injured at Berlin rally against coronavirus curbs. (https://www.dw.com/en/protests-in-germany-45-officers-injured-at-berlinrally-against-coronavirus-curbs/a-54402885, accessed on January 18, 2021).

Forschungsgruppe Durchgezählt (2020). Wir schätzen, dass sich wenigstens 45000 Menschen bei der Querdenken Demo in Leipzig auf dem Augustusplatz und in unmittelbarer Nähe versammelt haben. (https://twitter.com/durchgezaehlt/status/1325089227529400320, accessed on February 3, 2021.

Gadarian, S. K., S. W. Goodman, and T. B. Pepinsky (2020). Partisanship, health behavior, and policy attitudes in the early stages of the COVID-19 pandemic. SSRN Electronic Journal.

GESIS Panel Team (2020). GESIS Panel Special Survey on the Coronavirus SARS-CoV-2 Outbreak in Germany.

Grossman, G., S. Kim, J. M. Rexer, and H. Thirumurthy (2020). Political partisanship influences behavioral responses to governors' recommendations for COVID-19 prevention in the united states. Proceedings of the National Academy of Sciences 117(39), 24144-24153.

Harris, J. (2020). Geospatial analysis of the september 2020 coronavirus outbreak at the university of wisconsin - madison: Did a cluster of local bars play a critical role? NBER Working Paper Series (28132).

Hille, P. (2020). Deutschland verschärft Corona-Regeln. (https://www.dw.com/de/ deutschlandversch\%C3\% A4rft-corona-regeln/a-55724971, accessed on January 18, 2021).

Machowecz, M. (2020). Wut auf Rädern. Die Zeit 47, 27.

Makridis, C. and J. T. Rothwell (2020). The real cost of political polarization: Evidence from the COVID-19 pandemic. SSRN Electronic Journal.

Mellacher, P. (2021). The impact of corona populism: Empirical evidence from Austria and theory. Covid Economics (63), 98-125.

Mitteldeutscher Rundfunk (2020). Das war der November 2020. (https://www.mdr.de/ nachrichten/chronik/jahresrueckblick-november-ereignisse-nachrichten-100.html, accessed on January 18, 2021).

Morris, L. and L. Beck (2020). Germany's protests against coronavirus restrictions are becoming increasingly radical. (https://www.washingtonpost.com/world/europe/germany-coronaviruslockdown-protests/2020/11/12/3e9879ea-2422-11eb-9c4a-0dc6242c4814_story.html, accessed on January 18, 2021).

Nachtwey, O., R. Schäfer, and N. Frei (2020). Politische Soziologie der Corona-Proteste. SocArXiv.

Oltermann, P. (2020). Merkel forced to postpone plans to tighten lockdown rules. (https://www.theguardian.com/world/2020/nov/16/merkel-germany-soft-covid-lockdownchancellor-social-interaction, accessed on January 18, 2021). 
Pechtold, M., D. Friess, R. Röhrich, and S. Krieger (2020). Corona-Demo in Berlin: Polizei ermittelt gegen AfD-Abgeordneten. (https://www.fr.de/politik/corona-demo-berlin-karstenhilse-afd-abgeordneter-ermittelungen-zr-90103934.html, accessed on January 18, 2021).

Rieck, T., M. Feig, A. Siedler, and O. Wichmann (2018). Aktuelles aus der KV-Impfsurveillance - Impfquoten ausgewählter Schutzimpfungen in Deutschland. Epidemiologisches Bulletin (1), $1-14$.

Robert Koch Institut (2020a). COVID-19 Situation Report 02/11/2020. (https://www.rki.de/ DE/Content/InfAZ/N/Neuartiges_Coronavirus/Situationsberichte/2020-11-02en.pdf?__blob=publicationFile, accessed on January 18, 2021).

Robert Koch Institut (2020b). COVID-19 Situation Report 06/08/2020. (https://www.rki.de/ DE/Content/InfAZ/N/Neuartiges_Coronavirus/Situationsberichte/2020-08-08en.pdf?__blob=publicationFile, accessed on January 18, 2021).

Robert Koch Institut (2020c). COVID-19 Situation Report 22/03/2020. (https://www.rki.de/ DE/Content/InfAZ/N/Neuartiges_Coronavirus/Situationsberichte/2020-03-22en.pdf?__blob=publicationFile, accessed on January 18, 2021).

Robert Koch Institut (2020d). COVID-19 Situation Report 23/07/2020. (https://www.rki.de/ DE/Content/InfAZ/N/Neuartiges_Coronavirus/Situationsberichte/2020-07-23en.pdf?__blob=publicationFile, accessed on January 18, 2021).

Roose, J. (2020). Verschwörung in der Krise - Repräsentative Umfragen zum Glauben an Verschwörungstheorien vor und in der Corona-Krise. Konrad-Adenauer-Stiftung.

Süddeutsche Zeitung (2020a). Hunderte gehen gegen "Querdenken"-Demo auf die Straße. (https://www.sueddeutsche.de/politik/demonstrationen-duesseldorf-hunderte-gehen-gegenquerdenken-demo-auf-die-strasse-dpa.urn-newsml-dpa-com-20090101-201206-99-592039, accessed on January 18, 2021).

Süddeutsche Zeitung (2020b). Ist die AfD mittendrin oder nur dabei? (https://www.sueddeutsche.de/muenchen/freising/freising-querdenker-telegram-afd-politiker1.5145111, accessed on February 3, 2021).

Simonov, A., S. Sacher, J.-P. Dube, and S. Biswas (2020). The Persuasive Effect of Fox News: Non-Compliance with Social Distancing During the COVID-19 Pandemic. Becker Friedman Institute for Research In Economics Working Papers (2020-67).

Soldt, R. (2020). Die Organisationsstruktur hinter den "Hygiene-Demos". (https://www.faz.net/ aktuell/politik/inland/berlin-die-organisationsstruktur-hinter-den-corona-demos16888674.html, accessed on January 18, 2021).

Tagesspiegel (2020). Organisator von "Querdenker"-Protesten an Corona erkrankt. (https://www.tagesspiegel.de/politik/nach-demo-in-leipzig-am-7-november-organisatorvon-querdenker-protesten-an-corona-erkrankt/26712108.html, accessed on February 2, 2021). 
The Economist (2020). Anti-lockdown protests have been hijacked by conspiracy theorists. (https://www.economist.com/international/2020/09/06/anti-lockdown-protests-havebeen-hijacked-by-conspiracy-theorists, accessed on January 18, 2021).

YouGov Cambridge (2020). Globalism 2020 Guardian Conspiracy Theories. https://docs.cdn.yougov.com/msvke1lg9d/Globalism2020

Zeit Online (2020). Gegner von Corona-Politik bedrängen Abgeordnete im Parlamentsgebäude. (https://www.zeit.de/politik/deutschland/2020-11/bevoelkerungsschutzgesetz-berlincorona-proteste-abstimmung-corona-politik-regierungsviertel-infektionsschutzgesetz, accessed on January 18, 2021). 


\section{A Additional Material}

Table A1: Summary Statistics and Treatment Balancing

\begin{tabular}{|c|c|c|c|c|c|c|}
\hline Panel A: Summary Statistics & Mean & Median & $\mathrm{SD}$ & Min & Max & Counties \\
\hline 7 Day Incidence Rate on Nov 1, 2020 & 119.57 & 115.58 & 58.27 & 14.98 & 334.81 & 401 \\
\hline 7 Day Incidence Rate on Dec 1,2020 & 141.57 & 131.91 & 77.04 & 8.45 & 499.97 & 401 \\
\hline 7 Day Fatality Rate on Nov 1, 2020 & 1.58 & 1.10 & 1.84 & 0.00 & 13.06 & 401 \\
\hline 7 Day Fatality Rate on Dec 1, 2020 & 3.88 & 2.74 & 4.91 & 0.00 & 56.12 & 401 \\
\hline Counties with Honk for Hope Bus Stops & 0.54 & 1.00 & 0.50 & 0.00 & 1.00 & 401 \\
\hline in Cities below 50,000 Residents & 0.26 & 0.00 & 0.44 & 0.00 & 1.00 & 401 \\
\hline in Cities below 20,000 Residents & 0.10 & 0.00 & 0.31 & 0.00 & 1.00 & 401 \\
\hline Counties with FlixBus Bus Stops & 0.56 & 1.00 & 0.50 & 0.00 & 1.00 & 401 \\
\hline in Cities below 50,000 Residents & 0.31 & 0.00 & 0.46 & 0.00 & 1.00 & 401 \\
\hline in Cities below 20,000 Residents & 0.17 & 0.00 & 0.37 & 0.00 & 1.00 & 401 \\
\hline Measles Vaccination Rate at Age 15-Months & 88.95 & 90.30 & 4.92 & 72.40 & 97.50 & 401 \\
\hline Vote Share of AfD at EU Parliament Election 2019 & 11.47 & 9.56 & 5.53 & 3.99 & 32.21 & 401 \\
\hline Electoral Turnout at EU Parliament Election 2019 & 60.59 & 60.62 & 4.82 & 47.62 & 74.38 & 401 \\
\hline Population Density & 536.86 & 201.00 & 709.70 & 36.00 & 4777.00 & 401 \\
\hline Unemployment Rate & 5.36 & 5.00 & 2.41 & 1.50 & 14.00 & 401 \\
\hline GDP per Capita in EUR 1,000 & 37.09 & 33.10 & 16.05 & 16.40 & 172.40 & 401 \\
\hline Nursing Home Capacity per 10,000 Residents & 113.19 & 108.50 & 28.86 & 51.40 & 235.80 & 401 \\
\hline Asylum Applicants per 1,000 Residents & 5.39 & 5.10 & 2.57 & 0.00 & 31.90 & 401 \\
\hline \multirow[b]{2}{*}{ Panel B: Treatment Balancing } & \multicolumn{2}{|c|}{ Total } & \multicolumn{2}{|c|}{ Cities $<50,000$} & \multicolumn{2}{|c|}{ Cities $<20,000$} \\
\hline & Diff. & p-Value & Diff. & p-Value & Diff. & p-Value \\
\hline 7 Day Incidence Rate on Nov 1,2020 & -4.83 & 0.46 & 4.22 & 0.65 & -14.72 & $0.03^{* *}$ \\
\hline 7 Day Incidence Rate on Dec 1,2020 & 6.33 & 0.48 & 38.47 & $0.00 * * *$ & 6.64 & 0.49 \\
\hline 7 Day Fatality Rate on Nov 1, 2020 & 0.10 & 0.65 & 0.96 & $0.00 * * *$ & 0.04 & 0.86 \\
\hline 7 Day Fatality Rate on Dec 1, 2020 & 0.00 & 1.00 & 1.91 & $0.01^{* *}$ & 0.20 & 0.73 \\
\hline Measles Vaccination Rate at Age 15-Months & -0.63 & 0.30 & -0.97 & 0.26 & -0.71 & 0.27 \\
\hline Vote Share of AfD at EU Parliament Election 2019 & 2.80 & $0.00^{* * *}$ & 4.11 & $0.00^{* * *}$ & 3.72 & $0.00^{* * *}$ \\
\hline Electoral Turnout at EU Parliament Election 2019 & -1.83 & $0.00^{* * *}$ & -1.76 & $0.02^{* *}$ & -1.79 & $0.00^{* * *}$ \\
\hline Population Density & -31.36 & 0.16 & -109.53 & $0.00 * * *$ & -86.40 & $0.00 * * *$ \\
\hline Unemployment Rate & 1.20 & $0.00 * * *$ & 0.47 & 0.16 & 1.06 & $0.00 * * *$ \\
\hline GDP per Capita in EUR 1,000 & 1.10 & 0.28 & -0.49 & 0.74 & -0.40 & 0.71 \\
\hline Nursing Home Capacity per 10,000 Residents & 9.28 & $0.01^{* * *}$ & 5.80 & 0.22 & 9.46 & $0.01^{* * *}$ \\
\hline Asylum Applicants per 1,000 Residents & 0.39 & $0.08^{*}$ & 0.26 & 0.41 & 0.19 & 0.41 \\
\hline
\end{tabular}

Notes: Panel A reports summary statistics on the main outcome, treatment, and control variables for all 401 counties in Germany. Panel B shows level differences in the means of outcome and control variables between counties that have at least one Honk for Hope bus stop and those that do not for our estimation sample of rural counties. Statistical significance in mean differences is indicated by asterisks according to: ${ }^{*} p<0.10,{ }^{* *} p<0.05,{ }^{* * *} p<0.01$. 
Table A2: Event Study Results: Seven-Days-Incidence Rate

\begin{tabular}{|c|c|c|}
\hline Bus Stops (all) & $\begin{array}{l}\text { Bus Stops } \\
(<50,0000)\end{array}$ & $\begin{array}{l}\text { Bus Stops } \\
(<20,0000)\end{array}$ \\
\hline
\end{tabular}

(1)

$(2)$

(3)

\begin{tabular}{|c|c|c|c|}
\hline$D\left\{B u s_{c}=1\right\} * D\{j=-35\}$ & $\begin{array}{c}1.817 \\
(5.276)\end{array}$ & $\begin{array}{c}0.405 \\
(5.536)\end{array}$ & $\begin{array}{l}-1.403 \\
(8.239)\end{array}$ \\
\hline$D\left\{B u s_{c}=1\right\} * D\{j=-34\}$ & $\begin{array}{c}1.580 \\
(5.383)\end{array}$ & $\begin{array}{c}0.135 \\
(5.635)\end{array}$ & $\begin{array}{l}-2.542 \\
(8.395)\end{array}$ \\
\hline$D\left\{B u s_{c}=1\right\} * D\{j=-33\}$ & $\begin{array}{c}0.764 \\
(5.469)\end{array}$ & $\begin{array}{l}-0.257 \\
(5.763)\end{array}$ & $\begin{array}{l}-2.630 \\
(8.505)\end{array}$ \\
\hline$D\left\{B u s_{c}=1\right\} * D\{j=-32\}$ & $\begin{array}{l}-0.004 \\
(5.553)\end{array}$ & $\begin{array}{l}-0.287 \\
(5.911)\end{array}$ & $\begin{array}{l}-1.663 \\
(8.797)\end{array}$ \\
\hline$D\left\{B u s_{c}=1\right\} * D\{j=-31\}$ & $\begin{array}{c}0.121 \\
(5.627)\end{array}$ & $\begin{array}{c}0.110 \\
(5.968)\end{array}$ & $\begin{array}{l}-0.832 \\
(8.867)\end{array}$ \\
\hline$D\left\{B u s_{c}=1\right\} * D\{j=-30\}$ & $\begin{array}{c}0.567 \\
(5.651)\end{array}$ & $\begin{array}{c}0.395 \\
(6.002)\end{array}$ & $\begin{array}{l}-0.084 \\
(8.860)\end{array}$ \\
\hline$D\left\{B u s_{c}=1\right\} * D\{j=-29\}$ & $\begin{array}{c}0.178 \\
(5.736)\end{array}$ & $\begin{array}{l}-0.167 \\
(6.026)\end{array}$ & $\begin{array}{c}0.217 \\
(9.007)\end{array}$ \\
\hline$D\left\{B u s_{c}=1\right\} * D\{j=-28\}$ & $\begin{array}{c}0.808 \\
(5.760)\end{array}$ & $\begin{array}{c}0.756 \\
(6.001)\end{array}$ & $\begin{array}{c}1.844 \\
(8.863)\end{array}$ \\
\hline$D\left\{B u s_{c}=1\right\} * D\{j=-27\}$ & $\begin{array}{c}0.080 \\
(5.785)\end{array}$ & $\begin{array}{l}-0.718 \\
(6.103)\end{array}$ & $\begin{array}{c}3.212 \\
(9.031)\end{array}$ \\
\hline$D\left\{B u s_{c}=1\right\} * D\{j=-26\}$ & $\begin{array}{c}0.581 \\
(5.789)\end{array}$ & $\begin{array}{l}-0.936 \\
(6.055)\end{array}$ & $\begin{array}{c}4.191 \\
(8.828)\end{array}$ \\
\hline$D\left\{B u s_{c}=1\right\} * D\{j=-25\}$ & $\begin{array}{c}1.981 \\
(5.762)\end{array}$ & $\begin{array}{l}-0.986 \\
(5.902)\end{array}$ & $\begin{array}{c}5.559 \\
(8.641)\end{array}$ \\
\hline$D\left\{B u s_{c}=1\right\} * D\{j=-24\}$ & $\begin{array}{c}1.116 \\
(5.926)\end{array}$ & $\begin{array}{l}-2.511 \\
(6.101)\end{array}$ & $\begin{array}{c}5.047 \\
(9.013)\end{array}$ \\
\hline$D\left\{B u s_{c}=1\right\} * D\{j=-23\}$ & $\begin{array}{c}0.830 \\
(5.996)\end{array}$ & $\begin{array}{l}-3.645 \\
(6.155)\end{array}$ & $\begin{array}{c}3.636 \\
(9.097)\end{array}$ \\
\hline$D\left\{B u s_{c}=1\right\} * D\{j=-22\}$ & $\begin{array}{c}1.632 \\
(6.122)\end{array}$ & $\begin{array}{l}-3.276 \\
(6.216)\end{array}$ & $\begin{array}{c}5.700 \\
(9.216)\end{array}$ \\
\hline$D\left\{B u s_{c}=1\right\} * D\{j=-21\}$ & $\begin{array}{c}1.601 \\
(6.206)\end{array}$ & $\begin{array}{l}-3.972 \\
(6.257)\end{array}$ & $\begin{array}{c}4.140 \\
(9.303)\end{array}$ \\
\hline$D\left\{B u s_{c}=1\right\} * D\{j=-20\}$ & $\begin{array}{c}3.041 \\
(6.185)\end{array}$ & $\begin{array}{l}-2.416 \\
(6.175)\end{array}$ & $\begin{array}{c}4.815 \\
(9.196)\end{array}$ \\
\hline$D\left\{B u s_{c}=1\right\} * D\{j=-19\}$ & $\begin{array}{c}2.734 \\
(6.130)\end{array}$ & $\begin{array}{l}-2.197 \\
(6.151)\end{array}$ & $\begin{array}{c}3.715 \\
(9.249)\end{array}$ \\
\hline$D\left\{B u s_{c}=1\right\} * D\{j=-18\}$ & 2.520 & -1.632 & 1.684 \\
\hline
\end{tabular}




\begin{tabular}{|c|c|c|c|}
\hline & $(6.172)$ & $(6.169)$ & $(9.000)$ \\
\hline \multirow[t]{2}{*}{$D\left\{B u s_{c}=1\right\} * D\{j=-17\}$} & 0.708 & -2.933 & -0.360 \\
\hline & $(6.153)$ & $(6.196)$ & $(9.111)$ \\
\hline \multirow[t]{2}{*}{$D\left\{B u s_{c}=1\right\} * D\{j=-16\}$} & 0.877 & -1.660 & 1.353 \\
\hline & $(5.984)$ & $(6.096)$ & $(8.982)$ \\
\hline \multirow[t]{2}{*}{$D\left\{B u s_{c}=1\right\} * D\{j=-15\}$} & 1.702 & -0.426 & -0.340 \\
\hline & $(5.690)$ & $(5.804)$ & $(8.351)$ \\
\hline \multirow[t]{2}{*}{$D\left\{B u s_{c}=1\right\} * D\{j=-14\}$} & 3.573 & 2.276 & 3.068 \\
\hline & $(5.369)$ & $(5.559)$ & $(8.309)$ \\
\hline \multirow[t]{2}{*}{$D\left\{B u s_{c}=1\right\} * D\{j=-13\}$} & 4.164 & 2.759 & 2.017 \\
\hline & $(4.929)$ & $(5.064)$ & $(7.407)$ \\
\hline \multirow{2}{*}{$D\left\{B u s_{c}=1\right\} * D\{j=-12\}$} & 4.793 & 3.243 & 3.077 \\
\hline & $(4.621)$ & $(4.682)$ & $(7.187)$ \\
\hline \multirow[t]{2}{*}{$D\left\{B u s_{c}=1\right\} * D\{j=-11\}$} & 4.695 & 4.153 & 1.695 \\
\hline & $(4.471)$ & $(4.571)$ & $(6.951)$ \\
\hline \multirow[t]{2}{*}{$D\left\{B u s_{c}=1\right\} * D\{j=-10\}$} & 4.108 & 3.627 & 1.577 \\
\hline & $(4.290)$ & $(4.395)$ & $(6.595)$ \\
\hline \multirow[t]{2}{*}{$D\left\{B u s_{c}=1\right\} * D\{j=-9\}$} & 3.430 & 2.273 & -1.181 \\
\hline & $(4.103)$ & $(4.308)$ & $(6.519)$ \\
\hline \multirow[t]{2}{*}{$D\left\{B u s_{c}=1\right\} * D\{j=-8\}$} & 4.432 & 2.946 & 1.952 \\
\hline & $(3.839)$ & $(4.061)$ & $(5.789)$ \\
\hline \multirow{2}{*}{$D\left\{B u s_{c}=1\right\} * D\{j=-7\}$} & 1.411 & -0.053 & -0.947 \\
\hline & $(3.490)$ & $(3.747)$ & $(4.772)$ \\
\hline \multirow[t]{2}{*}{$D\left\{B u s_{c}=1\right\} * D\{j=-6\}$} & 0.855 & -0.698 & -1.752 \\
\hline & $(3.069)$ & $(3.344)$ & $(4.383)$ \\
\hline \multirow[t]{2}{*}{$D\left\{B u s_{c}=1\right\} * D\{j=-5\}$} & -1.448 & -1.847 & -1.916 \\
\hline & $(2.525)$ & $(2.759)$ & $(3.480)$ \\
\hline \multirow[t]{2}{*}{$D\left\{B u s_{c}=1\right\} * D\{j=-4\}$} & -1.395 & -2.765 & 1.240 \\
\hline & $(2.394)$ & $(2.559)$ & $(3.429)$ \\
\hline \multirow[t]{2}{*}{$D\left\{B u s_{c}=1\right\} * D\{j=-3\}$} & -0.570 & -1.525 & 0.341 \\
\hline & $(2.125)$ & $(2.317)$ & $(3.394)$ \\
\hline \multirow[t]{2}{*}{$D\left\{B u s_{c}=1\right\} * D\{j=-2\}$} & -1.244 & -1.520 & 1.501 \\
\hline & $(1.399)$ & $(1.501)$ & $(1.979)$ \\
\hline \multirow[t]{2}{*}{$D\left\{B u s_{c}=1\right\} * D\{j=0\}$} & 1.371 & 0.837 & 2.984 \\
\hline & $(1.683)$ & $(1.885)$ & $(2.770)$ \\
\hline \multirow[t]{2}{*}{$D\left\{B u s_{c}=1\right\} * D\{j=1\}$} & 2.316 & 2.422 & 5.183 \\
\hline & $(2.380)$ & $(2.576)$ & $(3.678)$ \\
\hline \multirow[t]{2}{*}{$D\left\{B u s_{c}=1\right\} * D\{j=2\}$} & 2.050 & 2.835 & 6.295 \\
\hline & $(2.876)$ & $(3.040)$ & $(4.392)$ \\
\hline$D\left\{B u s_{c}=1\right\} * D\{j=3\}$ & 2.444 & 4.726 & 7.984 \\
\hline
\end{tabular}




\begin{tabular}{|c|c|c|c|}
\hline & $(3.531)$ & $(3.849)$ & $(6.049)$ \\
\hline \multirow[t]{2}{*}{$D\left\{B u s_{c}=1\right\} * D\{j=4\}$} & 4.844 & 6.494 & $10.816^{*}$ \\
\hline & $(3.769)$ & $(4.175)$ & $(6.507)$ \\
\hline \multirow{2}{*}{$D\left\{B u s_{c}=1\right\} * D\{j=5\}$} & 6.998 & $8.700^{*}$ & $14.999^{*}$ \\
\hline & $(4.387)$ & $(5.019)$ & $(8.090)$ \\
\hline \multirow[t]{2}{*}{$D\left\{B u s_{c}=1\right\} * D\{j=6\}$} & 6.323 & 8.679 & $18.829 * *$ \\
\hline & $(4.967)$ & $(5.816)$ & $(9.561)$ \\
\hline \multirow[t]{2}{*}{$D\left\{B u s_{c}=1\right\} * D\{j=7\}$} & 7.613 & $10.927^{*}$ & $20.287^{*}$ \\
\hline & $(5.567)$ & $(6.613)$ & $(11.576)$ \\
\hline \multirow[t]{2}{*}{$D\left\{B u s_{c}=1\right\} * D\{j=8\}$} & 7.808 & $12.410^{*}$ & $24.723^{* *}$ \\
\hline & $(6.016)$ & $(7.162)$ & $(11.901)$ \\
\hline \multirow[t]{2}{*}{$D\left\{B u s_{c}=1\right\} * D\{j=9\}$} & $10.709 *$ & $15.224^{* *}$ & $28.727^{* *}$ \\
\hline & $(6.062)$ & $(7.033)$ & $(11.591)$ \\
\hline \multirow{2}{*}{$D\left\{B u s_{c}=1\right\} * D\{j=10\}$} & $11.277^{*}$ & $15.604^{* *}$ & $29.875^{* *}$ \\
\hline & $(6.187)$ & $(7.215)$ & $(11.741)$ \\
\hline \multirow{2}{*}{$D\left\{B u s_{c}=1\right\} * D\{j=11\}$} & 10.302 & $15.595^{* *}$ & $31.371^{* * *}$ \\
\hline & $(6.390)$ & $(7.395)$ & $(11.796)$ \\
\hline \multirow{2}{*}{$D\left\{B u s_{c}=1\right\} * D\{j=12\}$} & $11.098^{*}$ & $17.304^{* *}$ & $32.377^{* * *}$ \\
\hline & $(6.221)$ & $(7.086)$ & $(10.993)$ \\
\hline \multirow{2}{*}{$D\left\{B u s_{c}=1\right\} * D\{j=13\}$} & $11.855^{*}$ & $18.459^{* * *}$ & $34.063^{* * *}$ \\
\hline & $(6.317)$ & $(7.114)$ & $(10.922)$ \\
\hline \multirow[t]{2}{*}{$D\left\{B u s_{c}=1\right\} * D\{j=14\}$} & $12.922^{*}$ & $20.785^{* * *}$ & $37.731^{* * *}$ \\
\hline & $(6.777)$ & $(7.659)$ & $(11.388)$ \\
\hline \multirow{2}{*}{$D\left\{B u s_{c}=1\right\} * D\{j=15\}$} & $16.107^{* *}$ & $24.973^{* * *}$ & $42.070 * * *$ \\
\hline & $(7.556)$ & $(8.644)$ & $(13.415)$ \\
\hline \multirow{2}{*}{$D\left\{B u s_{c}=1\right\} * D\{j=16\}$} & $19.890^{* *}$ & $29.445^{* * *}$ & $44.053^{* * *}$ \\
\hline & $(8.049)$ & $(9.203)$ & $(14.255)$ \\
\hline \multirow[t]{2}{*}{$D\left\{B u s_{c}=1\right\} * D\{j=17\}$} & $19.752^{* *}$ & $29.058^{* * *}$ & $44.020 * * *$ \\
\hline & $(8.285)$ & $(9.345)$ & $(14.181)$ \\
\hline \multirow{2}{*}{$D\left\{B u s_{c}=1\right\} * D\{j=18\}$} & $20.471^{* *}$ & $29.780 * * *$ & $43.103^{* * *}$ \\
\hline & $(8.426)$ & $(9.462)$ & $(14.440)$ \\
\hline \multirow[t]{2}{*}{$D\left\{B u s_{c}=1\right\} * D\{j=19\}$} & $21.572^{* *}$ & $30.797 * * *$ & $45.546^{* * *}$ \\
\hline & $(8.587)$ & $(9.659)$ & $(14.796)$ \\
\hline \multirow[t]{2}{*}{$D\left\{B u s_{c}=1\right\} * D\{j=20\}$} & $25.494^{* * *}$ & $33.868^{* * *}$ & $47.997^{* * *}$ \\
\hline & $(8.888)$ & $(9.991)$ & $(15.221)$ \\
\hline \multirow[t]{2}{*}{$D\left\{B u s_{c}=1\right\} * D\{j=21\}$} & $26.897 * * *$ & $35.669^{* * *}$ & $49.741^{* * *}$ \\
\hline & $(9.097)$ & $(10.288)$ & $(15.754)$ \\
\hline \multirow[t]{2}{*}{$D\left\{B u s_{c}=1\right\} * D\{j=22\}$} & $26.913^{* * *}$ & $36.737 * * *$ & $54.245^{* * *}$ \\
\hline & $(9.335)$ & $(10.622)$ & $(16.663)$ \\
\hline$D\left\{B u s_{c}=1\right\} * D\{j=23\}$ & $26.449^{* * *}$ & $38.047^{* * *}$ & $57.151^{* * *}$ \\
\hline
\end{tabular}




$$
\begin{aligned}
& D\left\{B u s_{c}=1\right\} * D\{j=24\} \\
& D\left\{B u s_{c}=1\right\} * D\{j=25\} \\
& D\left\{B u s_{c}=1\right\} * D\{j=26\} \\
& D\left\{B u s_{c}=1\right\} * D\{j=27\} \\
& D\left\{B u s_{c}=1\right\} * D\{j=28\} \\
& D\left\{B u s_{c}=1\right\} * D\{j=29\} \\
& D\left\{B u s_{c}=1\right\} * D\{j=30\} \\
& D\left\{B u s_{c}=1\right\} * D\{j=31\} \\
& D\left\{B u s_{c}=1\right\} * D\{j=32\} \\
& D\left\{B u s_{c}=1\right\} * D\{j=33\} \\
& D\left\{B u s_{c}=1\right\} * D\{j=34\} \\
& D\left\{B u s_{c}=1\right\} * D\{j=35\}
\end{aligned}
$$
$28.436^{* * *}$ (10.441) $28.542^{* * *}$ $28.814^{* * *}$ (10.968) $30.493^{* * *}$ (11.504) $32.150^{* * *}$ $32.550^{* * *}$ (12.081) $34.325^{* * *}$ (12.320) $34.910^{* * *}$ (12.395) $38.713^{* * *}$ (12.628) $39.147^{* * *}$ (12.470) $39.530 * * *$ (12.832) $42.770^{* * *}$ (12.967)

7.11. Incidence $*$ Time FE

Observations

R-Squared
Yes Yes

(11.178)

(17.813) $41.065^{* * *}$ $59.008^{* * *}$ (12.088) (19.281) $42.129^{* * *}$ (12.163) $61.945^{* * *}$ (19.400) $42.533^{* * *}$ $61.547^{* * *}$ (12.618) (19.849) $46.335^{* * *}$ (13.411) 63.771*** (21.245) $48.419^{* * *}$ (14.174) 48.739*** $65.911^{* * *}$ (22.324) $62.856^{* * *}$ (14.072) (21.295) $48.398^{* * *}$ (14.302) $63.200 * * *$ (21.170) $48.749^{* * *}$ $65.445^{* * *}$ (14.384) (21.253) $66.896^{* * *}$ $51.916^{* * *}$ (21.801) (14.790) $68.025^{* * *}$ $52.194^{* * *}$ (14.577) (21.642) $50.721^{* * *}$ (14.902) $71.049^{* * *}$ (21.800) $52.873^{* * *}$ (14.923) $74.835^{* * *}$ (22.034) Yes Yes

$\begin{array}{lll}20945 & 20945 & 20945 \\ 0.706 & 0.711 & 0.711\end{array}$

Notes: The table reports event study estimates on the effect of the Querdenken demonstrations in Leipzig and Berlin on the seven days incidence rates in German counties. The treated group are counties with any Honk for Hope bus stops (column (1)), with bus stops in cities with fewer than 50,000 inhabitants (column (2)), or bus stops in cities with fewer than 20,000 inhabitants (columns (3)). The sample is restricted to rural counties and a 35-days window around November 18. All models control for county and day fixed effects, as well as interactions between days and the incidence rate on November 7 . Statistical significance: ${ }^{* * *} \mathrm{p}<0.01,{ }^{* *} \mathrm{p}<0.05,{ }^{*} \mathrm{p}<0.1$. 
(1)

\begin{tabular}{|c|c|c|c|c|}
\hline \multirow[t]{2}{*}{$D\left\{B u s_{c}=1\right\} * D\{j=-35\}$} & -5.890 & -2.528 & -6.839 & -3.524 \\
\hline & $(8.185)$ & $(8.403)$ & $(8.054)$ & $(8.383)$ \\
\hline \multirow{2}{*}{$D\left\{B u s_{c}=1\right\} * D\{j=-34\}$} & -7.240 & -3.865 & -8.197 & -4.863 \\
\hline & $(8.415)$ & $(8.688)$ & $(8.316)$ & $(8.700)$ \\
\hline \multirow{2}{*}{$D\left\{B u s_{c}=1\right\} * D\{j=-33\}$} & -7.413 & -4.114 & -8.319 & -4.984 \\
\hline & $(8.489)$ & $(8.781)$ & $(8.424)$ & $(8.805)$ \\
\hline \multirow[t]{2}{*}{$D\left\{B u s_{c}=1\right\} * D\{j=-32\}$} & -6.638 & -3.581 & -7.505 & -4.371 \\
\hline & $(8.789)$ & $(9.076)$ & $(8.701)$ & $(9.080)$ \\
\hline \multirow[t]{2}{*}{$D\left\{B u s_{c}=1\right\} * D\{j=-31\}$} & -6.079 & -3.197 & -6.990 & -4.128 \\
\hline & $(8.986)$ & $(9.287)$ & $(8.892)$ & $(9.297)$ \\
\hline \multirow[t]{2}{*}{$D\left\{B u s_{c}=1\right\} * D\{j=-30\}$} & -5.571 & -2.663 & -6.408 & -3.432 \\
\hline & $(8.994)$ & $(9.309)$ & $(8.904)$ & $(9.325)$ \\
\hline \multirow{2}{*}{$D\left\{B u s_{c}=1\right\} * D\{j=-29\}$} & -5.388 & -2.527 & -6.229 & -3.286 \\
\hline & $(9.307)$ & $(9.651)$ & $(9.220)$ & $(9.688)$ \\
\hline \multirow[t]{2}{*}{$D\left\{B u s_{c}=1\right\} * D\{j=-28\}$} & -3.654 & -0.625 & -4.335 & -1.284 \\
\hline & $(9.306)$ & $(9.685)$ & $(9.223)$ & $(9.724)$ \\
\hline \multirow[t]{2}{*}{$D\left\{B u s_{c}=1\right\} * D\{j=-27\}$} & -2.304 & 1.235 & -2.859 & 0.726 \\
\hline & $(9.388)$ & $(9.718)$ & $(9.279)$ & $(9.745)$ \\
\hline \multirow{2}{*}{$D\left\{B u s_{c}=1\right\} * D\{j=-26\}$} & -0.800 & 3.337 & -1.431 & 2.743 \\
\hline & $(9.281)$ & $(9.631)$ & $(9.157)$ & $(9.660)$ \\
\hline \multirow{2}{*}{$D\left\{B u s_{c}=1\right\} * D\{j=-25\}$} & 0.633 & 4.757 & -0.070 & 4.128 \\
\hline & $(9.165)$ & $(9.593)$ & $(9.089)$ & $(9.631)$ \\
\hline \multirow{2}{*}{$D\left\{B u s_{c}=1\right\} * D\{j=-24\}$} & -0.189 & 4.310 & -0.937 & 3.815 \\
\hline & $(9.475)$ & $(9.962)$ & $(9.426)$ & $(10.016)$ \\
\hline \multirow[t]{2}{*}{$D\left\{B u s_{c}=1\right\} * D\{j=-23\}$} & -1.358 & 3.830 & -1.791 & 3.559 \\
\hline & $(9.556)$ & $(9.968)$ & $(9.455)$ & $(10.002)$ \\
\hline \multirow[t]{2}{*}{$D\left\{B u s_{c}=1\right\} * D\{j=-22\}$} & 0.403 & 6.097 & 0.206 & 6.036 \\
\hline & $(9.616)$ & $(10.186)$ & $(9.571)$ & $(10.250)$ \\
\hline \multirow[t]{2}{*}{$D\left\{B u s_{c}=1\right\} * D\{j=-21\}$} & -1.508 & 4.175 & -1.973 & 3.820 \\
\hline & $(9.535)$ & $(10.090)$ & $(9.489)$ & $(10.171)$ \\
\hline \multirow[t]{2}{*}{$D\left\{B u s_{c}=1\right\} * D\{j=-20\}$} & -0.538 & 5.235 & -1.505 & 4.263 \\
\hline & $(9.451)$ & $(10.053)$ & $(9.477)$ & $(10.189)$ \\
\hline \multirow[t]{2}{*}{$D\left\{B u s_{c}=1\right\} * D\{j=-19\}$} & -2.458 & 3.166 & -3.485 & 1.951 \\
\hline & $(9.472)$ & $(10.023)$ & $(9.505)$ & $(10.176)$ \\
\hline \multirow[t]{2}{*}{$D\left\{B u s_{c}=1\right\} * D\{j=-18\}$} & -4.878 & 0.803 & -5.926 & -0.489 \\
\hline & $(9.146)$ & $(9.672)$ & $(9.124)$ & $(9.798)$ \\
\hline$D\left\{B u s_{c}=1\right\} * D\{j=-17\}$ & -7.064 & -1.386 & -7.854 & -2.540 \\
\hline
\end{tabular}




\begin{tabular}{|c|c|c|c|c|}
\hline & $(9.236)$ & $(9.723)$ & $(9.180)$ & $(9.822)$ \\
\hline \multirow[t]{2}{*}{$D\left\{B u s_{c}=1\right\} * D\{j=-16\}$} & -5.248 & 0.070 & -6.437 & -1.408 \\
\hline & $(8.985)$ & $(9.587)$ & $(9.021)$ & $(9.727)$ \\
\hline \multirow{2}{*}{$D\left\{B u s_{c}=1\right\} * D\{j=-15\}$} & -6.742 & -1.705 & -8.391 & -3.687 \\
\hline & $(8.465)$ & $(8.939)$ & $(8.406)$ & $(8.989)$ \\
\hline \multirow{2}{*}{$D\left\{B u s_{c}=1\right\} * D\{j=-14\}$} & -3.261 & 0.397 & -4.878 & -1.429 \\
\hline & $(8.271)$ & $(8.677)$ & $(8.231)$ & $(8.739)$ \\
\hline \multirow[t]{2}{*}{$D\left\{B u s_{c}=1\right\} * D\{j=-13\}$} & -3.868 & -0.788 & -5.420 & -2.691 \\
\hline & $(7.350)$ & $(7.648)$ & $(7.265)$ & $(7.663)$ \\
\hline \multirow[t]{2}{*}{$D\left\{B u s_{c}=1\right\} * D\{j=-12\}$} & -2.201 & -0.423 & -3.333 & -1.736 \\
\hline & $(7.213)$ & $(7.513)$ & $(7.202)$ & $(7.585)$ \\
\hline \multirow[t]{2}{*}{$D\left\{B u s_{c}=1\right\} * D\{j=-11\}$} & -2.315 & -1.707 & -3.281 & -2.699 \\
\hline & $(7.063)$ & $(7.340)$ & $(7.040)$ & $(7.384)$ \\
\hline \multirow{2}{*}{$D\left\{B u s_{c}=1\right\} * D\{j=-10\}$} & -1.638 & -1.708 & -2.474 & -2.649 \\
\hline & $(6.719)$ & $(6.949)$ & $(6.692)$ & $(7.002)$ \\
\hline \multirow{2}{*}{$D\left\{B u s_{c}=1\right\} * D\{j=-9\}$} & -3.227 & -2.985 & -3.959 & -3.920 \\
\hline & $(6.738)$ & $(6.853)$ & $(6.729)$ & $(6.969)$ \\
\hline \multirow{2}{*}{$D\left\{B u s_{c}=1\right\} * D\{j=-8\}$} & 0.724 & 0.364 & 0.461 & 0.245 \\
\hline & $(5.853)$ & $(6.035)$ & $(5.892)$ & $(6.161)$ \\
\hline \multirow[t]{2}{*}{$D\left\{B u s_{c}=1\right\} * D\{j=-7\}$} & -1.006 & -0.551 & -0.778 & -0.189 \\
\hline & $(5.007)$ & $(5.276)$ & $(5.014)$ & $(5.345)$ \\
\hline \multirow[t]{2}{*}{$D\left\{B u s_{c}=1\right\} * D\{j=-6\}$} & -1.732 & -1.611 & -0.956 & -0.531 \\
\hline & $(4.602)$ & $(4.809)$ & $(4.451)$ & $(4.695)$ \\
\hline \multirow{2}{*}{$D\left\{B u s_{c}=1\right\} * D\{j=-5\}$} & -1.558 & -0.981 & -0.610 & 0.354 \\
\hline & $(3.614)$ & $(3.759)$ & $(3.393)$ & $(3.581)$ \\
\hline \multirow[t]{2}{*}{$D\left\{B u s_{c}=1\right\} * D\{j=-4\}$} & 0.898 & 1.956 & 1.894 & 3.068 \\
\hline & $(3.608)$ & $(3.684)$ & $(3.298)$ & $(3.409)$ \\
\hline \multirow[t]{2}{*}{$D\left\{B u s_{c}=1\right\} * D\{j=-3\}$} & 0.059 & 1.060 & 0.914 & 1.992 \\
\hline & $(3.522)$ & $(3.585)$ & $(3.251)$ & $(3.325)$ \\
\hline \multirow[t]{2}{*}{$D\left\{B u s_{c}=1\right\} * D\{j=-2\}$} & 0.841 & 1.624 & 1.234 & 2.315 \\
\hline & $(2.044)$ & $(2.102)$ & $(1.948)$ & $(2.011)$ \\
\hline \multirow[t]{2}{*}{$D\left\{B u s_{c}=1\right\} * D\{j=0\}$} & 2.200 & 1.569 & 2.471 & 1.923 \\
\hline & $(2.600)$ & $(2.618)$ & $(2.509)$ & $(2.528)$ \\
\hline \multirow[t]{2}{*}{$D\left\{B u s_{c}=1\right\} * D\{j=1\}$} & 4.665 & 3.938 & 4.661 & 3.988 \\
\hline & $(3.596)$ & $(3.707)$ & $(3.575)$ & $(3.686)$ \\
\hline \multirow[t]{2}{*}{$D\left\{B u s_{c}=1\right\} * D\{j=2\}$} & 5.647 & 4.136 & 5.204 & 3.644 \\
\hline & $(4.328)$ & $(4.509)$ & $(4.369)$ & $(4.583)$ \\
\hline \multirow[t]{2}{*}{$D\left\{B u s_{c}=1\right\} * D\{j=3\}$} & 7.811 & 5.696 & 7.215 & 5.250 \\
\hline & $(6.189)$ & $(6.277)$ & $(6.209)$ & $(6.374)$ \\
\hline$D\left\{B u s_{c}=1\right\} * D\{j=4\}$ & $10.922^{*}$ & 8.994 & 10.280 & 8.488 \\
\hline
\end{tabular}




\begin{tabular}{|c|c|c|c|c|}
\hline & $(6.547)$ & $(6.680)$ & $(6.528)$ & $(6.761)$ \\
\hline \multirow[t]{2}{*}{$D\left\{B u s_{c}=1\right\} * D\{j=5\}$} & $15.909^{*}$ & 12.841 & $15.197^{*}$ & 12.079 \\
\hline & $(8.295)$ & $(8.191)$ & $(8.271)$ & $(8.388)$ \\
\hline \multirow[t]{2}{*}{$D\left\{B u s_{c}=1\right\} * D\{j=6\}$} & $19.953^{* *}$ & $16.837^{*}$ & $19.400^{* *}$ & $16.442^{*}$ \\
\hline & $(9.654)$ & $(9.517)$ & $(9.634)$ & $(9.769)$ \\
\hline \multirow[t]{2}{*}{$D\left\{B u s_{c}=1\right\} * D\{j=7\}$} & $22.275^{*}$ & $19.096^{*}$ & $21.127^{*}$ & 17.960 \\
\hline & $(11.887)$ & $(11.536)$ & $(11.809)$ & $(11.835)$ \\
\hline \multirow[t]{2}{*}{$D\left\{B u s_{c}=1\right\} * D\{j=8\}$} & $26.188^{* *}$ & $22.189^{*}$ & $24.886^{* *}$ & $20.929^{*}$ \\
\hline & $(12.339)$ & $(11.830)$ & $(12.173)$ & $(12.156)$ \\
\hline \multirow[t]{2}{*}{$D\left\{B u s_{c}=1\right\} * D\{j=9\}$} & $30.725^{* *}$ & $26.719^{* *}$ & $29.453^{* *}$ & $25.307^{* *}$ \\
\hline & $(11.989)$ & $(11.639)$ & $(11.770)$ & $(11.823)$ \\
\hline \multirow[t]{2}{*}{$D\left\{B u s_{c}=1\right\} * D\{j=10\}$} & $31.838^{* * *}$ & $28.229^{* *}$ & $30.409^{* *}$ & $26.530^{* *}$ \\
\hline & $(12.080)$ & $(11.798)$ & $(11.826)$ & $(11.948)$ \\
\hline \multirow{2}{*}{$D\left\{B u s_{c}=1\right\} * D\{j=11\}$} & $32.903^{* * *}$ & $29.213^{* *}$ & $31.311^{* * *}$ & $27.636^{* *}$ \\
\hline & $(12.160)$ & $(11.882)$ & $(11.877)$ & $(12.027)$ \\
\hline \multirow{2}{*}{$D\left\{B u s_{c}=1\right\} * D\{j=12\}$} & $33.243^{* * *}$ & $29.371^{* * *}$ & $31.676^{* * *}$ & $27.765^{* *}$ \\
\hline & $(11.266)$ & $(11.159)$ & $(10.907)$ & $(11.164)$ \\
\hline \multirow{2}{*}{$D\left\{B u s_{c}=1\right\} * D\{j=13\}$} & $33.738^{* * *}$ & $30.460 * * *$ & $31.785^{* * *}$ & $28.411^{* *}$ \\
\hline & $(11.126)$ & (11.195) & $(10.637)$ & $(11.000)$ \\
\hline \multirow{2}{*}{$D\left\{B u s_{c}=1\right\} * D\{j=14\}$} & $37.326^{* * *}$ & $33.861^{* * *}$ & $35.020 * * *$ & $31.344^{* * *}$ \\
\hline & (11.392) & $(11.679)$ & $(10.739)$ & $(11.276)$ \\
\hline \multirow[t]{2}{*}{$D\left\{B u s_{c}=1\right\} * D\{j=15\}$} & $41.748^{* * *}$ & $38.858^{* * *}$ & $38.782^{* * *}$ & $35.769^{* * *}$ \\
\hline & $(13.434)$ & $(13.762)$ & $(12.688)$ & $(13.226)$ \\
\hline \multirow{2}{*}{$D\left\{B u s_{c}=1\right\} * D\{j=16\}$} & $43.386^{* * *}$ & $40.994^{* * *}$ & $39.935^{* * *}$ & $37.554^{* * *}$ \\
\hline & $(14.281)$ & $(14.652)$ & $(13.496)$ & $(14.115)$ \\
\hline \multirow{2}{*}{$D\left\{B u s_{c}=1\right\} * D\{j=17\}$} & $43.106^{* * *}$ & $40.838^{* * *}$ & $39.813^{* * *}$ & $37.555^{* * *}$ \\
\hline & (14.192) & $(14.681)$ & $(13.478)$ & $(14.175)$ \\
\hline \multirow[t]{2}{*}{$D\left\{B u s_{c}=1\right\} * D\{j=18\}$} & $42.729 * * *$ & $40.565^{* * *}$ & $39.647^{* * *}$ & $37.460^{* *}$ \\
\hline & $(14.394)$ & (14.908) & $(13.816)$ & (14.537) \\
\hline \multirow{2}{*}{$D\left\{B u s_{c}=1\right\} * D\{j=19\}$} & $45.150 * * *$ & $43.378^{* * *}$ & $41.606^{* * *}$ & $39.800^{* * *}$ \\
\hline & $(14.544)$ & $(15.019)$ & $(13.889)$ & $(14.572)$ \\
\hline \multirow[t]{2}{*}{$D\left\{B u s_{c}=1\right\} * D\{j=20\}$} & $47.874^{* * *}$ & $45.989 * * *$ & $44.079 * * *$ & $42.025^{* * *}$ \\
\hline & (15.193) & $(15.673)$ & $(14.598)$ & $(15.325)$ \\
\hline \multirow[t]{2}{*}{$D\left\{B u s_{c}=1\right\} * D\{j=21\}$} & $48.647^{* * *}$ & $46.490^{* * *}$ & $45.021^{* * *}$ & $42.416^{* * *}$ \\
\hline & $(15.914)$ & $(16.425)$ & $(15.338)$ & $(16.122)$ \\
\hline \multirow[t]{2}{*}{$D\left\{B u s_{c}=1\right\} * D\{j=22\}$} & $52.904^{* * *}$ & $51.451^{* * *}$ & $48.893^{* * *}$ & $47.017^{* * *}$ \\
\hline & $(16.621)$ & $(17.115)$ & $(15.928)$ & $(16.700)$ \\
\hline \multirow[t]{2}{*}{$D\left\{B u s_{c}=1\right\} * D\{j=23\}$} & $55.845^{* * *}$ & $53.469^{* * *}$ & $51.493^{* * *}$ & $48.537^{* * *}$ \\
\hline & $(17.691)$ & $(18.054)$ & $(16.818)$ & $(17.472)$ \\
\hline$D\left\{B u s_{c}=1\right\} * D\{j=24\}$ & $57.128^{* * *}$ & $54.890 * * *$ & $51.775^{* * *}$ & $48.956^{* * *}$ \\
\hline
\end{tabular}




\begin{tabular}{|c|c|c|c|c|}
\hline & $(19.072)$ & $(19.418)$ & $(18.018)$ & $(18.707)$ \\
\hline$D\left\{B u s_{c}=1\right\} * D\{j=25\}$ & $\begin{array}{c}59.699^{* * *} \\
(19.338)\end{array}$ & $\begin{array}{c}57.193^{* * *} \\
(19.715)\end{array}$ & $\begin{array}{c}54.301^{* * *} \\
(18.154)\end{array}$ & $\begin{array}{c}51.166^{* * *} \\
(18.866)\end{array}$ \\
\hline$D\left\{B u s_{c}=1\right\} * D\{j=26\}$ & $\begin{array}{c}58.533^{* * *} \\
(19.966)\end{array}$ & $\begin{array}{c}55.958^{* * *} \\
(20.442)\end{array}$ & $\begin{array}{c}52.906^{* * *} \\
(18.712)\end{array}$ & $\begin{array}{c}49.694^{* *} \\
(19.509)\end{array}$ \\
\hline$D\left\{B u s_{c}=1\right\} * D\{j=27\}$ & $\begin{array}{c}59.914^{* * *} \\
(21.170)\end{array}$ & $\begin{array}{c}57.249^{* * *} \\
(21.610)\end{array}$ & $\begin{array}{c}53.876^{* * *} \\
(19.810)\end{array}$ & $\begin{array}{c}50.149^{* *} \\
(20.478)\end{array}$ \\
\hline$D\left\{B u s_{c}=1\right\} * D\{j=28\}$ & $\begin{array}{c}61.976^{* * *} \\
(22.112)\end{array}$ & $\begin{array}{c}58.664^{* * *} \\
(22.420)\end{array}$ & $\begin{array}{c}54.880^{* * *} \\
(20.390)\end{array}$ & $\begin{array}{c}50.652^{* *} \\
(20.981)\end{array}$ \\
\hline$D\left\{B u s_{c}=1\right\} * D\{j=29\}$ & $\begin{array}{c}59.369^{* * *} \\
(21.493)\end{array}$ & $\begin{array}{c}54.734^{* *} \\
(21.877)\end{array}$ & $\begin{array}{c}52.790 * * * \\
(20.031)\end{array}$ & $\begin{array}{c}46.806^{* *} \\
(20.668)\end{array}$ \\
\hline$D\left\{B u s_{c}=1\right\} * D\{j=30\}$ & $\begin{array}{c}58.749^{* * *} \\
(21.541)\end{array}$ & $\begin{array}{c}54.948^{* *} \\
(21.951)\end{array}$ & $\begin{array}{c}51.942^{* *} \\
(20.158)\end{array}$ & $\begin{array}{c}46.474^{* *} \\
(20.797)\end{array}$ \\
\hline$D\left\{B u s_{c}=1\right\} * D\{j=31\}$ & $\begin{array}{c}61.515^{* * *} \\
(21.559)\end{array}$ & $\begin{array}{c}56.987^{* * *} \\
(21.939)\end{array}$ & $\begin{array}{c}55.057^{* * *} \\
(20.139)\end{array}$ & $\begin{array}{c}48.720^{* *} \\
(20.760)\end{array}$ \\
\hline$D\left\{B u s_{c}=1\right\} * D\{j=32\}$ & $\begin{array}{c}63.299^{* * *} \\
(21.964)\end{array}$ & $\begin{array}{c}58.609^{* * *} \\
(22.439)\end{array}$ & $\begin{array}{c}56.519^{* * *} \\
(20.538)\end{array}$ & $\begin{array}{l}49.698^{* *} \\
(21.251)\end{array}$ \\
\hline$D\left\{B u s_{c}=1\right\} * D\{j=33\}$ & $\begin{array}{c}65.287^{* * *} \\
(22.034)\end{array}$ & $\begin{array}{c}61.449 * * * \\
(22.432)\end{array}$ & $\begin{array}{c}58.284^{* * *} \\
(20.595)\end{array}$ & $\begin{array}{c}51.764^{* *} \\
(21.199)\end{array}$ \\
\hline$D\left\{B u s_{c}=1\right\} * D\{j=34\}$ & $\begin{array}{c}68.657^{* * *} \\
(22.263)\end{array}$ & $\begin{array}{c}64.977^{* * *} \\
(22.777)\end{array}$ & $\begin{array}{c}61.172^{* * *} \\
(20.899)\end{array}$ & $\begin{array}{c}55.038^{* *} \\
(21.771)\end{array}$ \\
\hline$D\left\{B u s_{c}=1\right\} * D\{j=35\}$ & $\begin{array}{c}72.871^{* * *} \\
(22.346)\end{array}$ & $\begin{array}{c}69.886^{* * *} \\
(22.856)\end{array}$ & $\begin{array}{c}65.354^{* * *} \\
(21.194)\end{array}$ & $\begin{array}{c}59.996^{* * *} \\
(21.957)\end{array}$ \\
\hline County \& Time FE & Yes & Yes & Yes & Yes \\
\hline 7.11. Incidence $*$ Time FE & Yes & Yes & Yes & Yes \\
\hline FlixBus Stop $*$ Time FE & Yes & Yes & Yes & Yes \\
\hline Covid-Risk Controls $*$ Time FE & No & Yes & No & Yes \\
\hline Economic Controls $*$ Time FE & No & No & Yes & Yes \\
\hline Observations & 20945 & 20945 & 20945 & 20945 \\
\hline R-Squared & 0.713 & 0.719 & 0.722 & 0.729 \\
\hline
\end{tabular}

Notes: The table reports event study estimates on the effect of the Querdenken demonstrations in Leipzig and Berlin on the seven days incidence rates in German counties. The treated group are counties with Honk for Hope bus stops in cities with fewer than 20,000 inhabitants. The sample is restricted to rural counties and a 35-days window around November 18 . All models control for county and day fixed effects, as well as interactions between days and the incidence rate on November 7. Column (1) adds interactions between FlixBus stops and time fixed effects. Column (2) adds interactions between days and a county's population densisty, nursing home capacities per 10,000 residents, and rate of asylum seekers. Column (3) adds interactions between the days and the unemployment rate and GDP per capita. Column (4) controls for all control variables. Standard errors in parentheses are clustered by county. Statistical significance: ${ }^{* * *} \mathrm{p}<0.01,{ }^{* *} \mathrm{p}<0.05,{ }^{*} \mathrm{p}<0.1$. 
Table A4: Event Study Results: Alternative Outcomes

Norm.
Incidence

(1)
Log Incidence

(2)
Seven-Days-

Fatality

(3)

\begin{tabular}{|c|c|c|c|}
\hline$D\left\{B u s_{c}=1\right\} * D\{j=-35\}$ & $\begin{array}{l}-0.160 \\
(0.124)\end{array}$ & $\begin{array}{l}-0.113 \\
(0.205)\end{array}$ & $\begin{array}{c}0.134 \\
(0.446)\end{array}$ \\
\hline \multirow[t]{2}{*}{$D\left\{B u s_{c}=1\right\} * D\{j=-34\}$} & -0.137 & -0.149 & 0.094 \\
\hline & $(0.126)$ & $(0.196)$ & $(0.445)$ \\
\hline \multirow[t]{2}{*}{$D\left\{B u s_{c}=1\right\} * D\{j=-33\}$} & -0.106 & -0.140 & 0.085 \\
\hline & $(0.117)$ & $(0.195)$ & $(0.443)$ \\
\hline \multirow[t]{2}{*}{$D\left\{B u s_{c}=1\right\} * D\{j=-32\}$} & -0.063 & -0.094 & 0.037 \\
\hline & $(0.114)$ & $(0.200)$ & $(0.451)$ \\
\hline \multirow[t]{2}{*}{$D\left\{B u s_{c}=1\right\} * D\{j=-31\}$} & -0.043 & -0.060 & -0.022 \\
\hline & $(0.119)$ & $(0.197)$ & $(0.455)$ \\
\hline \multirow[t]{2}{*}{$D\left\{B u s_{c}=1\right\} * D\{j=-30\}$} & -0.007 & -0.033 & 0.105 \\
\hline & $(0.111)$ & $(0.195)$ & $(0.462)$ \\
\hline \multirow[t]{2}{*}{$D\left\{B u s_{c}=1\right\} * D\{j=-29\}$} & 0.008 & -0.019 & 0.044 \\
\hline & $(0.112)$ & $(0.190)$ & $(0.466)$ \\
\hline \multirow{2}{*}{$D\left\{B u s_{c}=1\right\} * D\{j=-28\}$} & 0.072 & 0.031 & 0.173 \\
\hline & $(0.101)$ & $(0.182)$ & $(0.474)$ \\
\hline \multirow[t]{2}{*}{$D\left\{B u s_{c}=1\right\} * D\{j=-27\}$} & 0.093 & 0.070 & 0.182 \\
\hline & $(0.093)$ & $(0.183)$ & $(0.491)$ \\
\hline \multirow[t]{2}{*}{$D\left\{B u s_{c}=1\right\} * D\{j=-26\}$} & 0.103 & 0.094 & 0.332 \\
\hline & $(0.085)$ & $(0.174)$ & $(0.514)$ \\
\hline \multirow{2}{*}{$D\left\{B u s_{c}=1\right\} * D\{j=-25\}$} & $0.128^{*}$ & 0.126 & 0.407 \\
\hline & $(0.076)$ & $(0.165)$ & $(0.512)$ \\
\hline \multirow{2}{*}{$D\left\{B u s_{c}=1\right\} * D\{j=-24\}$} & 0.124 & 0.107 & 0.430 \\
\hline & $(0.080)$ & $(0.169)$ & $(0.500)$ \\
\hline \multirow[t]{2}{*}{$D\left\{B u s_{c}=1\right\} * D\{j=-23\}$} & 0.107 & 0.071 & 0.356 \\
\hline & $(0.078)$ & $(0.167)$ & $(0.506)$ \\
\hline \multirow[t]{2}{*}{$D\left\{B u s_{c}=1\right\} * D\{j=-22\}$} & 0.128 & 0.114 & 0.460 \\
\hline & $(0.079)$ & $(0.166)$ & $(0.482)$ \\
\hline \multirow[t]{2}{*}{$D\left\{B u s_{c}=1\right\} * D\{j=-21\}$} & 0.092 & 0.077 & 0.450 \\
\hline & $(0.076)$ & $(0.164)$ & $(0.507)$ \\
\hline \multirow[t]{2}{*}{$D\left\{B u s_{c}=1\right\} * D\{j=-20\}$} & 0.092 & 0.089 & 0.510 \\
\hline & $(0.073)$ & $(0.159)$ & $(0.498)$ \\
\hline \multirow[t]{2}{*}{$D\left\{B u s_{c}=1\right\} * D\{j=-19\}$} & 0.084 & 0.066 & 0.557 \\
\hline & $(0.074)$ & $(0.158)$ & $(0.471)$ \\
\hline \multirow[t]{2}{*}{$D\left\{B u s_{c}=1\right\} * D\{j=-18\}$} & 0.065 & 0.027 & 0.651 \\
\hline & $(0.074)$ & $(0.151)$ & $(0.455)$ \\
\hline
\end{tabular}




\begin{tabular}{|c|c|c|c|}
\hline$D\left\{B u s_{c}=1\right\} * D\{j=-17\}$ & $\begin{array}{c}0.036 \\
(0.075)\end{array}$ & $\begin{array}{l}-0.010 \\
(0.152)\end{array}$ & $\begin{array}{c}0.673 \\
(0.482)\end{array}$ \\
\hline$D\left\{B u s_{c}=1\right\} * D\{j=-16\}$ & $\begin{array}{c}0.033 \\
(0.075)\end{array}$ & $\begin{array}{c}0.021 \\
(0.149)\end{array}$ & $\begin{array}{c}0.687 \\
(0.498)\end{array}$ \\
\hline$D\left\{B u s_{c}=1\right\} * D\{j=-15\}$ & $\begin{array}{c}0.019 \\
(0.069)\end{array}$ & $\begin{array}{l}-0.008 \\
(0.136)\end{array}$ & $\begin{array}{c}0.556 \\
(0.521)\end{array}$ \\
\hline$D\left\{B u s_{c}=1\right\} * D\{j=-14\}$ & $\begin{array}{c}0.046 \\
(0.067)\end{array}$ & $\begin{array}{c}0.051 \\
(0.135)\end{array}$ & $\begin{array}{c}0.485 \\
(0.524)\end{array}$ \\
\hline$D\left\{B u s_{c}=1\right\} * D\{j=-13\}$ & $\begin{array}{c}0.037 \\
(0.059)\end{array}$ & $\begin{array}{c}0.032 \\
(0.119)\end{array}$ & $\begin{array}{c}0.392 \\
(0.483)\end{array}$ \\
\hline$D\left\{B u s_{c}=1\right\} * D\{j=-12\}$ & $\begin{array}{c}0.036 \\
(0.060)\end{array}$ & $\begin{array}{c}0.050 \\
(0.115)\end{array}$ & $\begin{array}{c}0.230 \\
(0.475)\end{array}$ \\
\hline$D\left\{B u s_{c}=1\right\} * D\{j=-11\}$ & $\begin{array}{c}0.027 \\
(0.057)\end{array}$ & $\begin{array}{c}0.027 \\
(0.111)\end{array}$ & $\begin{array}{c}0.016 \\
(0.463)\end{array}$ \\
\hline$D\left\{B u s_{c}=1\right\} * D\{j=-10\}$ & $\begin{array}{c}0.029 \\
(0.053)\end{array}$ & $\begin{array}{c}0.025 \\
(0.105)\end{array}$ & $\begin{array}{c}0.052 \\
(0.454)\end{array}$ \\
\hline$D\left\{B u s_{c}=1\right\} * D\{j=-9\}$ & $\begin{array}{c}0.019 \\
(0.051)\end{array}$ & $\begin{array}{l}-0.020 \\
(0.104)\end{array}$ & $\begin{array}{c}0.000 \\
(0.430)\end{array}$ \\
\hline$D\left\{B u s_{c}=1\right\} * D\{j=-8\}$ & $\begin{array}{c}0.041 \\
(0.043)\end{array}$ & $\begin{array}{c}0.031 \\
(0.092)\end{array}$ & $\begin{array}{c}0.303 \\
(0.477)\end{array}$ \\
\hline$D\left\{B u s_{c}=1\right\} * D\{j=-7\}$ & $\begin{array}{c}0.002 \\
(0.038)\end{array}$ & $\begin{array}{l}-0.015 \\
(0.076)\end{array}$ & $\begin{array}{c}0.358 \\
(0.409)\end{array}$ \\
\hline$D\left\{B u s_{c}=1\right\} * D\{j=-6\}$ & $\begin{array}{c}0.005 \\
(0.037)\end{array}$ & $\begin{array}{l}-0.028 \\
(0.070)\end{array}$ & $\begin{array}{c}0.319 \\
(0.375)\end{array}$ \\
\hline$D\left\{B u s_{c}=1\right\} * D\{j=-5\}$ & $\begin{array}{l}-0.002 \\
(0.028)\end{array}$ & $\begin{array}{l}-0.030 \\
(0.055)\end{array}$ & $\begin{array}{c}0.302 \\
(0.361)\end{array}$ \\
\hline$D\left\{B u s_{c}=1\right\} * D\{j=-4\}$ & $\begin{array}{c}0.017 \\
(0.027)\end{array}$ & $\begin{array}{c}0.020 \\
(0.054)\end{array}$ & $\begin{array}{c}0.251 \\
(0.305)\end{array}$ \\
\hline$D\left\{B u s_{c}=1\right\} * D\{j=-3\}$ & $\begin{array}{c}0.010 \\
(0.025)\end{array}$ & $\begin{array}{c}0.006 \\
(0.054)\end{array}$ & $\begin{array}{l}-0.033 \\
(0.282)\end{array}$ \\
\hline$D\left\{B u s_{c}=1\right\} * D\{j=-2\}$ & $\begin{array}{c}0.019 \\
(0.014)\end{array}$ & $\begin{array}{c}0.024 \\
(0.031)\end{array}$ & $\begin{array}{c}0.114 \\
(0.220)\end{array}$ \\
\hline$D\left\{B u s_{c}=1\right\} * D\{j=0\}$ & $\begin{array}{c}0.033^{*} \\
(0.018)\end{array}$ & $\begin{array}{c}0.047 \\
(0.044)\end{array}$ & $\begin{array}{c}0.254 \\
(0.322)\end{array}$ \\
\hline$D\left\{B u s_{c}=1\right\} * D\{j=1\}$ & $\begin{array}{c}0.044^{*} \\
(0.024)\end{array}$ & $\begin{array}{c}0.082 \\
(0.058)\end{array}$ & $\begin{array}{c}0.569 \\
(0.494)\end{array}$ \\
\hline$D\left\{B u s_{c}=1\right\} * D\{j=2\}$ & $\begin{array}{c}0.044 \\
(0.029)\end{array}$ & $\begin{array}{c}0.099 \\
(0.068)\end{array}$ & $\begin{array}{c}0.490 \\
(0.519)\end{array}$ \\
\hline$D\left\{B u s_{c}=1\right\} * D\{j=3\}$ & $\begin{array}{c}0.047 \\
(0.038)\end{array}$ & $\begin{array}{c}0.122 \\
(0.091)\end{array}$ & $\begin{array}{c}0.834 \\
(0.544)\end{array}$ \\
\hline
\end{tabular}




\begin{tabular}{|c|c|c|c|}
\hline$D\left\{B u s_{c}=1\right\} * D\{j=4\}$ & $\begin{array}{c}0.067 \\
(0.041)\end{array}$ & $\begin{array}{l}0.164^{*} \\
(0.098)\end{array}$ & $\begin{array}{c}0.977^{*} \\
(0.533)\end{array}$ \\
\hline \multirow[t]{2}{*}{$D\left\{B u s_{c}=1\right\} * D\{j=5\}$} & $0.084^{*}$ & $0.222^{*}$ & 0.736 \\
\hline & $(0.046)$ & $(0.118)$ & $(0.551)$ \\
\hline \multirow[t]{2}{*}{$D\left\{B u s_{c}=1\right\} * D\{j=6\}$} & $0.101^{*}$ & $0.275^{* *}$ & 0.595 \\
\hline & $(0.058)$ & $(0.138)$ & $(0.597)$ \\
\hline \multirow{2}{*}{$D\left\{B u s_{c}=1\right\} * D\{j=7\}$} & 0.083 & $0.287^{*}$ & 0.349 \\
\hline & $(0.067)$ & $(0.160)$ & $(0.650)$ \\
\hline \multirow[t]{2}{*}{$D\left\{B u s_{c}=1\right\} * D\{j=8\}$} & 0.106 & $0.338^{* *}$ & 0.311 \\
\hline & $(0.065)$ & $(0.158)$ & $(0.610)$ \\
\hline \multirow[t]{2}{*}{$D\left\{B u s_{c}=1\right\} * D\{j=9\}$} & $0.145^{* *}$ & $0.385^{* *}$ & 0.794 \\
\hline & $(0.067)$ & $(0.150)$ & $(0.643)$ \\
\hline \multirow{2}{*}{$D\left\{B u s_{c}=1\right\} * D\{j=10\}$} & $0.143^{* *}$ & $0.398^{* * *}$ & 1.015 \\
\hline & $(0.069)$ & $(0.151)$ & $(0.664)$ \\
\hline \multirow[t]{2}{*}{$D\left\{B u s_{c}=1\right\} * D\{j=11\}$} & $0.149^{* *}$ & $0.412^{* * *}$ & 1.194 \\
\hline & $(0.070)$ & $(0.149)$ & $(0.724)$ \\
\hline \multirow{2}{*}{$D\left\{B u s_{c}=1\right\} * D\{j=12\}$} & $0.165^{* *}$ & $0.431^{* * *}$ & $1.461^{*}$ \\
\hline & $(0.067)$ & $(0.140)$ & $(0.767)$ \\
\hline \multirow[t]{2}{*}{$D\left\{B u s_{c}=1\right\} * D\{j=13\}$} & $0.181^{* * *}$ & $0.451^{* * *}$ & $1.489^{* *}$ \\
\hline & $(0.066)$ & $(0.138)$ & $(0.727)$ \\
\hline \multirow[t]{2}{*}{$D\left\{B u s_{c}=1\right\} * D\{j=14\}$} & $0.221^{* * *}$ & $0.480^{* * *}$ & $1.354^{*}$ \\
\hline & $(0.067)$ & $(0.137)$ & $(0.735)$ \\
\hline \multirow[t]{2}{*}{$D\left\{B u s_{c}=1\right\} * D\{j=15\}$} & $0.234^{* * *}$ & $0.509^{* * *}$ & 1.290 \\
\hline & $(0.076)$ & $(0.154)$ & $(0.806)$ \\
\hline \multirow{2}{*}{$D\left\{B u s_{c}=1\right\} * D\{j=16\}$} & $0.237^{* * *}$ & $0.519 * * *$ & 0.975 \\
\hline & $(0.080)$ & $(0.160)$ & $(0.780)$ \\
\hline \multirow{2}{*}{$D\left\{B u s_{c}=1\right\} * D\{j=17\}$} & $0.256^{* * *}$ & $0.510^{* * *}$ & 0.613 \\
\hline & $(0.079)$ & $(0.157)$ & $(0.688)$ \\
\hline \multirow[t]{2}{*}{$D\left\{B u s_{c}=1\right\} * D\{j=18\}$} & $0.252^{* * *}$ & $0.492^{* * *}$ & 0.391 \\
\hline & $(0.079)$ & $(0.157)$ & $(0.672)$ \\
\hline \multirow[t]{2}{*}{$D\left\{B u s_{c}=1\right\} * D\{j=19\}$} & $0.257^{* * *}$ & $0.515^{* * *}$ & 0.394 \\
\hline & $(0.079)$ & $(0.159)$ & $(0.688)$ \\
\hline \multirow[t]{2}{*}{$D\left\{B u s_{c}=1\right\} * D\{j=20\}$} & $0.267 * * *$ & $0.530 * * *$ & 0.897 \\
\hline & $(0.078)$ & $(0.159)$ & $(0.688)$ \\
\hline \multirow[t]{2}{*}{$D\left\{B u s_{c}=1\right\} * D\{j=21\}$} & $0.273^{* * *}$ & $0.537^{* * *}$ & 0.904 \\
\hline & $(0.075)$ & $(0.160)$ & $(0.731)$ \\
\hline \multirow[t]{2}{*}{$D\left\{B u s_{c}=1\right\} * D\{j=22\}$} & $0.281^{* * *}$ & $0.575^{* * *}$ & 0.927 \\
\hline & $(0.075)$ & $(0.167)$ & $(0.720)$ \\
\hline \multirow[t]{2}{*}{$D\left\{B u s_{c}=1\right\} * D\{j=23\}$} & $0.273^{* * *}$ & $0.587^{* * *}$ & 1.090 \\
\hline & $(0.078)$ & $(0.174)$ & $(0.763)$ \\
\hline
\end{tabular}




$$
\begin{aligned}
& D\left\{B u s_{c}=1\right\} * D\{j=24\} \\
& D\left\{B u s_{c}=1\right\} * D\{j=25\} \\
& D\left\{B u s_{c}=1\right\} * D\{j=26\} \\
& D\left\{B u s_{c}=1\right\} * D\{j=27\} \\
& D\left\{B u s_{c}=1\right\} * D\{j=28\} \\
& D\left\{B u s_{c}=1\right\} * D\{j=29\} \\
& D\left\{B u s_{c}=1\right\} * D\{j=30\} \\
& D\left\{B u s_{c}=1\right\} * D\{j=31\} \\
& D\left\{B u s_{c}=1\right\} * D\{j=32\} \\
& D\left\{B u s_{c}=1\right\} * D\{j=33\} \\
& D\left\{B u s_{c}=1\right\} * D\{j=34\} \\
& D\left\{B u s_{c}=1\right\} * D\{j=35\}
\end{aligned}
$$$$
0.263^{* * *}
$$$$
\text { (0.080) }
$$$$
0.270^{* * *}
$$$$
(0.079)
$$$$
0.268^{* * *}
$$$$
\text { (0.078) }
$$$$
0.259^{* * *}
$$$$
0.252^{* * *}
$$$$
\text { (0.087) }
$$$$
0.252^{* * *}
$$$$
\text { (0.086) }
$$$$
0.260^{* * *}
$$$$
\text { (0.084) }
$$$$
0.270^{* * *}
$$$$
0.276^{* * *}
$$$$
\text { (0.086) }
$$$$
0.277^{* * *}
$$$$
0.294^{* * *}
$$$$
0.304^{* * *}
$$$$
\text { (0.086) }
$$$$
0.578^{* * *}
$$

County \& Time FE

Yes

Yes

Yes

7.11. Incidence / Fatality $*$ Time FE

Yes

Yes

Yes

Observations

20945

20945

20945

R-Squared

0.808

0.626

0.520

Notes: The table reports event study estimates on the effect of the Querdenken demonstrations in Leipzig and Berlin the spread of COVID-19 in German counties. The treated group are counties with any Honk for Hope bus stops in cities with fewer than 20,000 inhabitants. The outcome variable is the normalized seven-days-incidence rate (column (1)), log seven-days-incidence rate (column(2)), and the seven-days-fatality rate. The sample is restricted to rural counties and a 35-days window around November 18. All models control for county and day fixed effects, as well as interactions between days and the incidence/fatality rate on November 7 . Statistical significance: $* * *$ $\mathrm{p}<0.01,{ }^{* *} \mathrm{p}<0.05, * \mathrm{p}<0.1$. 
Table A5: COVID-19 Deniers and Disease Spreading Mitigation Behavior

\begin{tabular}{|c|c|c|c|c|c|c|c|}
\hline & Avoid Places & Keep Distance & Wash Hands & Use Disinfectant & Reduced Contacts & Wear Masks & Oblige Curfew \\
\hline \multirow[t]{2}{*}{ COVID-19 Denier } & $-0.279^{* * *}$ & $-0.194^{* *}$ & $-0.134^{*}$ & -0.048 & $-0.250^{* * *}$ & $-0.039^{* * *}$ & $-0.233^{* * *}$ \\
\hline & $(0.091)$ & $(0.090)$ & $(0.075)$ & $(0.089)$ & $(0.086)$ & $(0.005)$ & $(0.085)$ \\
\hline \multirow[t]{2}{*}{ Female } & $0.054^{* * *}$ & $0.026^{*}$ & $0.041^{* * *}$ & $0.056^{* * *}$ & $0.058^{* * *}$ & 0.010 & $0.042^{* * *}$ \\
\hline & $(0.013)$ & $(0.014)$ & $(0.010)$ & $(0.018)$ & $(0.013)$ & $(0.007)$ & $(0.010)$ \\
\hline \multirow[t]{2}{*}{ Age: $26-60$} & $0.167^{* * *}$ & $0.196^{* * *}$ & -0.011 & -0.055 & $0.183^{* * *}$ & $0.036^{* * *}$ & 0.069 \\
\hline & $(0.056)$ & $(0.059)$ & $(0.034)$ & $(0.058)$ & $(0.055)$ & $(0.007)$ & $(0.045)$ \\
\hline \multirow[t]{2}{*}{ Age: $>60$} & $0.194^{* * *}$ & $0.261^{* * *}$ & 0.038 & $-0.150^{* *}$ & $0.227^{* * *}$ & $0.021^{* * *}$ & $0.093^{* *}$ \\
\hline & $(0.056)$ & $(0.059)$ & $(0.034)$ & $(0.059)$ & $(0.056)$ & $(0.007)$ & $(0.045)$ \\
\hline \multirow[t]{2}{*}{ Secondary Education } & $0.045^{*}$ & -0.019 & $0.046^{* *}$ & 0.029 & $0.043^{*}$ & 0.002 & -0.001 \\
\hline & $(0.025)$ & $(0.025)$ & $(0.021)$ & $(0.031)$ & $(0.024)$ & $(0.012)$ & $(0.016)$ \\
\hline \multirow[t]{2}{*}{ Tertiary Education } & $0.061^{* *}$ & 0.019 & $0.053^{* * *}$ & -0.023 & $0.067^{* * *}$ & -0.006 & -0.025 \\
\hline & $(0.024)$ & $(0.024)$ & $(0.020)$ & $(0.030)$ & $(0.023)$ & $(0.011)$ & $(0.016)$ \\
\hline \multirow[t]{2}{*}{ Persons in Household: 2} & 0.024 & 0.034 & $0.060^{* * *}$ & $0.124^{* * *}$ & $0.043^{*}$ & 0.011 & $0.031^{*}$ \\
\hline & $(0.022)$ & $(0.025)$ & $(0.020)$ & $(0.029)$ & $(0.023)$ & $(0.010)$ & $(0.017)$ \\
\hline \multirow[t]{2}{*}{ Persons in Household: $\geq 3$} & 0.024 & $0.078^{* * *}$ & $0.063^{* * *}$ & $0.096^{* * *}$ & $0.081^{* * *}$ & 0.009 & 0.028 \\
\hline & $(0.023)$ & $(0.026)$ & $(0.021)$ & $(0.030)$ & $(0.024)$ & $(0.010)$ & $(0.018)$ \\
\hline \multirow[t]{2}{*}{ Self-Employed } & 0.020 & -0.011 & -0.038 & 0.004 & -0.001 & $0.054^{* *}$ & $-0.052^{* *}$ \\
\hline & $(0.026)$ & $(0.031)$ & $(0.024)$ & $(0.036)$ & $(0.027)$ & $(0.021)$ & $(0.025)$ \\
\hline \multirow[t]{2}{*}{ Unemployed } & -0.053 & -0.082 & $-0.160^{* *}$ & 0.014 & -0.056 & -0.009 & -0.078 \\
\hline & $(0.066)$ & $(0.073)$ & $(0.067)$ & $(0.077)$ & $(0.064)$ & $(0.024)$ & $(0.059)$ \\
\hline \multirow[t]{2}{*}{ Out of Labor Force } & 0.017 & 0.023 & -0.021 & -0.038 & 0.014 & -0.005 & -0.003 \\
\hline & $(0.017)$ & $(0.020)$ & $(0.014)$ & $(0.024)$ & $(0.017)$ & $(0.009)$ & $(0.014)$ \\
\hline Outcome Mean & 0.847 & 0.803 & 0.911 & 0.600 & 0.855 & 0.035 & 0.918 \\
\hline adj. $R^{2}$ & 0.018 & 0.016 & 0.021 & 0.020 & 0.024 & 0.006 & 0.019 \\
\hline$N$ & 3,101 & 3,101 & 3,101 & 3,101 & 3,101 & 3,101 & 3,096 \\
\hline
\end{tabular}

Note: The table reports OLS regression results of dummy variables capturing COVID-19 mitigation behavior on a dummy variable COVID-19 Denier indicating whether an individual is categorized to be very skeptic about the threat posed by COVID-19. Control variables are listed. Information about whether an individual is male, younger than 25 , holds a lower secondary school degree, lives in a single household, or is employed is omitted due to multicollinearity. Robust standard errors are displayed in parentheses. Statistical significance is indicated by asterisks according to: ${ }^{*} p<0.10,{ }^{* *} p<0.05,{ }^{* * *} p<0.01$. 
Table A6: COVID-19 Deniers and Trust

\begin{tabular}{|c|c|c|c|c|c|c|c|}
\hline & Local Health Office & Health Ministry & RKI & WHO & Federal Government & Angela Merkel & Scientists \\
\hline \multirow[t]{2}{*}{ COVID-19 Denier } & $-0.411^{*}$ & $-0.738^{* * *}$ & $-0.590^{* *}$ & $-0.790^{* * *}$ & $-0.668^{* * *}$ & $-0.633^{* *}$ & $-0.612^{* * *}$ \\
\hline & $(0.239)$ & $(0.264)$ & $(0.244)$ & $(0.241)$ & $(0.249)$ & $(0.251)$ & $(0.212)$ \\
\hline \multirow[t]{2}{*}{ Female } & $0.099^{* * *}$ & $0.155^{* * *}$ & 0.023 & $0.224^{* * *}$ & $0.130^{* * *}$ & $0.206^{* * *}$ & -0.013 \\
\hline & $(0.034)$ & $(0.036)$ & $(0.028)$ & $(0.034)$ & $(0.037)$ & $(0.041)$ & $(0.029)$ \\
\hline \multirow[t]{2}{*}{ Age: $26-60$} & -0.043 & -0.125 & 0.039 & $-0.291^{* * *}$ & 0.038 & 0.112 & -0.113 \\
\hline & $(0.103)$ & $(0.117)$ & $(0.083)$ & $(0.101)$ & $(0.127)$ & $(0.140)$ & $(0.108)$ \\
\hline \multirow[t]{2}{*}{ Age: $>60$} & 0.055 & 0.077 & $0.140^{*}$ & $-0.327^{* * *}$ & $0.291^{* *}$ & $0.406^{* * *}$ & -0.016 \\
\hline & $(0.104)$ & $(0.120)$ & $(0.083)$ & $(0.102)$ & $(0.129)$ & $(0.142)$ & $(0.105)$ \\
\hline \multirow[t]{2}{*}{ Secondary Education } & 0.015 & 0.002 & -0.014 & -0.080 & 0.051 & 0.037 & 0.063 \\
\hline & $(0.061)$ & $(0.067)$ & $(0.047)$ & $(0.064)$ & $(0.070)$ & $(0.079)$ & $(0.056)$ \\
\hline \multirow[t]{2}{*}{ Tertiary Education } & -0.050 & 0.029 & 0.024 & -0.005 & $0.127^{*}$ & $0.189^{* *}$ & $0.145^{* * *}$ \\
\hline & $(0.059)$ & $(0.064)$ & $(0.044)$ & $(0.060)$ & $(0.066)$ & $(0.075)$ & $(0.053)$ \\
\hline \multirow[t]{2}{*}{ Persons in Household: 2} & -0.072 & -0.025 & 0.021 & 0.013 & -0.067 & -0.064 & -0.005 \\
\hline & $(0.054)$ & $(0.059)$ & $(0.049)$ & $(0.057)$ & $(0.060)$ & $(0.068)$ & $(0.047)$ \\
\hline \multirow{2}{*}{ Persons in Household: $\geq 3$} & -0.037 & -0.015 & -0.016 & 0.011 & -0.035 & -0.056 & -0.037 \\
\hline & $(0.056)$ & $(0.062)$ & $(0.051)$ & $(0.060)$ & $(0.063)$ & $(0.072)$ & $(0.048)$ \\
\hline \multirow[t]{2}{*}{ Self-Employed } & -0.054 & $-0.171^{* *}$ & $-0.154^{* * *}$ & $-0.250^{* * *}$ & $-0.181^{* *}$ & -0.116 & $-0.158^{* *}$ \\
\hline & $(0.071)$ & $(0.081)$ & $(0.059)$ & $(0.082)$ & $(0.078)$ & $(0.088)$ & $(0.064)$ \\
\hline \multirow[t]{2}{*}{ Unemployed } & -0.228 & -0.265 & $-0.353^{*}$ & -0.176 & -0.280 & -0.247 & -0.121 \\
\hline & $(0.178)$ & $(0.178)$ & $(0.188)$ & $(0.153)$ & $(0.188)$ & $(0.181)$ & $(0.149)$ \\
\hline \multirow[t]{2}{*}{ Out of Labor Force } & 0.000 & 0.005 & -0.017 & -0.015 & -0.005 & -0.010 & 0.018 \\
\hline & $(0.047)$ & $(0.051)$ & $(0.042)$ & $(0.047)$ & $(0.053)$ & $(0.059)$ & $(0.043)$ \\
\hline Outcome Mean & 3.808 & 3.818 & 4.442 & 3.965 & 3.660 & 3.567 & 4.239 \\
\hline $\operatorname{adj.} R^{2}$ & 0.006 & 0.019 & 0.013 & 0.027 & 0.021 & 0.025 & 0.015 \\
\hline$N$ & 2,858 & 3,053 & 3,027 & 3,032 & 3,063 & 3,059 & 3,036 \\
\hline
\end{tabular}

Note: The table reports OLS regression results of variables capturing trust in the respective institution on a dummy variable COVID-19 Denier indicating whether an individual is categorized to be very skeptic about the threat posed by COVID-19. Dependent variables vary on a five-point Likert scale ranging from "Don't trust at all" to "Entirely trust". Control variables are listed. Information about whether an individual is male, younger than 25 , holds a lower secondary school degree, lives in a single household, or is employed is omitted due to multicollinearity. Robust standard errors are displayed in parentheses. Statistical significance is indicated by asterisks according to: ${ }^{*} p<0.10,{ }^{* *} p<0.05,{ }^{* * *} p<0.01$. 
Table A7: COVID-19 Deniers and Media Usage

\begin{tabular}{|c|c|c|c|c|c|}
\hline & \multicolumn{2}{|c|}{ TV and Radio } & \multirow{2}{*}{ Newspaper } & \multirow{2}{*}{ Social Media } & \multirow{2}{*}{ Other } \\
\hline & Public & Commercial & & & \\
\hline \multirow[t]{2}{*}{ COVID-19 Denier } & $-0.264^{* * *}$ & -0.143 & $-0.229^{* *}$ & 0.032 & 0.015 \\
\hline & $(0.091)$ & $(0.090)$ & $(0.092)$ & $(0.091)$ & $(0.064)$ \\
\hline \multirow[t]{2}{*}{ Female } & $0.021^{* *}$ & -0.016 & -0.012 & $0.054^{* * *}$ & $-0.039^{* * *}$ \\
\hline & $(0.010)$ & $(0.018)$ & $(0.017)$ & $(0.016)$ & $(0.012)$ \\
\hline \multirow[t]{2}{*}{ Age: $26-60$} & $0.191^{* * *}$ & 0.032 & $0.171^{* * *}$ & $-0.255^{* * *}$ & 0.010 \\
\hline & $(0.054)$ & $(0.060)$ & $(0.061)$ & $(0.060)$ & $(0.044)$ \\
\hline \multirow[t]{2}{*}{ Age: $>60$} & $0.270^{* * *}$ & -0.048 & $0.325^{* * *}$ & $-0.434^{* * *}$ & -0.039 \\
\hline & $(0.053)$ & $(0.061)$ & $(0.061)$ & $(0.060)$ & $(0.045)$ \\
\hline \multirow[t]{2}{*}{ Secondary Education } & 0.007 & -0.038 & 0.039 & 0.012 & 0.024 \\
\hline & $(0.017)$ & $(0.032)$ & $(0.030)$ & $(0.027)$ & $(0.016)$ \\
\hline \multirow[t]{2}{*}{ Tertiary Education } & $0.029^{*}$ & $-0.229^{* * *}$ & $0.129^{* * *}$ & -0.021 & $0.099^{* * *}$ \\
\hline & $(0.017)$ & $(0.030)$ & $(0.028)$ & $(0.025)$ & $(0.016)$ \\
\hline \multirow[t]{2}{*}{ Persons in Household: 2} & 0.020 & 0.007 & $0.063^{* *}$ & -0.033 & -0.001 \\
\hline & $(0.016)$ & $(0.030)$ & $(0.029)$ & $(0.026)$ & $(0.020)$ \\
\hline \multirow[t]{2}{*}{ Persons in Household: $\geq 3$} & 0.023 & -0.017 & $0.080^{* * *}$ & -0.005 & -0.017 \\
\hline & $(0.018)$ & $(0.031)$ & $(0.030)$ & $(0.028)$ & $(0.021)$ \\
\hline \multirow[t]{2}{*}{ Self-Employed } & 0.006 & $-0.062^{*}$ & 0.036 & 0.015 & $-0.051^{* *}$ \\
\hline & $(0.019)$ & $(0.037)$ & $(0.035)$ & $(0.033)$ & $(0.024)$ \\
\hline \multirow[t]{2}{*}{ Unemployed } & -0.097 & $-0.134^{*}$ & -0.063 & $0.144^{*}$ & 0.004 \\
\hline & $(0.063)$ & $(0.073)$ & $(0.082)$ & $(0.076)$ & $(0.055)$ \\
\hline \multirow[t]{2}{*}{ Out of Labor Force } & -0.006 & -0.020 & $0.070^{* * *}$ & 0.031 & $-0.034^{* *}$ \\
\hline & $(0.014)$ & $(0.024)$ & $(0.023)$ & $(0.022)$ & $(0.016)$ \\
\hline Outcome Mean & 0.923 & 0.450 & 0.670 & 0.271 & 0.137 \\
\hline $\operatorname{adj} . R^{2}$ & 0.040 & 0.042 & 0.049 & 0.048 & 0.025 \\
\hline$N$ & 3,099 & 3,099 & 3,099 & 3,099 & 3,099 \\
\hline
\end{tabular}

Note: The table reports OLS regression results of dummy variables capturing whether individuals inform themselves about COVID-19 via the respective media source on a dummy variable COVID-19 Denier indicating whether an individual is categorized to be very skeptic about the threat posed by COVID-19. Control variables are listed. Information about whether an individual is male, younger than 25 , holds a lower secondary school degree, lives in a single household, or is employed is omitted due to multicollinearity. Robust standard errors are displayed in parentheses. Statistical significance is indicated by asterisks according to: ${ }^{*} p<0.10,{ }^{* *} p<0.05,{ }^{* * *} p<0.01$. 
Figure A1: Robustness of the Event Study Results

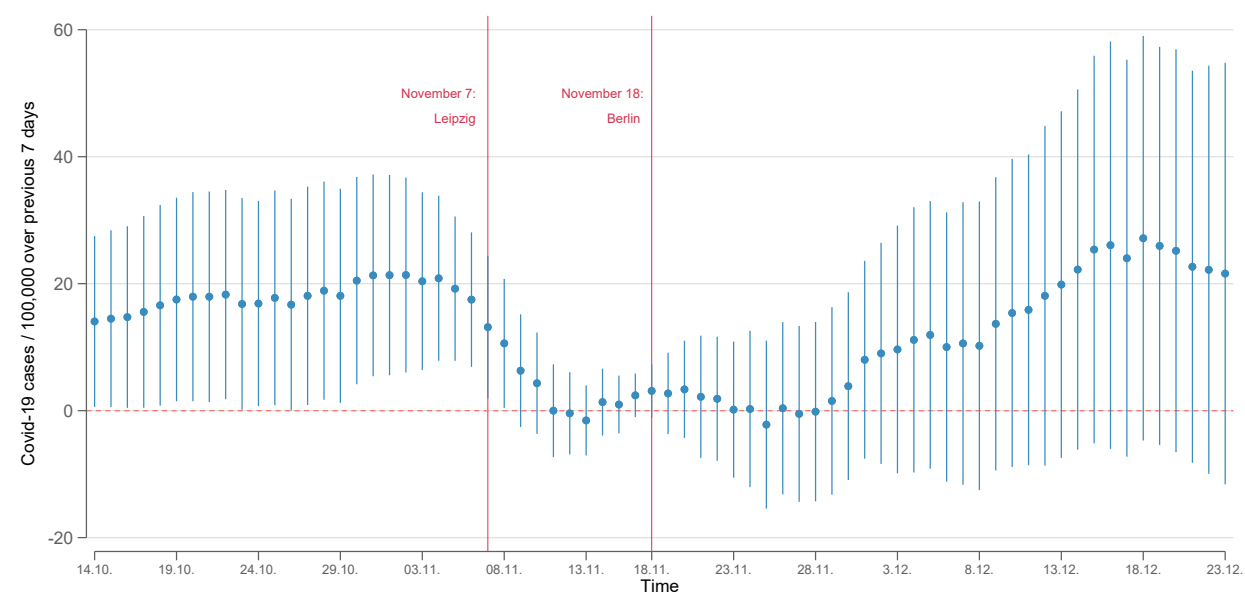

(a) Control Treatment: FlixBus Stops $(<20,000)$

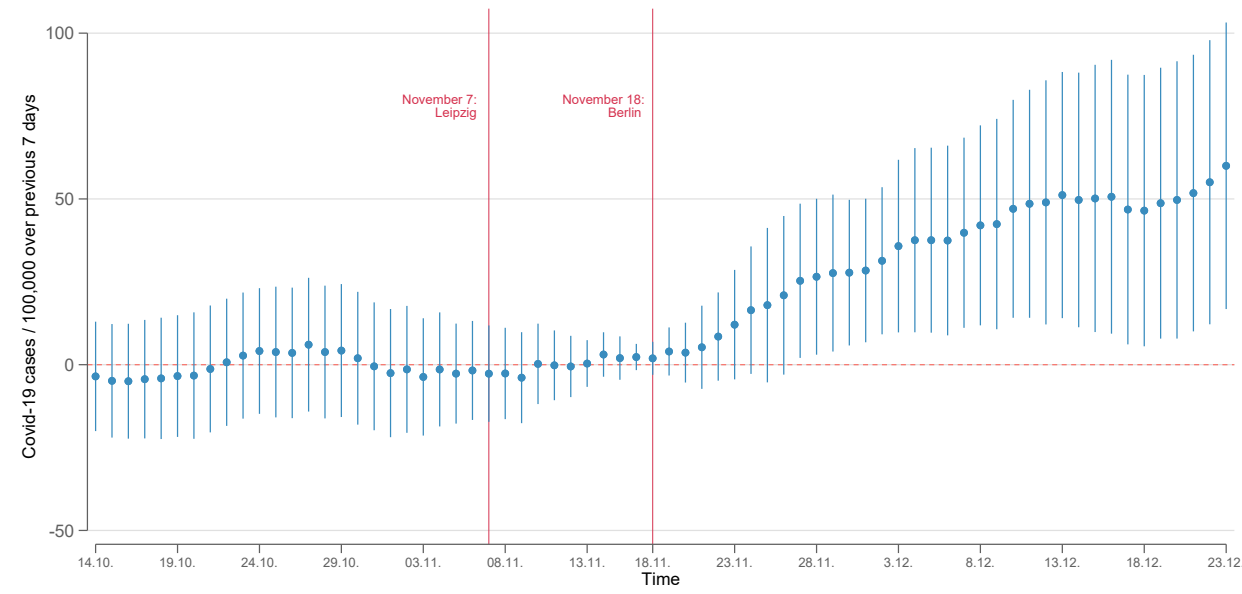

(b) Full Set of Control Variables

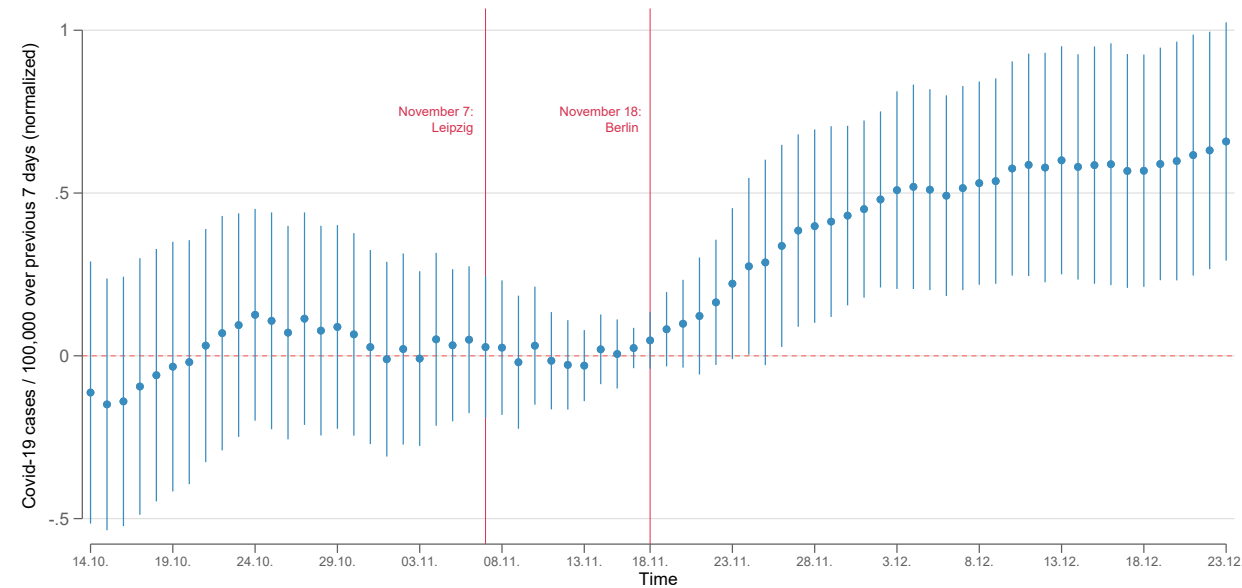

(c) Outcome: Normalized Seven-Days-Incidence Rate

Notes: The figures plots event study coefficients and their 95 percent confidence intervals for different robustness checks. In (a), the treated group includes counties with FlixBus stops in cities with fewer than 20,000 inhabitants (while controlling for Honk for Hope dummies). In (b), the treatment group is the same as in the main specification, we add the full set of control variables interacted with time dummies. In (c), the treatment group is the same as in the main specification, but the outcome is normalized. The sample in all specifications is restricted to rural counties and a 35-days window around November 18. All models control for county and day fixed effects, as well as interactions between days and the incidence rate on November 7 . 
Figure A2: Robustness: Drop Federal States I

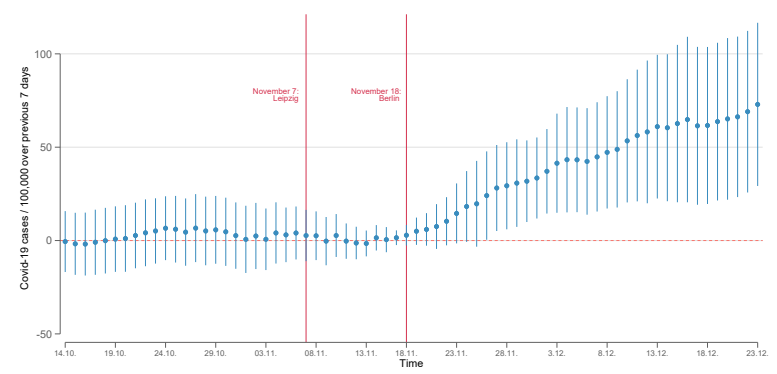

(a) Exclude Schleswig-Holstein

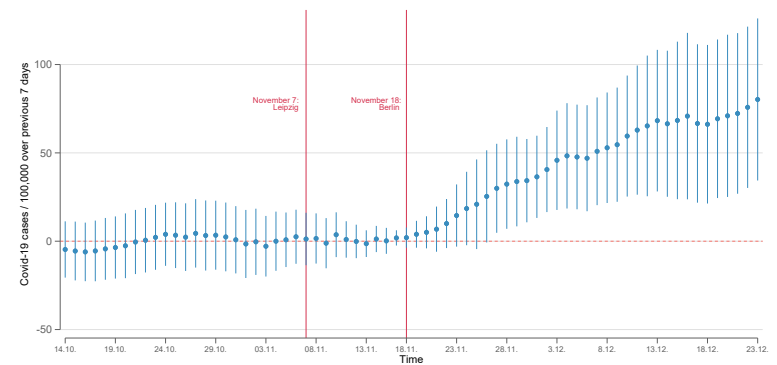

(c) Exclude Lower Saxony

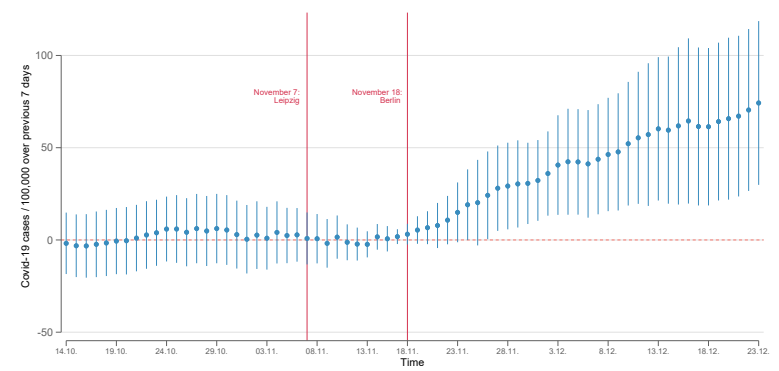

(e) Exclude North Rhine-Westphalia

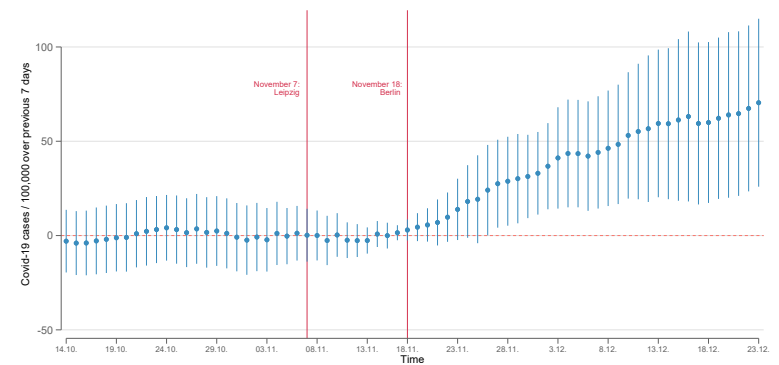

(g) Exclude Rhineland-Palatinate

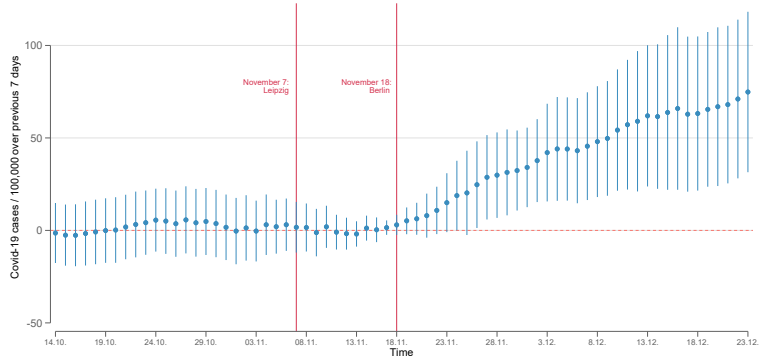

(b) Exclude Hamburg

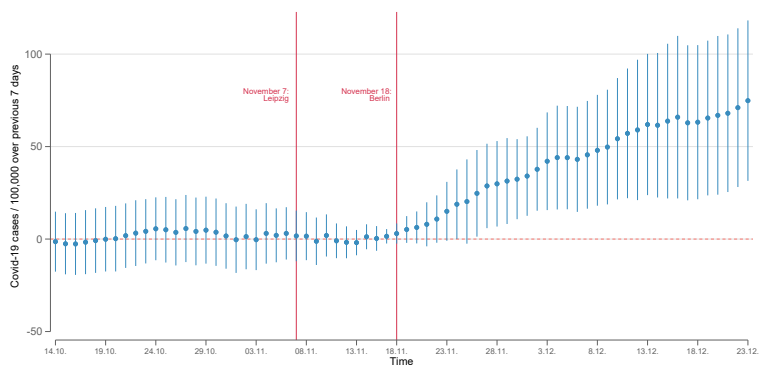

(d) Exclude Bremen

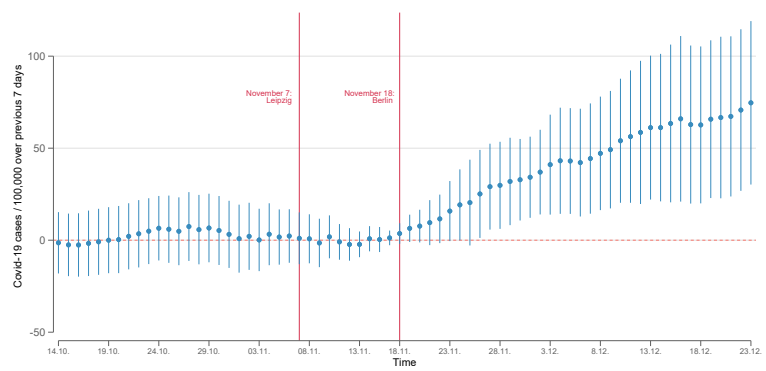

(f) Exclude Hesse

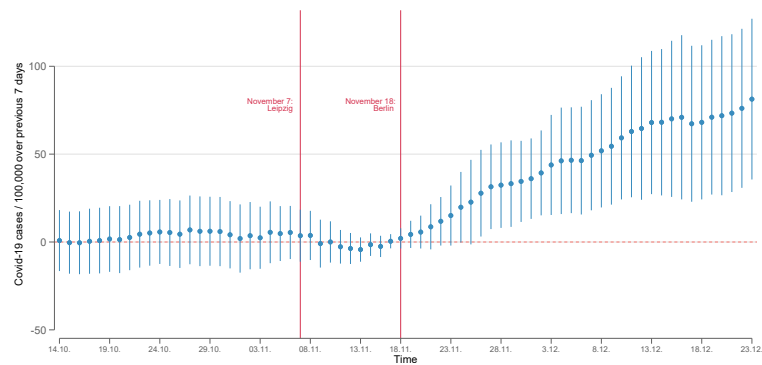

(h) Exclude Baden-Württemberg

Notes: The figures plot the event study coefficients and their 95 percent confidence intervals on the effect of the Querdenken demonstrations in Leipzig and Berlin on the seven days incidence rates in German counties. Each subfigure excludes the state noted in the respective caption. The treated group are counties with Honk for Hope bus stops in cities with fewer than 20,000 inhabitants. The sample is restricted to rural counties and a 35-days window around November 18 . All models control for county and day fixed effects, as well as interactions between days and the incidence rate on November 7 . 
Figure A3: Robustness: Drop Federal States II

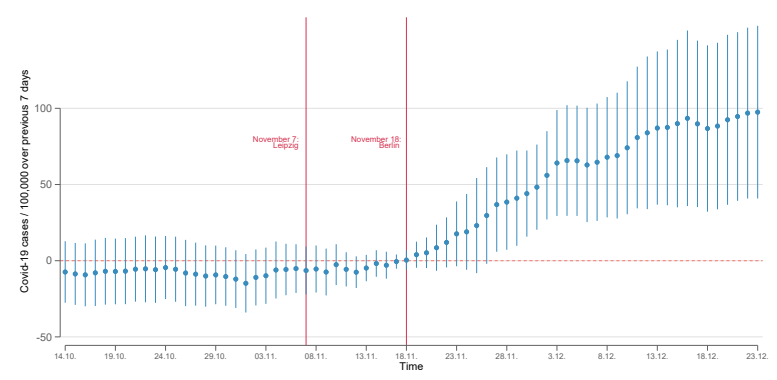

(a) Exclude Bayern

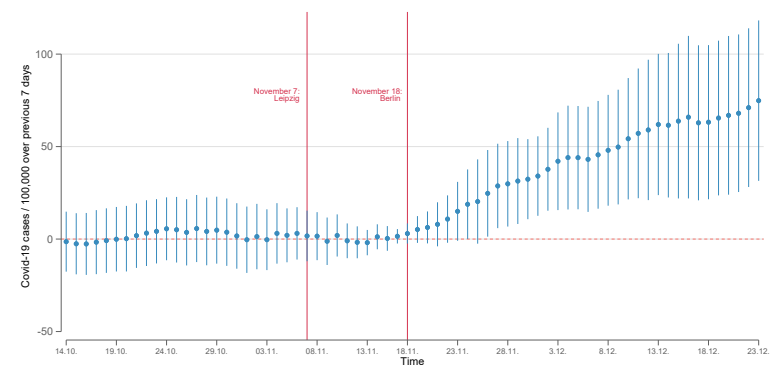

(c) Exclude Berlin

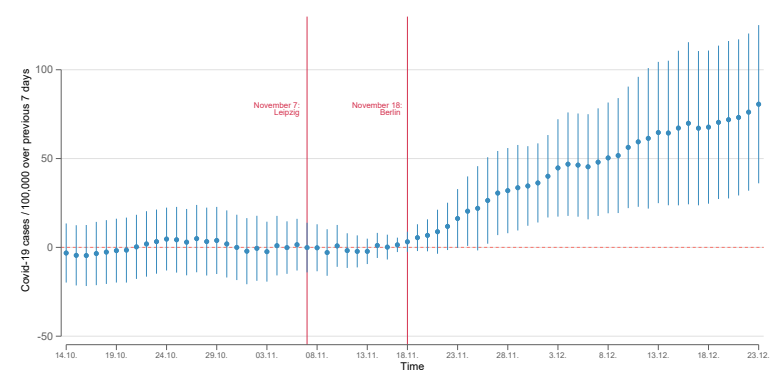

(e) Exclude Mecklenburg-Vorpommern

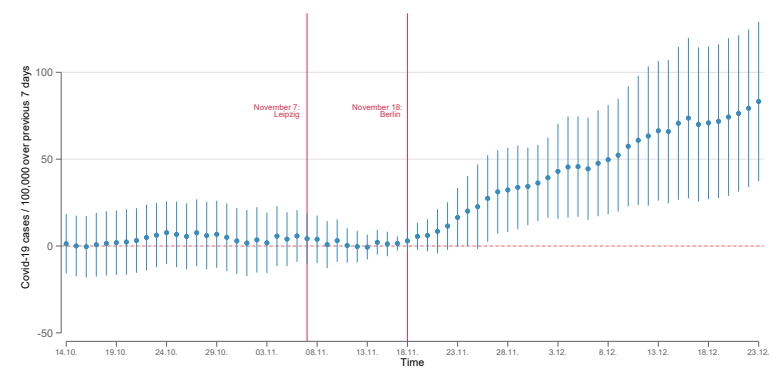

(g) Exclude Sachsen-Anhalt

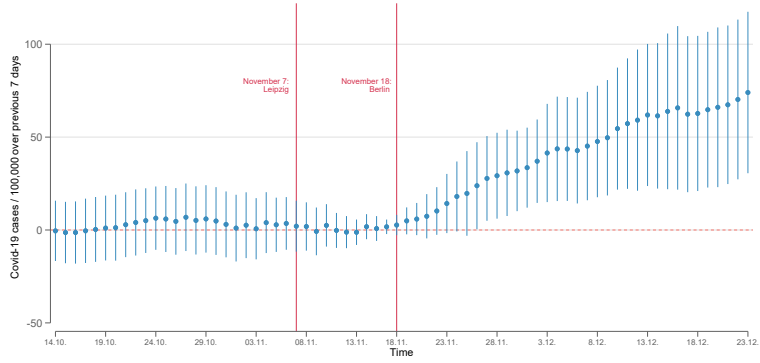

(b) Exclude Saarland

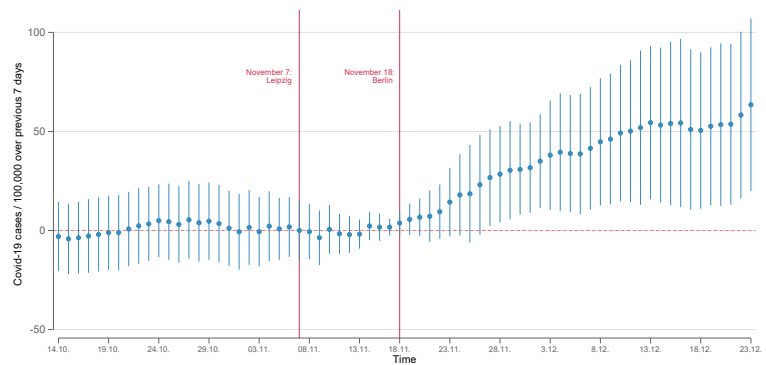

(d) Exclude Brandenburg

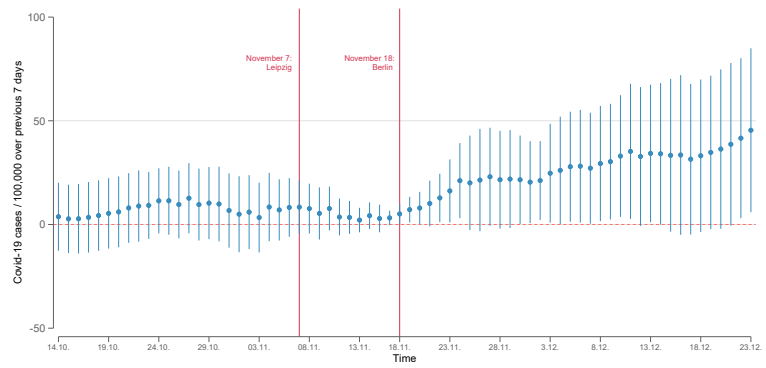

(f) Exclude Sachsen

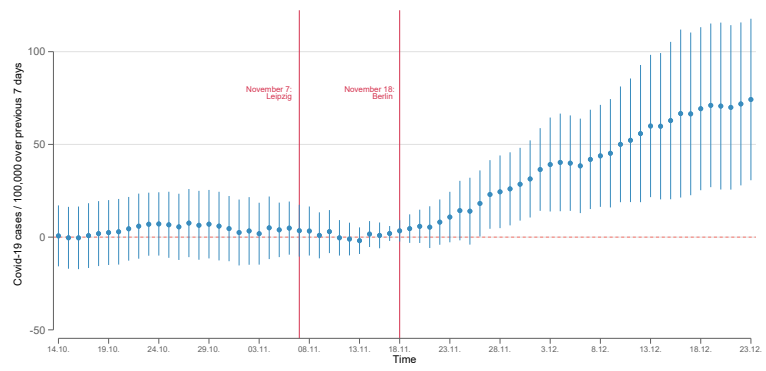

(h) Exclude Thüringen

Notes: The figures plot the event study coefficients and their 95 percent confidence intervals on the effect of the Querdenken demonstrations in Leipzig and Berlin on the seven days incidence rates in German counties. Each subfigure excludes the state noted in the respective caption. The treated group are counties with Honk for Hope bus stops in cities with fewer than 20,000 inhabitants. The sample is restricted to rural counties and a 35-days window around November 18 . All models control for county and day fixed effects, as well as interactions between days and the incidence rate on November 7 . 
Figure A4: Robustness: Leipzig Bus Stops vs. Berlin Bus Stops

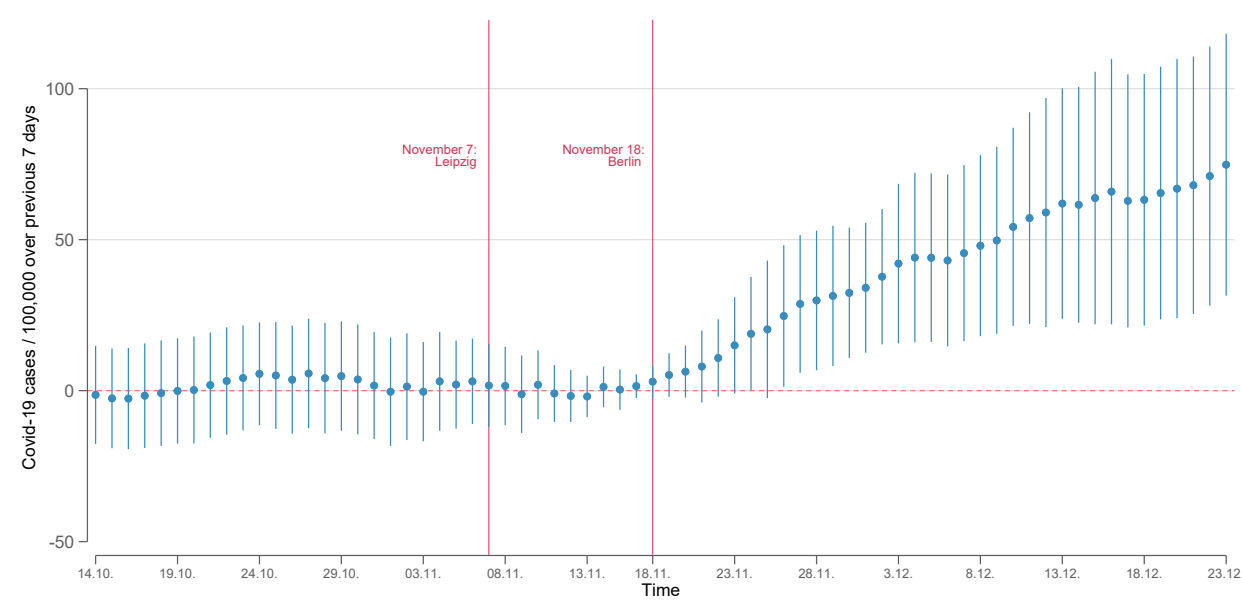

(a) Treated: HfH in general (cities smaller than 20,000)

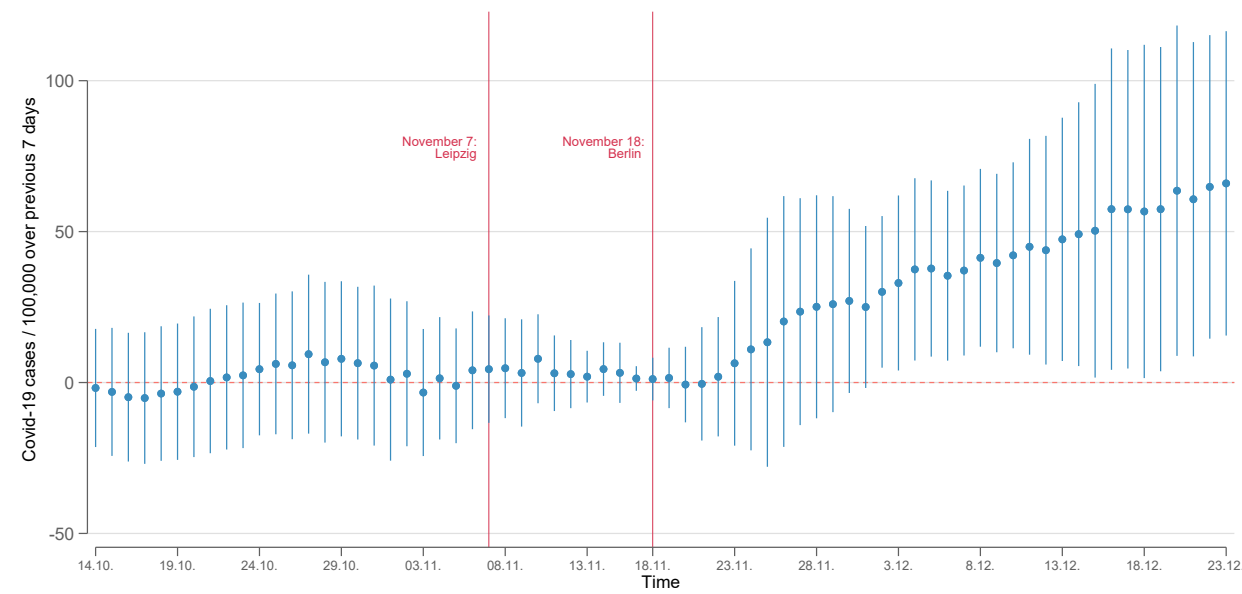

(b) Treated: HfH to Leipzig (cities smaller than 20,000)

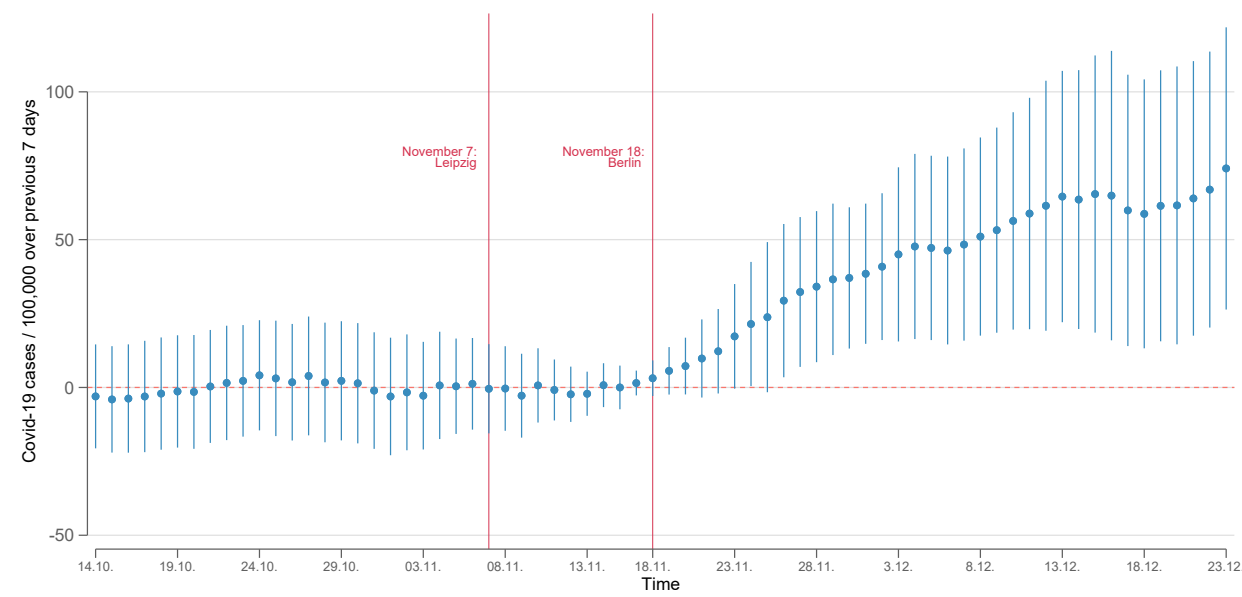

(c) Treated: HfH to Berlin (cities smaller than 20,000)

Notes: The figures plot the event study coefficients and their 95 percent confidence intervals on the effect of the Querdenken demonstrations in Leipzig and Berlin on the seven-days-incidence rates in German counties. The treated group are counties with Honk for Hope bus stops in cities with fewer than 20,000 inhabitants. The Honk for Hope bus stops are based on the available stops for different demonstrations as indicated in the respective captions. The sample is restricted to rural counties and a 35-days window around November 18. All models control for county and day fixed effects, as well as interactions between days and the incidence rate on November 7 . 
Download ZEW Discussion Papers from our ftp server:

http://ftp.zew.de/pub/zew-docs/dp/

or see:

https://www.ssrn.com/link/ZEW-Ctr-Euro-Econ-Research.html

https://ideas.repec.org/s/zbw/zewdip.html

$$
\text { // }
$$

IMPRINT

ZEW - Leibniz-Zentrum für Europäische Wirtschaftsforschung GmbH Mannheim

ZEW - Leibniz Centre for European

Economic Research

L 7,1 68161 Mannheim · Germany

Phone +49621 1235-01

info@zew.de·zew.de

Discussion Papers are intended to make results of ZEW research promptly available to other economists in order to encourage discussion and suggestions for revisions. The authors are solely responsible for the contents which do not necessarily represent the opinion of the ZEW. 